University of San Diego

Digital USD

2019-8

\title{
The Replication of the GLOBE Study in Turkey: Understanding the Effects of Social, Economical, and Political Changes on Cultural Dimensions and Leadership Ideals: A Mixed Methods Study
}

Zeki Pagda

University of San Diego

Follow this and additional works at: https://digital.sandiego.edu/dissertations

Part of the Industrial and Organizational Psychology Commons, International Business Commons, Leadership Studies Commons, and the Organizational Behavior and Theory Commons

\section{Digital USD Citation}

Pagda, Zeki, "The Replication of the GLOBE Study in Turkey: Understanding the Effects of Social, Economical, and Political Changes on Cultural Dimensions and Leadership Ideals: A Mixed Methods Study" (2019). Dissertations. 159.

https://digital.sandiego.edu/dissertations/159

This Dissertation: Open Access is brought to you for free and open access by the Theses and Dissertations at Digital USD. It has been accepted for inclusion in Dissertations by an authorized administrator of Digital USD. For more information, please contact digital@sandiego.edu. 
THE REPLICATION OF THE GLOBE STUDY IN TURKEY:

UNDERSTANDING THE EFFECTS OF SOCIAL, ECONOMICAL AND

POLITICAL CHANGES ON CULTURAL DIMENSIONS AND LEADERSHIP

IDEALS: A MIXED METHODS STUDY

\author{
by \\ Zeki Pagda \\ A dissertation submitted in partial fulfillment \\ of the requirements for the degree of \\ Doctor of Philosophy
}

May 2019

Dissertation Committee

Afsaneh Nahavandi, Ph. D., Chair

Fred Galloway, Ph. D., Member

Juan F. Roche, Ph. D., Member

Secil Bayraktar, Ph. D., Member

University of San Diego 
(C) Copyright by Zeki Pagda

All Rights Reserved 2019 


\section{University of San Diego}

\section{School of Leadership and Education Sciences}

CANDIDATE'S NAME: Zeki Pagda

TITLE OF DISSERTATION: REPLICATION OF THE GLOBE PROJECT IN TURKEY

APPROVAL:

, Chair

Afsaneh Nahavandi, PhD , Member

Fred J. Galloway, EdD , Member

Juan F. Roche, $\mathrm{PhD}$ , Member

Secil Bayraktar, $\mathrm{PhD}$ 


\begin{abstract}
Starting in 1995, the GLOBE (Global Leadership and Organizational Behavior Effectiveness) project has conducted a comprehensive study of cultural values and leadership ideals of 62 countries. GLOBE has identified nine cultural and six leadership dimensions, examined the relationship between cultural values and leadership ideals, grouped countries into clusters, and presented culturally derived leadership ideals. According to the 1995 GLOBE findings, Turkey fits in the Middle Eastern cluster with its corresponding expectations regarding leadership ideals. However, in the past thirty years, Turkey has undergone dramatic social, economic and political changes that may have affected ideals of leadership. The goal of this study was to explore whether such changes may have impacted both cultural dimensions and leadership ideals.
\end{abstract}

To that end, this study replicated the GLOBE methodology regarding cultural values and leadership ideals and further supplemented it with interviews to explore the possible reasons for value and ideal shifts. In a first phase, using GLOBE surveys, 271 participants identified Turkish cultural dimensions and 237 participants identified Turkish ideals of leadership. In a second phase, interviews with six respondents explored the social, political, and economic factors that may have contributed to changes in cultural and leadership ideals.

Results show no significant shifts in Turkish culture since 1995 although four out of nine cultural dimensions, Uncertainty Avoidance, Performance Orientation, Institutional Collectivism, and Humane Orientation practices, shifted down one level. For the ideals of leadership, participants indicated a higher value placed on Autonomous leadership and Participative leadership and a lower value on TeamOriented leadership when compared to 1995. 
Further analyses show that women endorsed Self-Protective leadership to a higher extent than men and that older participants more than younger ones endorsed Charismatic/Value-Based, Team-Oriented, Humane-Oriented and Autonomous leadership. Finally, respondents with more education endorsed Team-Oriented leadership and Charismatic/Value-Based leadership to a higher extent. The interview results further reinforce the survey findings indicating some, but no drastic cultural shifts.

The study's findings are discussed in terms of the impact of social and political changes on culture and leadership ideals and the speed at which culture may change. The implications for further GLOBE research are also discussed. 


\section{DEDICATION}

To every woman who has never been given a chance to make the world a better place. Especially, to women in my life, my mom, Citipat, and my aunts Muzo and Muku. They sacrificed everything for us. Of course, my wife, my best friend, Tubis, has made my life worth living, I could not do anything without your love and support. 


\section{ACKNOWLEDGEMENTS}

$\mathrm{A} \mathrm{PhD}$ program is an arduous and long journey for a student. Courage, passion and dedication are not always enough to complete this journey. We also need support, guidance, input, inspiration, coaching and encouragement of others. I incredibly appreciate those who were with me and provided whatever they could throughout my program.

First of all, Dr. Afsaneh Nahavandi. She was not only a true mentor, an academic guide and a coach, but a visionary leader who led me to the direction that I had no insight. Without her enthusiasm and direction, I could not complete this program. Dr. Afsaneh will be a lifelong friend for whom I will always be grateful.

I am also thankful to Dr. Johanna Hunsaker for believing and trusting in me. In my second year, as a $\mathrm{PhD}$ student, she gave me the lifetime opportunity that changed not only my life but my family's life as well. Without the support of Dr. Hunsaker, I could not have finished my $\mathrm{PhD}$, and become a fulfilled person as I am now. I have been doing my dream job because of Dr. Hunsaker. I will always remember how she changed my life.

To all my committee members, thank you very much. I have learned so much from Dr. Fred Galloway; his perspective, methodological skillset and knowledge prepared me to successfully complete my program. Besides his wisdom, Dr. Galloway's friendship helped me to finish my dissertation. Since the first day I met him, I admired Dr. Juan Roche's passion and achievements. He was my idol and shaped my dreams and possibilities in life. Thank you for amazing inputs and encouragement Dr. Roche. I could not complete my survey, analysis and research without Dr. Secil Bayraktar's support. I am grateful to her for answering my emails from overseas and for being willing to support someone she never met before. 
Without her inputs and assistance from thousands of miles away, I could not have finished my dissertation. Thank you Dr. Bayraktar for showing the world how much a Turkish woman can achieve and can raise the bar for others.

I also want to give my special thanks to all my friends who gave credence to me and helped me to gather data and to reach out to organizations for my dissertation. I am thankful to my mother-in-law, Ayla, as she travelled all the way from Istanbul to San Diego to support us every year.

Finally, I want to say "thank you" to all my $\mathrm{PhD}$ and business school colleagues and my professors who shared a drink with me on this journey. 


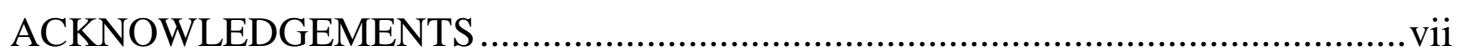

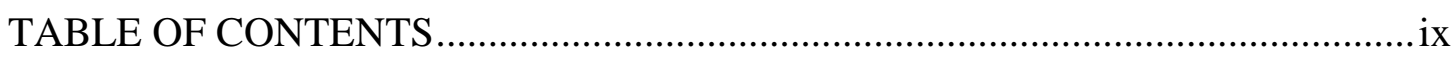

CHAPTER ONE: BACKGROUND AND INTRODUCTION .................................. 1

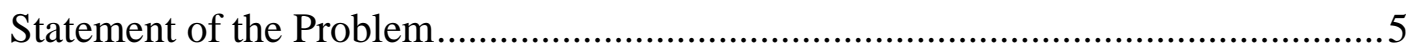

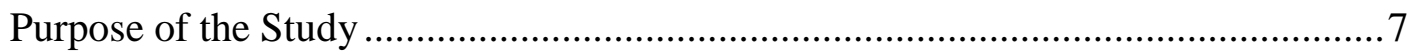

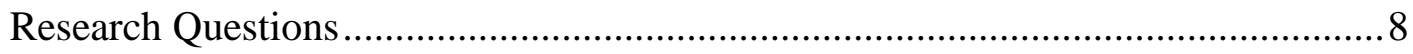

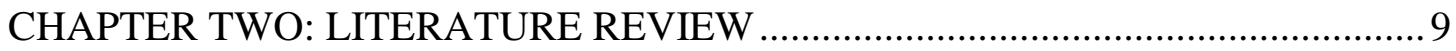

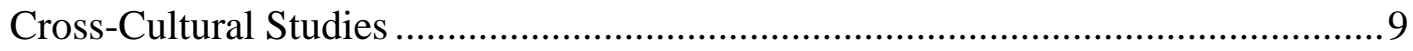

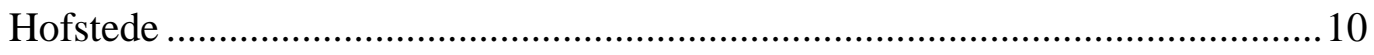

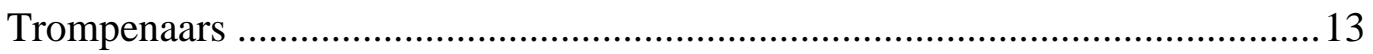

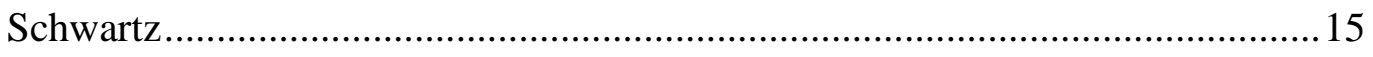

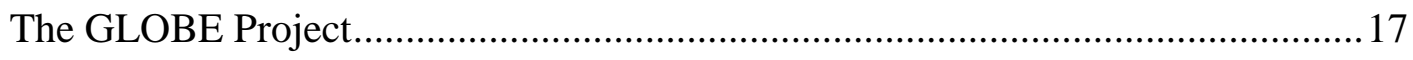

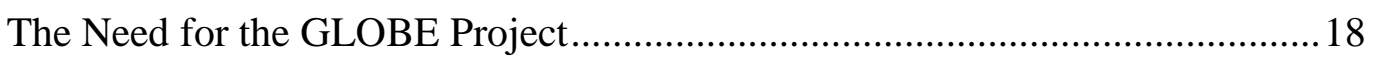

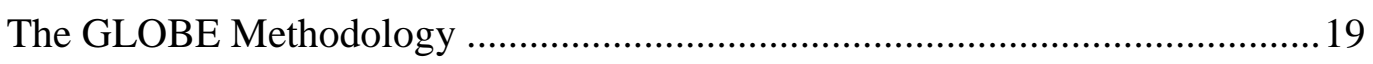

The Cultural Dimensions in the GLOBE Project ..............................................20

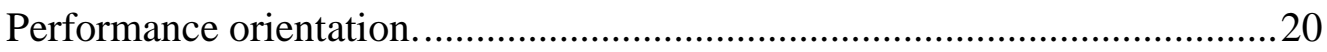

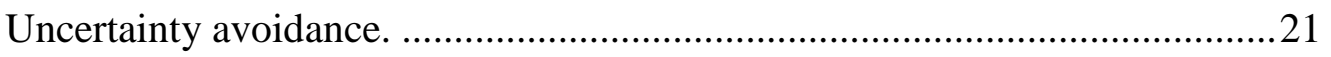

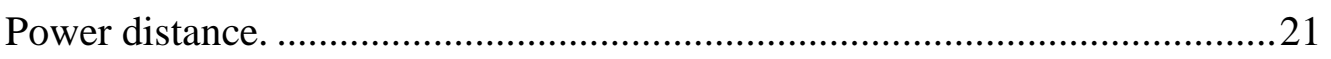

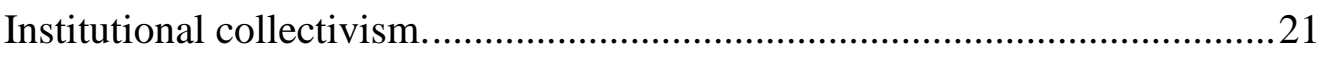

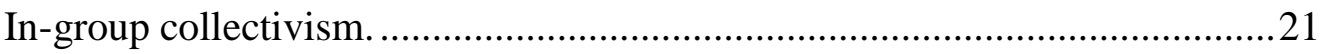

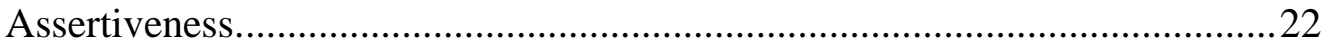

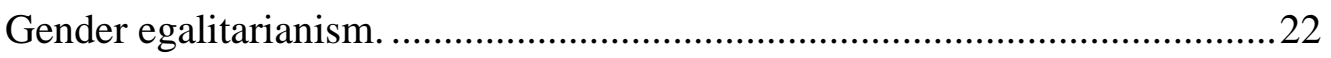

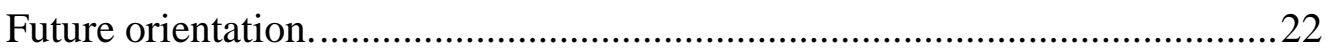


Humane orientation.

Culturally Endorsed Implicit Theory of Leadership in the GLOBE Project .......23

Charismatic/value-based leadership..........................................................24

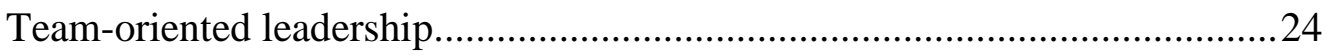

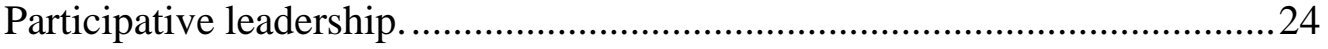

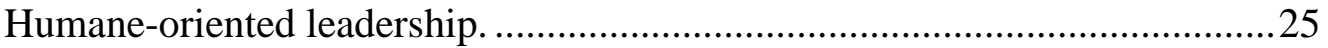

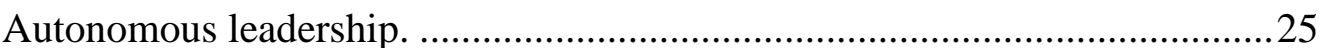

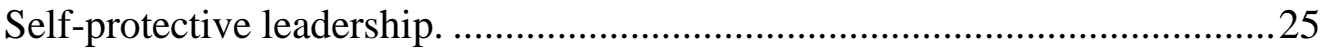

Regional Clustering of Societal Cultures ........................................................25

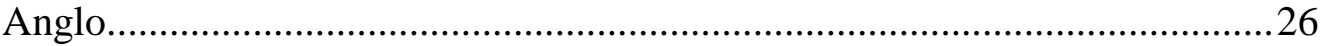

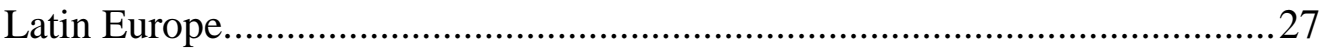

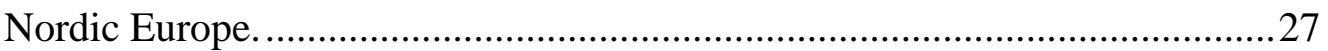

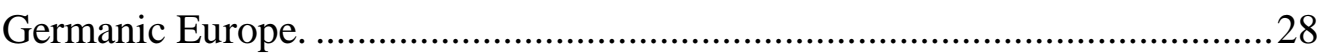

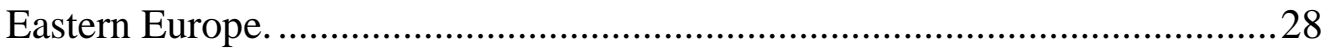

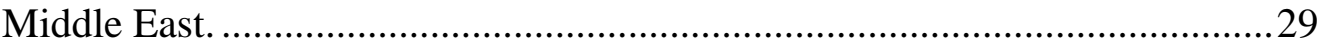

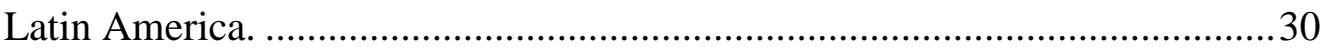

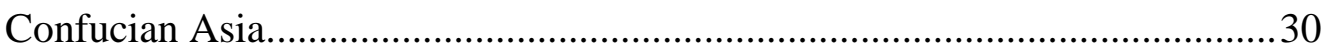

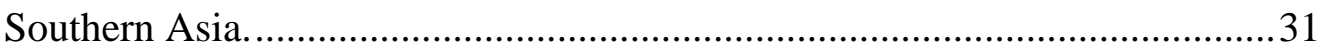

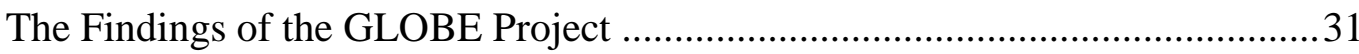

Further Research with the GLOBE Framework ...............................................33

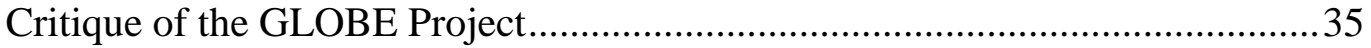

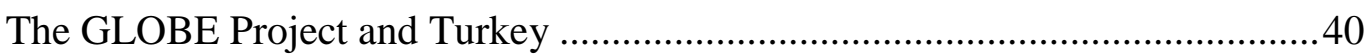

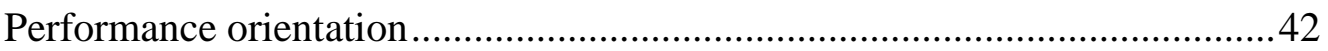

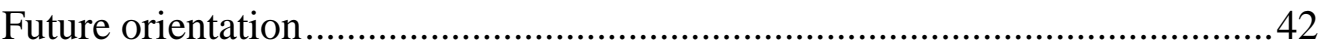

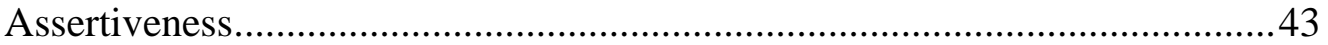




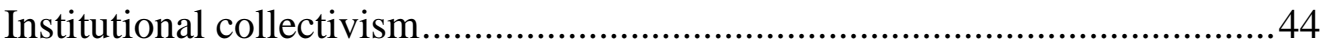

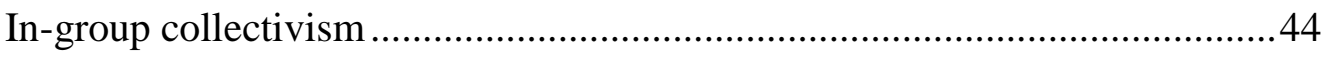

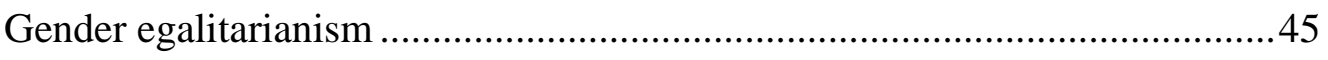

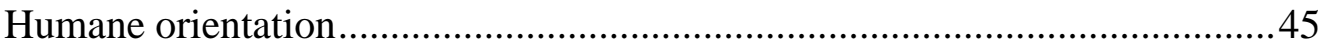

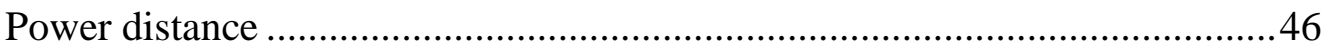

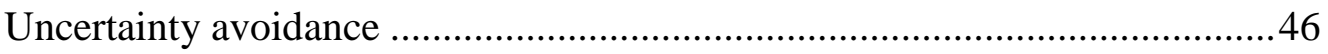

Cultural Movement in Turkey ................................................................. 47

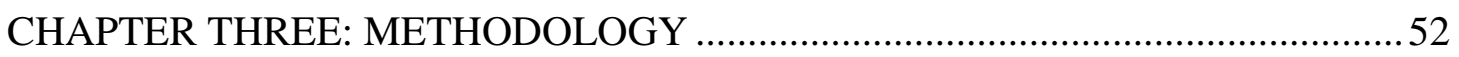

Sampling Strategy (Participants) …............................................................5

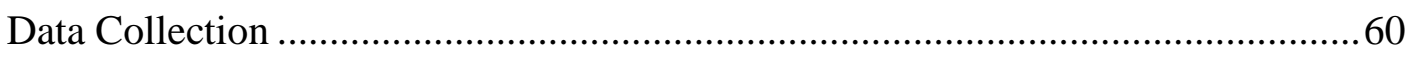

Quantitative Data Collection (Survey) .........................................................6

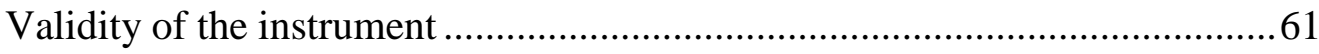

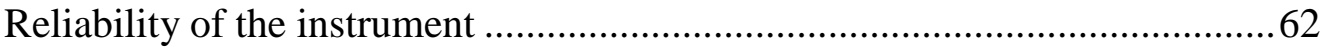

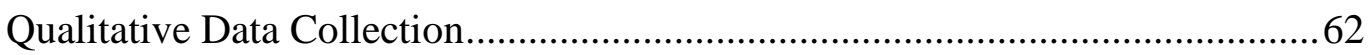

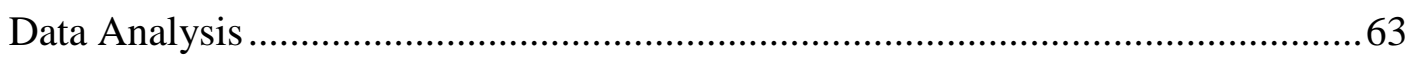

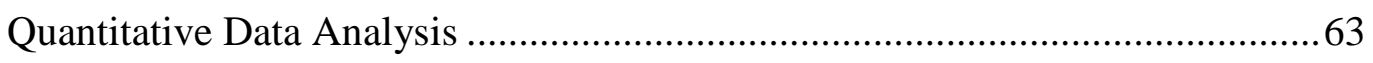

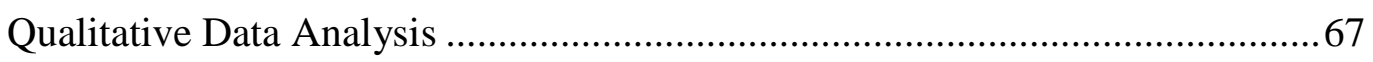

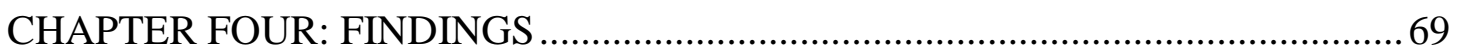

Calculations of Cultural Practice and Leadership Scores .....................................69

The Calculation of Societal Cultural Practices .................................................6 69

The Calculation of Leadership Attributes ........................................................ 70

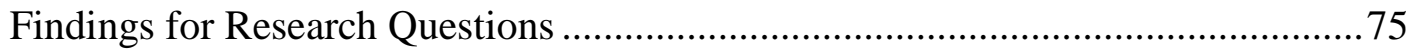

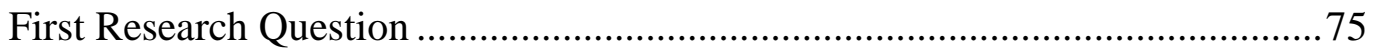

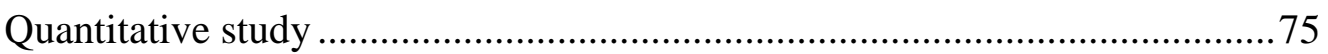


Qualitative study .81

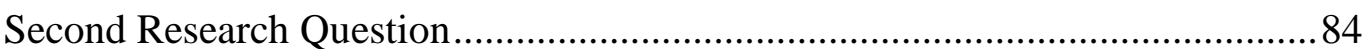

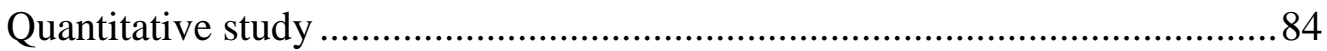

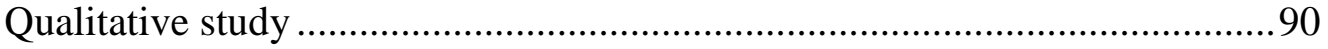

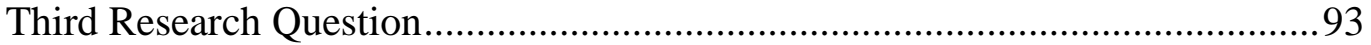

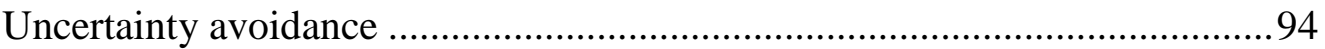

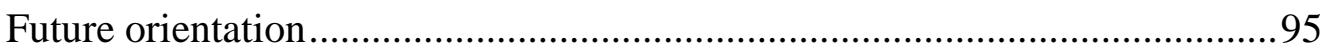

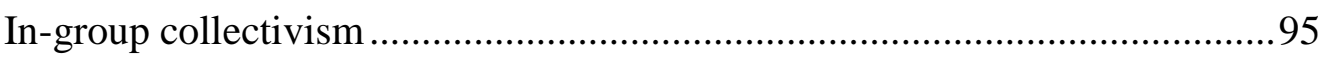

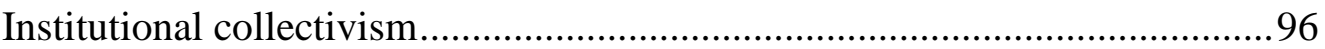

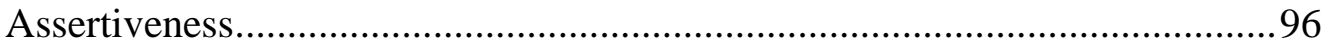

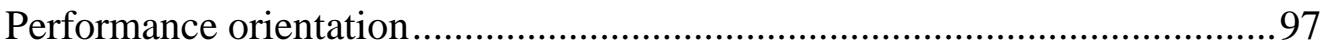

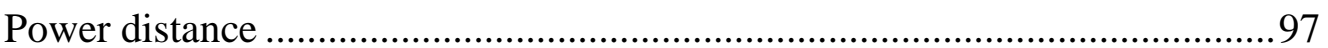

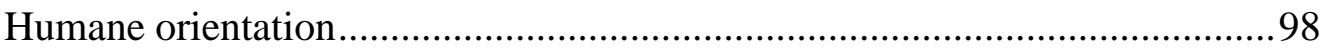

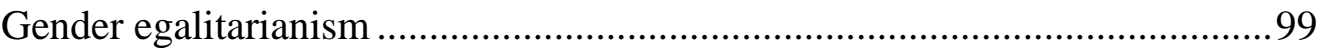

CHAPTER FIVE: DISCUSSION AND IMPLICATIONS ................................... 102

GLOBE Project and Business Community ....................................................... 105

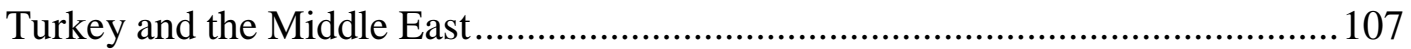

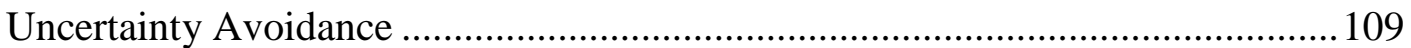

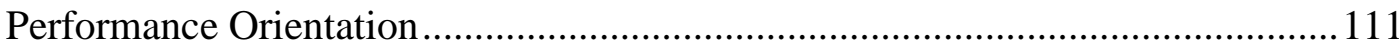

Institutional Collectivism/In-Group Collectivism ............................................ 113

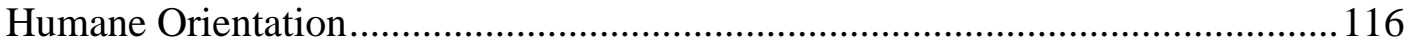

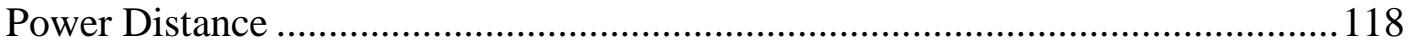

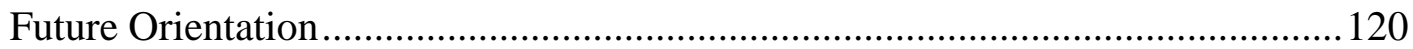

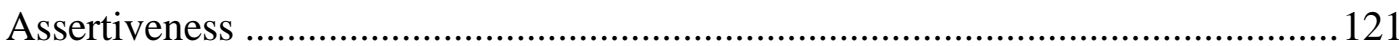


Gender Egalitarianism

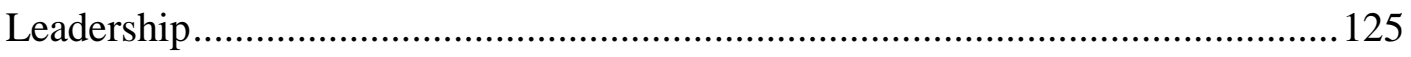

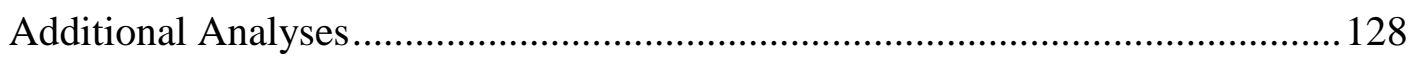

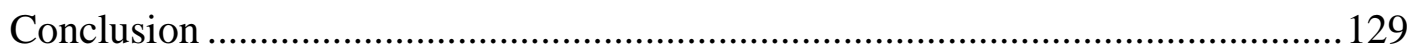

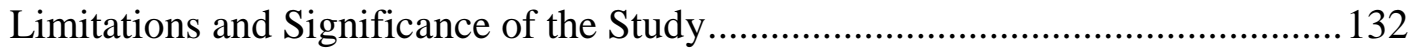

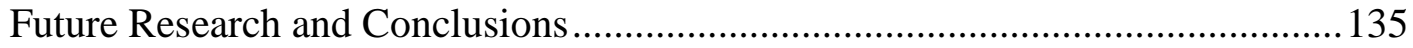

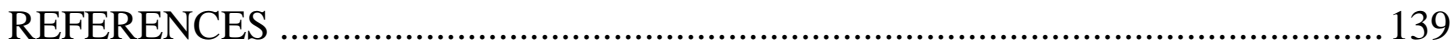

APPENDIX A Survey Questions (Quantitative Part) .............................................. 154

APPENDIX B Interview Questions (Qualitative Part) ........................................ 167 


\section{LIST OF TABLES}

Table 1. Major Cultural Clusters in the World by Region....................................... 26

Table 2. Comparison of the Companies that did and did not Participate in the Survey

Table 3. Demographic Characteristics of GLOBE Survey Participants .................... 59

Table 4. Demographic Characteristics of the Turkish Workforce ............................. 59

Table 5. Aggregate GLOBE Societal Cultural Practice Scores and Standard

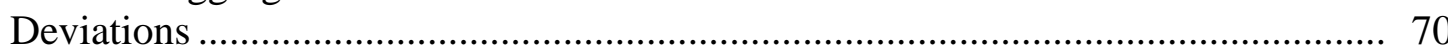

Table 6. GLOBE Leadership Subscales............................................................. 71

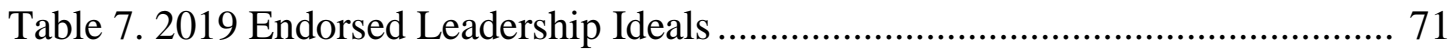

Table 8. Correlations between Societal Culture Dimensions and CLTs in 2019 ....... 73

Table 9. Correlations between Societal Culture Dimensions and CLTs in 1995 .........74

Table 10. Comparison of the Scores and Bands for Societal Culture Practices ......... 76

Table 11. t-test Results Comparing Males and Females on Societal Cultural

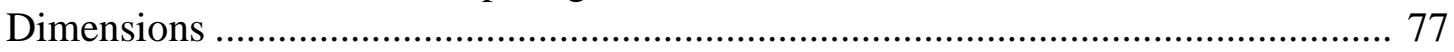

Table 12. t-test Results Comparing Spoken-Language on Societal Cultural

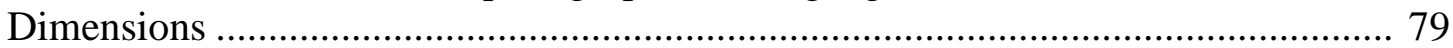

Table 13. Regression Analysis for Age on Societal Cultural Dimensions ................ 80

Table 14. Regression Analysis for Education on Societal Cultural

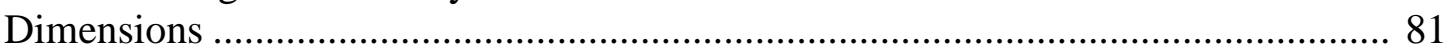

Table 15. Answers to the Question "Did you expect any major change in the Turkish

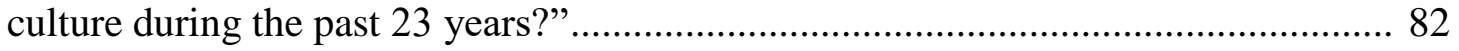

Table 16. Comparison of 1995 and 2019 GLOBE CLTs ........................................ 85

Table 17. t-test Results Comparing Males and Females on CLTs..............................86

Table 18. t-test Results Comparing Spoken-Language on CLTs ............................. 87

Table 19. Regression Analysis for Age on CLTs …............................................ 88

Table 20. Regression Analysis for Education on CLTs.......................................... 89 
Table 21. Answers to the Question "What is the ideal leadership in Turkey?" 90

Table 22. Expectations Regarding Change in Societal Culture

Dimensions in 2019

Table 23. Summary of the First Four Findings of the Qualitative Study 101 
CHAPTER ONE:

\section{BACKGROUND AND INTRODUCTION}

Throughout human history, people have evolved in societies with distinct characteristics due to political boundaries, ethnicity, and geography. Only after the 20th century did an increase in international business and improvements in communication technology enable societies to learn widely and extensively about one another (House, Hanges, Javidan, Dorfman, \& Gupta, 2004). With increased globalization and political walls coming down, organizational leadership cannot afford to practice solely within the limits of the sovereign territories of countries. To be competitive and successful in international business, leaders must understand the ways that societies differ, as well as how they are similar to each other. While societies become financially interdependent, global leadership becomes crucial for the survival of corporations. Not surprisingly, McKinsey reports that $76 \%$ of corporate executives believe that developing global leadership competencies is imperative for organizations in the 21st century (Dobbs et al., 2013). Even though there is no consensus on the definition of global leadership, the researcher relies on MartinelliLee and Duncan's (2015) proposed description: "The bridging of people between organizations yet across established demarcations, boundaries, and borders through the reciprocal benefit of culture, resources pooling, and intellectual property."

Other researchers also expressed the essentiality of understanding culture to effective global leadership. International business professor Erin Meyer (2014) discusses the importance of understanding different cultures for effective global leadership when arguing: 
What's new is the requirement for twenty-first century leaders to be prepared to understand a wider, richer array of work styles than ever before and to be able to determine what aspects of an interaction are simply a result of personality and which are a result of differences in cultural perspective. ( $\mathrm{p}$. 252)

Furthermore, House et al. (2004) assert that societal culture not only substantially shapes the behavior of the leader, but also the expectations of the leader and the privileges granted to them. Finally, Hofstede (1994) highlights the importance of understanding the national culture to be competitive in global business in his famous article titled "The Business of International Business is Culture."

Hofstede (1980) defines culture as a set of deeply embedded and predominantly unconscious shared values and beliefs of a group of people. Understanding national culture can help international corporations predict organizational, managerial and leadership behavior. Numerous cross-cultural studies show a positive correlation between culture and leadership styles (House, Wright, \& Aditya, 1997). Most of the early leadership literature, however, was written based on Western beliefs, cultures, and values for an effective leadership model across geographic regions (Steers, Sanchez-Runde \& Nardon, 2012). Global leadership has now been identified as an essential success factor for major multinational corporations (Javidan, Dorfman, De Luque, \& House, 2006). Early writings on the topic of culture and how to develop global leaders seem to give general advice or practical information about different countries. Although helpful, these writings are somewhat limited in the theoretical and practical aspects of leading an organization in a foreign country. Four prominent streams of research - Hofstede (1980), Trompenaars (1993), 
Schwartz (1992), and the GLOBE study - have consistently shown the relationship between culture, leadership, and organizational effectiveness. The cultural model developed by these prominent researches have attracted interest both from academia and the business community. One of the critical areas of their research relates to national culture and how cultural differences affect leadership, management, and performance.

One of the most comprehensive methods of assessing cultural values related to leadership has been the GLOBE project. This project began in August 1991 with the goal of creating a framework to estimate the correlation between national culture, organizational practices, and leadership effectiveness in 62 societies. GLOBE's major premise is that leader effectiveness is situational and contextual. In other words, the societal norms, beliefs, and values of followers determine the perception of effective leaders that can vary from culture to culture. As a result, the GLOBE project developed societal and organizational measures of 62 cultures that directly affect their leadership attributes and practices. Specifically, GLOBE empirically established nine cultural dimensions and six global leader behaviors by using previous leadership and cross-cultural literature to capture the similarities and differences between different cultures. The GLOBE team aimed to identify effective leadership characteristics that can be linked to cultural attributes of those societies. Data from 17,300 mid-level managers from 951 organizations were collected in 1995 to map the nine cultural dimensions of 62 different societies to be able to link them to six global leader behaviors.

The GLOBE project then formed ten cultural clusters within 62 nations according to nine cultural dimensions (House, Javidan, Hanges, \& Dorfman, 2002). 
The GLOBE researchers believed that managers need an understanding of cultural differences and expectations of leadership to be effective in international trade. One of the ten cultural clusters of the GLOBE project is the Middle East. Leadership in the Middle East has been largely ignored and was never thoroughly investigated before the GLOBE project (Kabasakal, Dastmalchian, Karacay, \& Bayraktar, 2012). Turkey, a highly populated nation (78.7 million), is part of the Middle Eastern cluster (United Nations Development Programme, 2016). The results of the Turkish survey conducted with 323 middle-level managers reveal that the "As Is" scores (how the current norms, values, and practices are) of Turkish society were high in the following categories: In-group Collectivism, Power Distance and Assertiveness. All three of these dimensions had high absolute scores among other GLOBE societies. Turkey has low absolute and relative scores in dimensions such as Uncertainty Avoidance, Humane Orientation, and Future Orientation. However, the "As Is" score for Gender Egalitarianism in Turkish society is low in the absolute scale, but still similar to most GLOBE societies that have gender inequality practices. Finally, for both Performance Orientation and Institutional Collectivism, Turkey scores low and moderate respectively (Kabasakal \& Bodur, 2007).

Historically, Turkish culture is characterized as having elements of western influence, traditions, and Islam. Increasing globalization in recent years, however, has created new lifestyles -- especially among the younger population. On the other hand, the rise of the Islamist movement, especially after 2003, has created a conflict between modern seculars and conservatives that may have altered the national culture since 1995. Recently, Turkish society has been experiencing major political, social and economic setbacks after the Gezi Protest in 2013, the coup attempt in 2016, and 
the collapse of the economy in 2019 - all of which may have had a tremendous impact on Turkish society. Understanding the change in national culture and its effect on leadership effectiveness is crucial for the leadership development process of Turkish companies and multinational organizations operating in Turkey.

\section{Statement of the Problem}

The GLOBE research program was aimed at filling a substantial knowledge gap concerning the cross-cultural influence on effective leadership and organizational practices. After the GLOBE study, the cross-cultural and international business literature started to include many examples of analysis based on the original GLOBE findings. All of the research related to the GLOBE project, however, used the data collected in 1995. Because of the quarter decade-old data, the results of the research may be outdated, raising questions as to the applicability of its findings to 21 stcentury global leadership training. Moreover, the GLOBE project investigated and compared societal culture and leadership based on a dataset of middle managers in 1995. As time passes, a new generation of employees started to take over mid-level manager positions in organizations. Compared to the group of middle managers in 1995, this new generation of mid-level managers grew up and socialized in a more globalized world by sharing more universal values across cultures. From this perspective, one might expect a change in the middle managers' perception of cultural values and effective leadership. If it happened, comprehending this change would be crucial for cross-cultural literature and multinational organizations. A new follow-up study of 62 societies worldwide, therefore, may be useful for not only the investigation of current societal culture and leadership, but also for understanding the new generation of middle managers' cultural values and leadership expectations, as 
well as their differences from the previous middle managers. Additionally, this new study might be helpful in broadening the empirical basis used to identify how nine cultural dimensions have changed.

Hofstede (1998) and Schwartz (1999) both claim that cultural values are based on centuries of indoctrination that make national culture relatively stable and do not change quickly. On the contrary, Friedman (2016) emphasizes that humans and organizations have been struggling to adapt to profound and rapid change since the 1940s in his prominent book Thank You for Being Late. Furthermore, the European Value Survey states that median values may change when one generation succeeds another generation (Keating, Martin, \& Szabo, 2002). Additionally, Helson, Jones, and Kwan (2002) suggest that people's values change over their lifetime. As a result, the time required to change the culture of a society could be shorter than Hofstede (1998) and Schwartz (1999) suggested.

Since 1995, both the world and global businesses have experienced significant economic, social, and political events (such as the 9/11 terrorist attacks, Iraq and Afghanistan wars, 4th industrial revolution, 2008 global financial crisis, Syria conflict, refugee crisis, ISIS terror attacks, increased nationalism, etc.) that may have altered the findings of the GLOBE project. As an immediate neighbor to major conflicts and wars in Iraq and Syria, Turkish society has been dramatically influenced by these events. Consequently, the political and socioeconomic factors in the past 24 years may have altered the culture of Turkey and the leadership perspectives of middle managers. Furthermore, previous research has not adequately explained the mechanism and context behind the quantitative results. There is a need, therefore, to 
revisit the quantitative study and interpret the findings in more detail, especially regarding actual respondent feedback and perspectives.

As a result, a follow-up study of Turkish culture that replicates the GLOBE methodology will be useful in understanding current Turkish culture and the ways it may have changed since 1995 . The results of the study will also be helpful for multinational organizations, corporate leaders, business executives, and expats who work in Turkey to better position themselves according to the latest state of Turkish culture and leadership perspectives.

\section{Purpose of the Study}

The initial purpose of this study is to re-investigate Turkish culture using the nine cultural dimensions in GLOBE. This study also aims to understand the relationship between Turkish cultural values and current organizational practices, and the human condition of the new generation of Turkish middle managers regarding GLOBE's nine cultural dimensions.

The second purpose of the study is to compare the 1995 findings of the GLOBE Project by repeating the same survey in 2019 with a similar sample of Turkish mid-level managers operating in similar industries. The research aims to learn how major socioeconomic and political events have influenced the national culture of Turkey (and accordingly the management practices) and leadership perceptions. In the first quantitative phase of the survey, the GLOBE Phase2 Beta Questionnaire was used to collect data from mid-level managers of corporations operating in Turkey to update the GLOBE Project findings.

The third and last purpose of the study is to conduct several extensive qualitative interviews to understand and help explain the new quantitative findings in 
an effort to determine how significant political and socioeconomic events may have changed the previous findings of GLOBE study. In this explanatory follow-up, the purpose is to gather the views of a small sample of current mid-level managers and examine their perceptions of the cultural changes that may have occurred as a result of the significant political and social events since 1995. These in-depth interviews will also identify any possible discrepancies between the quantitative and qualitative data findings.

\section{Research Questions}

The following overarching research questions serve as a guide for the study.

1. Where do Turkey and Turkish culture stand regarding nine GLOBE cultural dimensions in 2019 ?

2. How have ideals and perceptions of leadership changed in the past 25 years?

3. What social, political, and economic factors may explain any possible changes in cultural values and leadership ideals in Turkey?

The next chapter further examines the literature that guided this study. 


\section{CHAPTER TWO:}

\section{LITERATURE REVIEW}

This section of the document is structured into five sections. The first section includes a review of prior literature on the most prominent cross-cultural research and theory. The second is a detailed description of the general GLOBE approach and the GLOBE literature. The third section includes a critique of the GLOBE project. The fourth section will be a brief description of the factors that may have altered Turkish culture and values since 1994 and therefore would warrant further study of culture and leadership in Turkey. Lastly, this section concludes with recommendations for future research.

\section{Cross-Cultural Studies}

Global leadership has been identified as an essential success factor for major multinational corporations (Javidan, Dorfman, et al., 2006). However, many challenges are facing global executives and corporations and how they can develop useful global leadership capabilities. Early writings on the topic seemed to give general advice (e.g., being sensitive and open-minded of other cultures) or particular information about a country (e.g., not showing the soles of the shoes when seated as a guest in an Arab country) (Javidan, Dorfman, et al.). Although helpful, these writings are somewhat limited in the theoretical and practical aspects of leading an organization in a foreign country. One of the critical areas of international business research relates to national culture and how cultural differences affect leadership, management, and performance. Understanding the national culture can help organizations predict managerial and leadership behavior. 
There is considerable evidence in the literature that suggests a relationship between culture, leadership, and organizational effectiveness. In particular, four prominent streams of research have consistently shown such relationships. The cultural model developed by Hofstede (1980), Trompenaars (1993), Schwartz (1992, 1994), and the newer GLOBE study (House et al., 2004) have attracted much research interest.

\section{Hofstede}

Hofstede (1980), a pioneer of cultural studies, defines culture as a set of deeply embedded and predominantly unconscious shared values and beliefs of a group of people. Hofstede ranked the countries by cultural dimensions that were collected between 1967 and 1973; this research has been replicated several times and has shown that fundamental cultural values change very slowly (Hofstede, 1980; Hoppe, 1993). Hofstede's seminal book, published in 1980, elevated cross-cultural analysis as the new frontier in international business research (Tung \& Verbeke, 2010). Hofstede (1994) made the famous assertion that the "business of international business is culture" (p. 1).

Hofstede (1980) defined characteristics of culture-especially in the workplace — based on a large research project across subsidiaries of a multinational corporation (IBM) in 72 countries, which then decreased to 40. Originally, Hofstede identified four dimensions after factor analysis of his data: (a) power distance, (b) uncertainty avoidance, (c) individualism vs. collectivism, and (d) masculinity vs. femininity. Power Distance is defined as the difference between the degree to which the boss can determine the behavior of subordinates and the extent to which subordinates can determine the behavior of the boss (Hofstede, 2001). Uncertainty 
avoidance is defined as the shunning of ambiguity (Hofstede, 1980). Individualism vs. collectivism refers to how people from individualist countries see themselves as separate identities, whereas people from collective countries define their identity as long-lasting group membership (Hofstede, 1980). Hofstede's (1980) definition of masculinity vs. femininity is the difference between countries who value assertiveness and those who value nurturance, which is considered controversial because it is not related with gender (Smith, Fischer, Vignoles, \& Bond, 2013). After years of adaptation and fine-tuning, Hofstede (2001) listed another fifth dimension of culture in the global workplace: long-term vs. short-term orientation. Lastly, Hofstede increased the number of dimensions to six by adding indulgence vs. restraint: Indulgence stands for a society that allows relatively free gratification of basic and natural human drives related to enjoying life and having fun. Restraint stands for a society that suppresses gratification of needs and regulates it by means of strict social norms. (Hofstede Insights, 2019, "Indulgence Versus Restraint," para. 1)

Using data from 598 studies representing over 200,000 individuals, Taras, Kirkman, \& Steel (2010) analyzed the relationship between Hofstede's (1980) original four cultural value dimensions and a set of organizational outcomes. They predicted certain organizational and employee outcomes (e.g., organizational commitment and identification, team-related attitudes and perceptions) similar to or stronger than other individual differences (e.g., personality traits; Taras, Kirkman, et al., 2010). They also found that the predictive power of cultural values depends on contingency factors, such as demographic characteristics, primary versus secondary 
data, and the cultural tightness/looseness of the countries in which the data were collected (Taras, Kirkman, et al., 2010).

Hofstede's (1980) work is subject to several criticisms. First, Hofstede's national culture dimension measures are not based on extensive theoretical and empirical research (Venaik \& Brewer, 2013). Second, since the initial aim of Hofstede was not academic or scientific research — he was a consultant for IBMHofstede did not follow the steps required for academic research. Javidan, House, Dorfman, Hanges, and De Luque (2006) called Hofstede's research “nonaction research," which should follow steps such as fact-finding, planning, action, evaluation, and amended plans. Third, Hofstede did not have a random sampling strategy. Hofstede's sample was from IBM, where all respondents shared a common organizational culture that can be very different from a national culture considering IBM is a U.S.-based company (Smith, Dugan, \& Trompenaars, 1996).

Furthermore, while designing his questionnaire, Hofstede had to integrate the needs, purposes, and aims of IBM since he was contracted not for a scientific project, but for a particular need of IBM. For example, the short- versus long-term orientation dimension was later added and it was not a part of the initial questionnaire since IBM was not interested in this cultural dimension (Javidan, House, et al., 2006). Next, Hofstede analyzed his data at the national level, not at the individual level, which means he treated each nation as a single case. Therefore, Hofstede had to calculate average scores of respondents in each nation regardless of the sample size because he could not control the number of respondents from each country (e.g., 11,384 from Germany, but 58 from Singapore; Smith et al., 2013). Consequently, the items used to measure Hofstede's national dimensions did not measure an individual level, but 
instead the average of a national level and therefore cannot be used for management theories (Venaik \& Brewer, 2013). Finally, Javidan, House, et al. (2006) claimed that Hofstede ignored vital statistics and psychometrics in his seminal 1980 book. For example, for evidence of aggregability, statistical analysis is ignored. As a result, Hofstede's work has generalizability issues related to the lack of proper scientific steps, relevant statistical analysis, and designing his survey according to IBM's needs.

The GLOBE project is directed toward filling the substantial knowledge and methodological gaps in Hofstede's (1980) model concerning the cross-cultural forces relevant to effective leadership and organizational practices. The GLOBE project is a multiphase, multi-method project to develop an empirical theory to analyze, understand, and predict the impact of particular culture on leadership effectiveness (House et al., 2002). Consequently, the GLOBE project's research is a better tool to understand the effect of societal culture on leadership.

The other prominent cultural model researcher is Trompenaars (1993) who, unlike Hofstede, searched for preferred behavior in both work and leisure contexts. It is imperative to understand Trompenaars' cultural studies and model to appreciate the advances in the GLOBE's project design.

\section{Trompenaars}

Trompenaars (1993) is a Dutch-French management consultant and organizational theorist who proposed a model of seven fundamental dimensions of national culture for understanding cultural differences in business in his book, Riding the Waves of Culture. Some of Trompenaars' questionnaire items aimed to obtain values by asking respondents how they would act in a series of briefly described 
hypothetical situations, while other items provided a forced choice between two value statements.

Trompenaars' (1993) first five dimensions explain the interactions people have with each other, including (a) individualism vs. collectivism, (b) universalism vs. particularism, (c) specific vs. diffuse, (d) neutral vs. emotional, and (e) achievement vs. ascription. These five dimensions are derived directly from Parsons and Shils' (1951) value dilemmas. The concept of achievement vs. ascription indicates the characteristics of a person's ability to determine their status. The sixth dimension - internal direction vs. external direction — is derived from the work of Rotter (1966) and measures behavior toward the environment. The seventh dimension - sequential vs. synchronous - is derived from Cottle (1968) and measures the time perception of cultures.

Trompenaars' (1993) research instrument was based on existing theory. However, his research samples were small, and the sample of nine countries he studied was statistically insufficient to develop a multidimensional model (Hofstede, 1996). Furthermore, Trompenaars did not present the scores of the countries in the data on his six dimensions as GLOBE did, which is an important tool for practitioners in order to compare countries. Hofstede (1996) critiqued Trompenaars' approach by claiming that Trompenaars confused conceptual categories with dimensions and based his assertion on Parsons and Shils (1951) theory. Trompenaars (1993) created his five dimensions according to Parsons and Shils (1951) research. Hofstede claims that Parsons and Shils' theory is speculative because the philosophy is dated back to the 1940s, and there is no research supporting it. Finally, Hofstede (1996) asserted that 
Trompenaars' research lacked content validity because his instrument did not cover the universe of relevant aspects of national culture literature.

The GLOBE project is directed toward addressing Trompenaars' (1993) validity issues and the methodological gap concerning the cross-cultural forces relevant to effective leadership and organizational practices. The GLOBE's research is theory-driven, as they first identified the general nature of the constructs they wanted to measure before creating the GLOBE scales. This vital process determines how the items should be written and which statistical analysis needs to be performed to evaluate the sufficiency of the scales. As a result, the GLOBE's research program is a better project to identify the effect of societal culture on leadership.

Schwartz's $(1992,1994)$ approach was one of the essential examples that the GLOBE project team used in their process which is to follow a theory-driven approach in developing their value survey. One should review Schwartz's (1992, 1994) work, one of the pioneering research projects that has identified cultural dimensions of values, to understand the GLOBE project better.

\section{Schwartz}

Schwartz $(1992,1994)$ is a social psychologist and a cross-cultural researcher. The GLOBE project attempted to follow the theory-driven approach that Schwartz took when developing the questionnaire scales (as cited in House et al., 2004). Before developing the value survey, Schwartz reviewed the philosophical, religious, and empirical literature from numerous cultures to identify several values and then grouped these values into 10 categories he believed to be universally appropriate (Smith \& Schwartz, 1997). Furthermore, Smith et al. (1996) suggested that Schwartz is one of the pioneering researchers who has directly aimed at identifying cultural 
dimensions of values. Consequently, Schwartz is worthy of mention in this literature review since House et al. (2004) suggested that Schwartz's values survey is a distinct example of the utility of developing scales according to a theory-driven approach.

Schwartz (1992) did a parallel series of individual-level studies of a set of specific values within 67 different nations. Then, in 1994, Schwartz widened his individual-level classification of human values to the society level to differentiate cultures by dimensions (House et al., 2004). Schwartz developed a 56-value survey and then grouped them into 10 categories. He then developed a model of interrelations among those categories (Schwartz, 1992, 1994). The GLOBE project team used a similar approach when developing the GLOBE scales. The 10 values include: (a) selfdirection, (b) stimulation, (c) hedonism, (d) achievement, (e) power, (f) security, (g) conformity, (h) tradition, (i) benevolence, and (j) universalism. After analyzing value data from each country, Schwartz created seven dimensions to differentiate societies: (a) embeddedness, (b) harmony, (c) egalitarian, (d) commitment, (e) intellectual autonomy, (f) affective autonomy, (g) mastery, and (h) hierarchy.

The GLOBE project expects strong relationships and the correlation between Schwartz's (1992) scales and the GLOBE societal and cultural values (Should Be) scales. For example, Schwartz's Egalitarian Commitment dimension is significantly positively related to GLOBE's (2004) societal Gender Egalitarianism cultural values measure and negatively related to GLOBE's societal Assertiveness cultural values scale. Also, Schwartz's Hierarchy dimension is significantly positively related to the GLOBE societal Power Distance scale (House et al., 2004). There are also some similarities between Hofstede's classification and Schwartz's classification even though they use different names. For example, Schwartz's Hierarchy vs. 
Egalitarianism is very close to Hofstede's Power Distance definition. Another is Embeddedness vs. Autonomy of Schwartz, which is very similar to Hofstede's (1980) individualism vs. collectivism.

Even though Brett and Okumura (1998) stated that Schwartz's (1992) framework is more advanced than Hofstede's model, there are several criticisms of Schwartz. For example, Steenkamp (2001) asserted that Schwartz's framework has not been tested through application for validity. Moreover, the items Schwartz had in his data sets were developed to measure individual-level value dimensions that limit the derivation of the cultural dimensions (Steenkamp, 2001). As a result, Schwartz's framework has not been used widely for international business purposes. Another reason why Schwartz's framework has yet to be applied widely could be characteristics of his sample. Since Schwartz (1992) collected data from 44,000 school teachers and university students in 54 countries, there may be a representativeness issue for corporate context.

However, the GLOBE project is focused on filling the gaps and the methodological issues in Schwartz's (1992) model concerning the cross-cultural forces relevant to effective leadership and organizational practices. The GLOBE project is the largest and most prestigious study of its kind in the cross-cultural literature with more than 200 researchers from 62 societies studying more than 17,000 midlevel managers (House et al., 2004). Therefore, the GLOBE is a superior tool to study cultural dimensions and its effect on leadership perception.

\section{The GLOBE Project}

One of the most comprehensive methods of assessing cultural values in relation to leadership is the GLOBE project, which defines culture as "shared motives, 
values, beliefs, identities, and interpretations or meanings of significant events that result from common experiences of members of collectives that are transmitted across generations" (House et al., 2004, p. 15). The GLOBE researchers argue that culture affects leadership characteristics, attributes, and behaviors and moderates the outcomes resulting from different styles of leadership (House et al., 2004). With more than 200 researchers from 62 societies studying more than 17,000 midlevel managers from 951 local industries in the initial phases, the 2004 GLOBE study is the largest and most prestigious study of its kind in the social sciences. The GLOBE developed a set of measures that led to a new perspective on the measurement of cultural similarities and differences and formed 10 cultural clusters within 62 societies (House et al., 2002).

The GLOBE is an ongoing project; in the latest 2014 study, more than 70 researchers collected data from over 100 CEOs and 5,000 senior executives in corporations in a variety of industries in 24 countries. The latest study demonstrated the considerable influence of culture on societal leadership expectations and the importance of matching CEO behaviors to expectations for leadership effectiveness. The next section explains the GLOBE project in greater detail.

\section{The Need for the GLOBE Project}

Globalization and the increased size of international trade after the 1980s are the primary drivers for the GLOBE project (Javidan, Dorfman, et al., 2006). The GLOBE team believed that effective leaders should understand cultural differences and expectations of leadership for successful international trade. One key lesson arising from the project is that the development of global managers requires more than just acquiring experience with and general knowledge of different countries 
(Javidan \& Dastmalchian, 2009). Unfortunately, the literature shows that crosscultural research in the last 15 years before GLOBE is often theoretic and fraught with methodological problems. Therefore, previous research not only lacks the guidance for leaders for global challenges but also creates more questions about the culturally contingent aspects of leadership. Subsequently, the GLOBE research program is directed toward filling a substantial knowledge gap concerning the cross-cultural forces relevant to effective leadership and organizational practices (House et al., 2004).

\section{The GLOBE Methodology}

The GLOBE is a worldwide, multiphase, multimethod project started in the summer of 1991. By the end of 1993, 735 questionnaire items were developed, and more than 200 researchers started to collect data in 62 cultures to better understand how national culture influences leadership and organizational behavior over a 10-year period. From three industries and 951 organizations, 17,370 middle managers completed the questions asking them about their organization's culture, their society's culture, and their beliefs about the effectiveness of various attributes for outstanding leaders.

The theoretical base that guides the GLOBE research program is an integration of implicit leadership theory (Lord \& Maher, 1991), value/belief theory of culture (Hofstede, 1980), implicit motivation theory (McClelland, 1985), and structural contingency theory of organizational form and effectiveness (Pfeffer, 1982). A notable strength of the GLOBE research design is the combination of the quantitative and qualitative methodologies. Quantitative processes involve a hierarchical model that assesses both absolute and relative standings on dimensions as 
well as multiple measures from multiple perspectives (Dickson, Aditya, \& Chhokar, 2000). Qualitative methodologies are used to help understand the variation in meanings during development of the questionnaire and scales. The elimination of conventional method and common source variance is another strength of the GLOBE design strategy (House et al., 1999).

To differentiate societal attributes, the GLOBE research team developed 735 questionnaire items after reviewing prior literature. There were three significant innovations in the project. First, GLOBE participants rated individual perceptions and aggregated perceptions of others as a social group in their society or organization. Second, half of the respondents rated their organization, and the other half rated their society. This approach allows the connections between these two sets of measures as well as links with the measures of leadership to be tested in an unbiased manner. The third and most important innovation is that participants completed two sets of ratings that describe their society or organization "as it is" and "as it should be," leading to measures of practices and values respectively (Grove, 2005). After two pilot studies and several psychometric tests (e.g., factor analysis, generalizability, item analysis, cluster analysis), nine significant attributes of culture were identified—six of them derived from Hofstede's original four — named as Cultural Dimensions, and serve as independent variables.

\section{The Cultural Dimensions in the GLOBE Project}

This section describes each of the nine Cultural Dimensions in detail.

Performance orientation. This cultural dimension refers to the degree to which a group encourages and awards group members for demonstrating 
advancement in performance and high standards in execution. The focus of this dimension is future-oriented (House et al., 2004).

Uncertainty avoidance. This cultural dimension denotes the extent to which the members of a group strive to abstain from uncertainty by adhering to socially accepted rules and practices to reduce the possibility of unpredictable and undesirable events. The desire of people to minimize or eliminate uncertainty leads them to look for "orderliness, consistency, structure, formalized procedures and laws" (House et al., 2004, p. 603).

Power distance. This cultural dimension measures the extent to which the members of a group hold the idea that power should be unevenly distributed and concentrated at higher levels of a social or an organizational structure. In countries that score high in Power Distance, those in authority positions not only anticipate, but also receive obedience. Lower Power Distance provides people with better access to information, greater involvement in decision-making processes and higher upward social mobility (House et al., 2004).

Institutional collectivism. This cultural dimension measures the importance that institutions place on "collective distribution of resources and collective action" (House et al., 2004, p. 30). Organizations in high Institutional Collectivistic countries tend to promote group performance and rewards.

In-group collectivism. In contrast to Institutional Collectivism, this social dimension gauges to what extent society approves of attitudes that confirm and promote an individual's pride and loyalty to one's inner group or family. Authority figures tend to be highly respected in societies that have high In-group Collectivism (House et al., 2004). 
Assertiveness. This social dimension refers to the degree to which individuals favor the demonstration of confrontational and aggressive behaviors to maintain their relationships with others (House et al., 2004).

Gender egalitarianism. This social dimension relates to the degree to which an organization or a society minimizes gender inequality, thereby maximizing equality in gender status, roles, and impact in society. Northern European countries which are feminine compared to other countries score high on Gender Egalitarianism. Organizations operating in countries that have a high score in this dimension tend to create an environment that is conducive to the diversity of opinions and individuals (House et al., 2004).

Future orientation. This social dimension measures the amount of futureoriented behaviors that the members of a group are involved in. These attitudes include delaying gratification both at the individual and group level, systematic planning, and devoting time, energy and money in the future. Organizations in high Future-oriented countries tend to be averse to risk-taking and opportunistic decisionmaking, contrasted with organizations in low Future-oriented countries (House et al., 2004).

Humane orientation. This social dimension refers to the degree to which organizations or societies appreciate and encourage their members "for being fair, altruistic, friendly, generous, caring and kind to others" (House et al., 2004, p. 30). Countries that rank high on this cultural practice tend to rank high in femininity in social groups. 


\section{Culturally Endorsed Implicit Theory of Leadership in the GLOBE Project}

The dependent variables are defined in this section to create a relationship between the nine core GLOBE cultural dimensions and leadership dimensions impacted by culture. The dependent variables originate from culturally endorsed implicit leadership theory (CLT), the Human Development Index, gross national product per capita (GNP), and measures of the psychological and physical welfare of members and additionally include several variables related to the human condition in each society. A fundamental concept in the GLOBE program is the CLT developed from the implicit leadership theory literature, which will be described in detail in the following sections (De Luque, Lelchook, \& Quigley, 2015).

The implicit beliefs of individuals concerning the fundamental nature of leadership have a direct influence on CLT. Additionally, societal culture may influence leadership behaviors and attributes, which will, in turn, determine whether the leader is effective and accepted by followers, although CLT moderates this relationship.

The primary purpose of the GLOBE project is to identify which effective leadership characteristics can be linked to cultural attributes of societies. Initially, 21 primary leader behaviors are identified as effective leadership contributors, and eight leadership attributes are identified as impediments of effective leadership in all societies. Also, the GLOBE team identified 35 leader behaviors as either a contributor or an impediment in different societies. Finally, the research team identifies six global leader attributes to use as dependent variables. The GLOBE project reported an aggregated nine cultural dimension score for each society. However, the links between each of the nine dimensions and the final six global leader behaviors are 
reported globally instead of for each society. These global leader behaviors (leadership dimensions) are briefly defined as follows:

Charismatic/value-based leadership. This leadership dimension refers to the ability to encourage, to galvanize and to look for high performance results from others grounded in strongly held essential values (Dorfman, Javidan, Hanges, Dastmalchian, \& House, 2012). Charismatic/Value-Based leadership is commonly stated to contribute to outstanding leadership (Javidan, Dorfman, et al., 2006). The six primary leadership dimensions included in this dimension are visionary, inspirational, selfsacrifice, integrity, decisive, and performance oriented (Dorfman et al., 2012).

Team-oriented leadership. This is a global leadership dimension that reflects the skills needed to build highly effective teams and to execute collective goals among team members (Dorfman et al., 2012). Team-Oriented leadership is generally stated to contribute to outstanding leadership (Javidan, Dorfman, et al., 2006). Five primary leadership dimensions are covered in Team-Oriented leadership. These are collaborative team orientation, team integrator, diplomatic, malevolent and administratively competent (Dorfman et al., 2012).

Participative leadership. This global leadership dimension indicates to what degree managers tend to include others in decision making processes and implementation of those decisions (Dorfman et al., 2012). Even though there are differences among participant countries and clusters, Participative leadership is mostly perceived as the contributor to exceptional leadership (Javidan, Dorfman, et al., 2006). Nonparticipative and autocratic are two primary leadership dimensions that are included in Participative leadership (Dorfman et al., 2012). 
Humane-oriented leadership. This global leadership dimension refers to encouraging, sensitive, and concerned leadership. Those leaders who demonstrate Humane-Oriented leadership are also compassionate and generous (Dorfman et al., 2012). Humane-Oriented leadership is conceived as either a neutral or moderate contributor to outstanding leadership (Javidan, Dorfman, et al., 2006). The two primary leadership dimensions included in this leadership dimension are modesty and humane orientation (Dorfman et al., 2012).

Autonomous leadership. This recently defined leadership dimension emphasizes independence and individualism (Dorfman et al., 2012). This leadership dimension is seen as a hindrance to exceptional leadership by some societies and a contributor to exceptional leadership to some degree (Javidan, Dorfman, et al., 2006). The Autonomous leadership dimension is represented by a single primary leadership dimension categorized as Autonomous leadership. This primary leadership dimension consists of individualistic, independence, autonomous, and unique attributes (Dorfman et al., 2012).

Self-protective leadership. This is a newly defined global leadership dimension that refers to safeguarding the individual and team through status improvement and face-saving (Dorfman et al., 2012). The countries and clusters generally perceive Self-Protective leadership as hindering outstanding leadership (Javidan, Dorfman, et al., 2006). This leadership dimension includes five primary leadership dimensions that are self-centered, status-conscious, conflict induces, facesaver, and procedural (Dorfman et al., 2012).

\section{Regional Clustering of Societal Cultures}


This part of the paper presents the conceptual and empirical process by which GLOBE grouped the 62 societies into a set of 10 regional clusters. The GLOBE wanted to understand the similarities and differences among the 62 societies. Table 1 presents the 62 societies and their regional clusters.

Table 1

Major Cultural Clusters in the World by Region

\begin{tabular}{|c|c|}
\hline $\begin{array}{l}\text { Cultural } \\
\text { Cluster }\end{array}$ & Countries \\
\hline \multirow[t]{2}{*}{ Anglo } & Australia, Canada, England, Ireland, New Zealand, White \\
\hline & South Africa \\
\hline Nordic Europe & Denmark, Finland, Sweden \\
\hline Germanic Europe & Austria, Germany, German Switzerland, the Netherlands \\
\hline Latin Europe & France, Israel, Italy, Portugal, Spain, French Switzerland \\
\hline \multirow[t]{2}{*}{ Eastern Europe } & Albania, Azerbaijan, Estonia, Georgia, Greece, Hungary, \\
\hline & Kazakhstan, Poland, Romania, Russia, Slovenia \\
\hline \multirow[t]{2}{*}{ Confucian Asia } & China, Hong Kong, Japan, Singapore, South Korea, \\
\hline & Taiwan \\
\hline Southern Asia & India, Indonesia, Iran, Malaysia, the Philippines, Thailand \\
\hline \multirow[t]{2}{*}{ Latin America } & Argentina, Bolivia, Brazil, Colombia, Costa Rica, Ecuador, \\
\hline & El Salvador, Guatemala, Mexico, Peru, Venezuela \\
\hline Middle East & Egypt, Kuwait, Morocco, Qatar, Turkey \\
\hline South Pacific & Fiji, Salomon Islands, Tonga, Vanuatu \\
\hline
\end{tabular}

Note. Data from the GLOBE project (House et al., 2004).

Anglo. The Anglo cluster scores high on Performance Orientation and low on In-group Collectivism. It is in the mid-score range on the rest of the societal 
dimensions (House et al., 2004). Performance orientation is generally perceived as an achievement of material wealth in countries of this cluster, especially in the United States and South Africa (White) (Ashkanasy, Trevor-Roberts, \& Earnshaw, 2002). The Anglo cluster confirms Charismatic/Value-Based leadership very strongly by having the highest score among all clusters. This cluster also approves of TeamOriented leadership and Humane Oriented elements of Participative leadership somewhat strongly. All Anglo countries highly value person-oriented leadership that means that a leader should perform as a part of a team while delivering the results. Self-protective behaviors are rather disregarded by the countries in this cluster (Chhokar, Brodbeck, \& House, 2007).

Latin Europe. The Latin Europe cluster scores low on the Humane Orientation and Institutional Collectivism dimensions of societal culture. This cluster is in the middle range for the rest of the dimensions (House et al., 2004). In this cluster, the outstanding leader is expected to demonstrate Charismatic/Value-Based leadership supported by Team-Oriented and Participative leadership. HumaneOriented leadership takes the fourth place in importance. Autonomous and SelfProtective leadership are less respected leadership attributes in the Latin Europe cluster (Jesuino, 2002).

Nordic Europe. The Nordic cluster scores high on Institutional Collectivism, Gender Egalitarianism, Future Orientation and Uncertainty Avoidance and low on Assertiveness, In-group Collectivism and Power Distance. This cluster falls in the middle range of scores on Humane and Future Orientation (House et al., 2004). When it comes to leadership, the countries in this cluster strongly support a mixture of high Charismatic/Value-Based and Team-Oriented leadership along with substantial 
attributes of Participative leadership. Self-Protective leadership is perceived as completely negative by this cluster. The Nordic Europe demonstrates tolerance for Autonomous leadership (House et al., 2004).

Germanic Europe. The Germanic Europe cluster has high scores on Assertiveness, Future Orientation, Performance Orientation and Uncertainty Avoidance and low scores on Human Orientation, Institutional Collectivism and Ingroup Collectivism. Gender Egalitarianism and Power Distance are societal culture dimensions where this cluster scores in the middle-range (House et al., 2004). High scores on the particular societal cultural elements signify the tendency of this cluster toward standardization, rules, hierarchy, and assertiveness (Szabo et al., 2002). Concerning the most effective leadership, this cluster strongly favors Participative leadership. Indeed, the cluster has the highest score for Participative leadership among all 10 clusters. The high-level endorsement of Participative leadership in these countries seems to be greatly impacted by the existing models of relationship between "labor" and "capital." Cooperation and coordinated actions lie at the center of these relations in pursuit of creating better economic equilibrium (Szabo et al., 2002). On the other end of the spectrum, this cluster views Self-Protective leadership very negatively (House et al., 2004).

Eastern Europe. This cluster scores high on Assertiveness, Gender Egalitarianism, and In-group Collectivism and low on Future Orientation, Performance Orientation, and Uncertainty Avoidance. Its scores on Humane Orientation, Institutional Collectivism, and Power Distance range in the middle (House et al., 2004). The high "group orientated power distance" is the distinctive characteristic of this cluster in the global perspective. Compared to the GLOBE 
countries as a whole, the countries in this cluster seemed to demonstrate more tolerance to uncertainty and behave from a more gender-egalitarian standpoint (Bakacsi, Sandor, Andras, \& Viktor, 2002). In this cluster, the image of an outstanding leader has a blend of Team-Oriented leadership with Charismatic/ValueOriented leadership, which appears to originate from the high power stratification in the countries of this cluster (Bakacsi et al., 2002; House et al., 2004). The same ideal leader image also carries the characteristics of reasonably high levels of Autonomous leadership and Self-Protective leadership behaviors (House et al., 2004).

Middle East. This cluster scored high on the In-group and family collectivism and Power Distance dimensions of societal culture. The scores on these dimensions were higher than the average of the countries included in the GLOBE's worldwide sample. Its scores on the Assertiveness, Humane Orientation, Institutional Collectivism, and Performance Orientation dimensions were in the medium range. The Middle East cluster had low scores on Gender Egalitarianism, Future Orientation, and Uncertainty Avoidance (House et al., 2004). In the Middle East cluster, individuals not only had strong ties with their families, but they also identified themselves in relation to their family. Moreover, the self is suppressed for the wellbeing of the family. In addition to the family, being part of other groups in society plays a crucial role for the societies in this cluster. The focus of the individuals on strong commitment to their in-group relationships diminishes the attention directed toward Performance and Future Orientation (Kabasakal \& Bodur, 2002).

The Middle Eastern cluster viewed Team-Oriented leadership and Charismatic/Value-Based leadership as the attributes contributing most to outstanding leadership (House et al., 2004). While Participative and Humane-Oriented leadership 
are perceived to contribute to the effectiveness of a leader to a small degree, SelfProtective and Autonomous leaders are assumed to have a slight negative impact on effective leadership in the Middle East cluster (Kabasakal \& Bodur, 2002).

Latin America. The In-group-Collectivism dimension of societal culture was the only dimension on which Latin America scored high. Its scores for Assertiveness, Gender Egalitarianism, Human Orientation, and Power Distance were in the midrange. This cluster scored low on Future Orientation, Institutional Collectivism, Performance Orientation, and Uncertainty Avoidance (House et al., 2004). As the scores of this cluster demonstrate, Latin American countries seem to reject intervening in life and tend to put too much emphasis on results. These societies would worry about the protection of In-group Collectivism and the status of individuals (Gupta, Hanges, \& Dorfman, 2002). When it comes to leadership, this cluster values Charismatic/Value-Based leadership combined with Team-Oriented leadership. There is a moderate endorsement for Participative leadership and Humane-Oriented leadership in this cluster (House et al., 2004).

Confucian Asia. This cluster scored high on In-group Collectivism, Institutional Collectivism, and Performance Orientation. The scores for the Confucian Asia cluster on the remaining dimensions of societal culture range in the middle (House et al., 2004). It is not surprising that the Confucian Asia cluster had high scores on societal collectivism since this cluster has historically been impacted by Chinese culture, which is differentiated by its focus on networks and trust (Ashkanasy, 2002). According to the Confucian Asia cluster, an outstanding leader has a combination of Charismatic/Value-Based leadership and Team-Oriented leadership. This cluster also positively endorses Humane-Oriented leadership and 
Participative leadership. Although Self-Protective leadership is seen as indifferent or preventing outstanding leadership in this cluster, the cluster received the highest score in this dimension among all the clusters (House et al., 2004).

Southern Asia. This cluster scored high on Humane Orientation and In-group Collectivism. The remaining dimensions of societal culture were in the midrange in the Southern Asia (House et al., 2004). Gupta, Surie, Javidan, and Chhokar (2002) indicated that social division of labor (e.g., the caste system in India) and hierarchal order are forged into the DNA of societies. The Southern Asia cluster strongly endorses Charismatic/Value-Based leadership and Team-Oriented leadership (House et al., 2004). In other words, the countries in this cluster saw leaders who are ingenious, inspirational, and determined and who have a high level of morals as ready to make personal sacrifices as outstanding leaders and as capable of building and maintaining inspiring teams (Gupta, Surie, et al., 2002). Participative leadership and Humane-Oriented leadership were also valued positively by the countries in this cluster (House et al., 2004).

\section{The Findings of the GLOBE Project}

The GLOBE Project results are presented in the form of quantitative data based on responses from more than 17,000 managers which describes how each of 62 societies scores on nine dimensions of cultures and six global leader behaviors (leadership dimensions) in the researchers' 2004 book with more than 800 pages, five editors, and 20 contributing authors (House et al., 2004). The GLOBE project found that there is wide variation in the values and practices regarding the nine dimensions of cultures and also wide variation in perceptions of effective and ineffective leader behaviors. The GLOBE also ranks 62 societies concerning nine cultural dimensions of 
their cultures (House et al., 2004). For example, Javidan and House (2001) reported that countries such as Malaysia, Ireland, and the Philippines value human relations and sympathy as well as support for the weak and vulnerable. Javidan and House (2001) also highlighted that cultural acumen may mitigate problems associated with cultural differences in a multinational team. In addition, the researchers (Javidan \& House, 2001) recommended that executives remain mindful of Power Distance and Uncertainty Avoidance cultures, continually remind colleagues about specific cultural differences, and exhibit a good sense of humor.

The GLOBE project also showed empirical findings on how societal culture influences organizational culture, and how these two elements influence culturally endorsed implicit theories of leadership (House et al., 2004). The GLOBE findings supported the hypothesis that selected cultural differences strongly influence the way people think about leaders and norms concerning the status, influence, and privileges granted to leaders (House et al., 2004). Different national cultures dictate different leadership expectations in their societies that indirectly influence leadership behaviors (House et al., 2004). Leaders who behave according to expectations are the most effective (Dorfman et al., 2012). For example, the GLOBE team found only a small number of universal leadership attributes/behaviors (such as trustworthy, decisive, informed) (House et al., 2004). Most of the leader attributes/behaviors were culturally dependent, and their desirability was strongly related to culture (House et al., 2004). Autonomous leadership was more suited for performance-oriented societies but less effective in collectivistic and human-oriented societies (House et al., 2004). Charismatic/Value-Based leadership was more suited for Gender Egalitarian, FutureOriented, Humane-Oriented, Collectivistic, and Performance-Oriented cultures but 
less effective in high Power Distance societies (Hanges, Aiken, Park, \& Su, 2016). Self-Protective leadership varies by culture but tends to be negatively endorsed, and Autonomous leadership is often perceived as harmful. Many outstanding global leaders are associated with the performance orientation (Grove, 2005). The newly developed culture measures were assessed for variability and deviations (House et al., 2004). For seven of the nine cultural dimensions, the values and practices measures were found to be negatively correlated with one another (House et al., 2004).

Finally, the GLOBE project presented a set of cultural dimensions that are strongly related with GNP, country competitiveness, country prosperity and the physical and psychological welfare of members of the societies (House et al., 2004).

\section{Further Research with the GLOBE Framework}

The GLOBE findings were used as a basis for conceptualizing global leadership differences (Javidan, Dorfman, et al., 2006). Javidan, Dorfman, et al. (2006) employed a hypothetical case of an U.S. executive in charge of four similar teams in Brazil, France, Egypt, and China to discuss cultural implications for the U.S. executive. This approach allowed the researchers to interact effectively with employees from different cultures in five different countries (Javidan, Dorfman, et al., 2006). Similarly, the critical results from the GLOBE study were applied to a real-life case of a North European business school that was developing an extensive executive program for a large South Asian corporation (Javidan, Stahl, Brodbeck, \& Wilderom, 2005). According to the researchers (Javidan, et. al, 2005), executives need to take a proactive and systematic approach to dealing with cultural differences. Javidan and his colleagues (2005) also mentioned that executives need to define common goals and success criteria in cross-border transfer of knowledge, be mindful of their 
potential cultural challenges, ensure proper management of the relationship, and treat every case of cross-border knowledge transfer as a learning opportunity to improve their chances for the future.

Mensah and Chen (2012) extended the GLOBE results by deriving a quantitative statistical model of country cultural clustering using observable data from countries used in the original GLOBE study. More specifically, the multivariate discriminant analysis was used to examine the observable attributes of these countries, based on factors of racial/ethnic distribution, religious distribution, geographic proximity of the countries, primary language distribution, and colonial heritage (Mensah \& Chen, 2012). McCrae, Terracciano, Realo, and Allik (2008) remind that stereotypes can be powerful social forces even when they are unfounded. By comparing GLOBE scales with aggregate assessed personality traits and measures of perceived national character, McCrae et al. (2008) show that GLOBE scales are better construed as unfounded stereotypes than as actual depictions of the society members' personality traits. Instead of individual-level metric structures, Peterson and Castro (2006) proposed aggregating individual-level data, such as scales and items before they are analyzed at the aggregate level in cross-cultural research. This approach allowed the higher-level characteristics to be measured based on relationships among items or scales.

A comparison of the Hofstede and the GLOBE (House et al., 2004) studies has led to much debate regarding the applicability of the two most influential frameworks in cross-cultural international business research. A particular issue of the Journal of International Business Studies published articles from the originators of these frameworks in 2006 (Leung, 2006). In a critical article, Hofstede (2006) noted that the 
GLOBE research study expanded Hofstede's model of five dimensions of national cultures to 18 , but a re-analysis of the GLOBE data produced only five meta-factors that are mostly derived from Hofstede's model. For example, one factor was highly correlated with GNP/capita and Power Distance (one of Hofstede's dimensions) (Hofstede, 2006). Also, three other factors were highly correlated with Hofstede's dimensions of Individualism, Uncertainty Avoidance, and Long-term Orientation (Hofstede, 2006). The fifth factor was closely related to Hofstede's dimension of masculinity versus femininity (Hofstede, 2006). In a rebuttal, Javidan, House, et al. (2006) show why there is no theoretical or empirical basis for Hofstede's criticism that GLOBE measures of values are too abstract or for his contention that national and organizational cultures are topics of different social sciences.

\section{Critique of the GLOBE Project}

The GLOBE project created an opportunity to empirically confirm the theorized positive relationship between different aspects of culture. However, results did not support the hypothesis of value-practice consistency (Taras, Steel, \& Kirkman, 2010). Results showed a significant negative correlation in seven of nine cultural dimensions between values and practices. According to Maseland and Van Hoorn (2009), the limitations of self-report questionnaires is the reason for this relationship. Maseland and Van Hoorn claimed that the words "should be" in the survey measure marginal preferences instead of measuring values. In Maseland and Van Hoorn's view, the survey questions should focus on the respondents' general inclinations rather than changes to their present situation. In consumer theory, individuals are assumed to have specific objectives that form the utility function of the individual with different weights. Drawing similar parallels, Maseland and Van 
Hoorn argued that the GLOBE questions should also focus on the desired states (corresponding to weights) rather than desired changes (similar marginal preferences). To this end, they developed a survey format that is less likely to evoke marginal preferences.

Several researchers (e.g., Shi \& Wang, 2011) have noted the weaknesses in the GLOBE model and suggested that future research should move away from values surveys toward theories and frameworks that enhance the understanding of linkages between culture, perceptions, actions, organizations, and structures. Furthermore, characterizing national cultures either by aggregated self-perceptions or aggregated perceptions of others in one's society are not equivalent procedures (Smith, 2006) and may lead to inherent errors. The number of nations also limits the number of dimensions of national culture. Therefore, the relationship between national wealth and other aspects of culture should be considered instead.

As the primary architect of the leader-member exchange theory (LMX), Graen (2006) criticized the GLOBE's approach by claiming that the only appropriate unit of analysis for a leadership study is the relationship between leaders and members. Graen (2006) also asserts that GLOBE questionnaires are developed without collaboration of large groups of heterogeneous scholars and calls the total process an insular process. Graen (2006) claims the questionnaires do not have construct validity, even though GLOBE employs 160 scholars from 62 societies where 145 of them are referred to as country co-investigators (House, Javidan, Dorfman, \& De Luque, 2006). Hofstede (2006) also contributed to the same topic, claiming that because all 25 editors and authors of GLOBE have management or psychology degrees from U.S. universities, the GLOBE's project design and analysis reflect only the U.S. 
perspective of leadership. However, the GLOBE team suggests that their project liberates the cross-cultural, leadership and organizational behavior research which used to be entirely U.S.-centric.

The GLOBE team used two formats in the survey: "in this society" and "in this organization." Half of the respondents received one format; the second half received the other format. The same items were used in both formats, and in the project, the researchers categorized the responses to the first format as "societal" and those to the second as "organizational" culture. However, Hofstede (2006) suggested that national cultures and organizational cultures are phenomena of different orders so the same survey should not measure them.

The GLOBE survey has a 7-point scale of "as is" and "should be" formats (House et al., 2004). In the first section, there are "as is" questions, which the GLOBE refers to as "practices" (House et al., 2004). In the third section, there are "should be" questions, which are referred to as "values" (House et al., 2004). Nevertheless, Hofstede (2006) asserted that "as is" answers and "should be" answers are not independent because of the negative country-level correlations between "as is" and “should be." In addition, McCrae et al. (2008) also objected to the way GLOBE uses “as is" questions_-practice scores_-by stating that respondents' descriptions of their fellow citizens are actually nothing but national character stereotypes_-as in, when respondents are asked to characterize the average personality traits of their fellow citizens. McCrae et al. (2008) gave an example of where respondents were asked if, in their culture, parents live with their adult children and if people in their society are aggressive or nonaggressive. McCrae and colleagues (2008) asserted that the first question relies on the respondent's knowledge of local family traditions, whereas the 
second question needs a judgment of typical personality traits which they call very problematic by definition. Accordingly, Minkov and Blagoev (2012) claim that GLOBE presents conclusive internal evidence that their practices scores cannot be entirely reliable.

The GLOBE project (House et al., 2004) states that six of the nine dimensions of cultural variation were derived from Hofstede's (1980) original four dimensions following the conceptual framework developed by Hofstede and Kluckhohn and Strodtbeck (1961). However, Venaik and Brewer (2008) describe significant contradictions between the GLOBE studies and the Hofstede model, especially in the critical dimension of Uncertainty Avoidance, which is defined as a society's tolerance for uncertainty and ambiguity. More specifically, there is a significant negative correlation between GLOBE Uncertainty Avoidance practices measures and Hofstede's Uncertainty Avoidance index for specific cultures (Venaik and Brewer). One possible reason for the anomaly is that the cultural dimensions of the nations surveyed may have changed significantly over the time between the Hofstede and GLOBE studies. In a subsequent paper, Venaik and Brewer (2013) demonstrate that the GLOBE and Hofstede national culture scores are averages of items that are not related and they do not form a valid and reliable scale for the culture dimensions at the level of individuals or organizations. Hence, these scores are not useful when connecting individual-level behavior and preferences. By the same token, Venaik, Zhu, and Brewer (2013) show that the Hofstede long-term orientation (LTO) and the GLOBE's Future-Orientation (FO) dimensions capture different aspects of time orientation of societies after extending the GLOBE framework. In particular, Hofstede's LTO compares the past (tradition) and future (thrift) aspects of societies, 
the GLOBE's FO practices compares the present and future (planning) practices of societies, and the GLOBE's FO values reflect societal aspirations and preferences for planning.

Furthermore, Smith (2006) argues that the GLOBE never made evident for readers whether the researchers aggregated each survey item to the society level before the interrelations between items were explored, which is a procedure that has been used by almost all subsequent nation-level researchers. Hofstede (2006) also shows that a factor analysis of GLOBE's data proposes five independent dimensions, instead of nine. Hofstede also argues that some of the GLOBE's measurements, despite similar names, are indeed very different phenomena than his original concepts.

Another critique from Graen (2006) is that the GLOBE team used convenience sampling for their study. Nevertheless, the GLOBE sampling strategy had the following criteria: (a) respondents should be middle managers, (b) there should be more than one respondent, (c) there should be more than two organizations from each industry, (d) industries should include at least two of financial, food processing, or telecommunication, and (e) for each society, there should be at least two industries (House et al., 2004).

Methodologically, the GLOBE project team used both qualitative and quantitative methods to develop the scales as well as to measure the constructs that were tested by these scales (House et al., 2004). However, the GLOBE team did not use a supportive qualitative methodology to understand in-depth underpinning factors of quantitative findings (House et al., 2004). A mixed-method study could have provided a more detailed understanding of the cultural and leadership phenomena 
than quantitative or qualitative methods alone provide. The GLOBE project team used qualitative methodology only for ensuring the accuracy of questionnaire translations, culture-specific interpretations of local behaviors, norms, and practice and writing country-specific descriptions of cultures (House et al., 2004). Using an explanatory sequential design for each society could have not only explained the findings in more detail but also clarified surprising, contradictory quantitative results with qualitative data.

The GLOBE project team reported findings for nine cultural dimensions based on the average scores of the respondents in each society at the individual level (House et al., 2004). However, culturally endorsed leadership theory (CLT) dimensions are reported globally instead of by each society by examining each cultural dimension at the organizational and societal level (House et al.). However, analyzing each culturally endorsed leadership theory (CLT) dimension at an individual level by society would help organizations to design their leadership training accordingly.

The GLOBE project has one of the most comprehensive methods of assessing cultural values concerning leadership with several conceptual and methodological issues as described above. However, the GLOBE project is almost 25 years old, and acceleration of change in $21^{\text {st }}$ century societies is much faster than in the $19^{\text {th }}$ and $20^{\text {th }}$ centuries. There is a need for future research to address all of the critiques and gaps of the GLOBE project mentioned above.

\section{The GLOBE Project and Turkey}

Turkey is part of the Middle East cluster with Qatar, Morocco, Egypt, and Kuwait. The Republic of Turkey is located in Western Asia, Northern Mesopotamia and partly in Southeastern Europe. Its geographical location between two continents 
serves as a cultural bridge between East and West. Turkey is bordered in the east by Georgia, Armenia, and Iran, in the south by Iraq and Syria, and in the west by Greece and Bulgaria. Turkish land is 297,000 square miles and is surrounded by the Mediterranean Sea, Aegean Sea, and the Black Sea (Central Intelligence Agency, 2019).

Turkey is a densely-populated nation (78.7 million), and most of the population lives in the west, mainly the northwest region of the country (United Nations Development Programme, 2016). Eighty percent of the Turkish population is considered Turkish even though there are various ethnicities beneath Turkish identities, such as Arabs, Lazs, Chechens, and Kazaks. A significant portion of the Kurdish population resides in the Southeast, and Armenians, Jews, and Greek Orthodox form the minority (Central Intelligence Agency, 2019).

The GLOBE Survey in Turkey was performed in late 1995. Self-administered questionnaires were given to 323 middle-level managers employed in 23 firms, with 150 employed in the financial sector and 173 employed in the food-processing sector. The average age of the sample is 35.2 years old. The sample population has an average of 14 years of formal education. The gender split is $71.5 \%$ male and $28.5 \%$ female. The mean work experience is 14.4 years, with 11.2 years of managerial experience and 6.7 years of tenure (Kabasakal \& Bodur, 2007).

The results of the survey conducted with 323 middle-level managers reveal that "As Is" scores (how are the current norms, values, and practices) of Turkish society are high in In-group Collectivism $(\mathrm{M}=5.88$, Rank 5), Power Distance $(\mathrm{M}=$ 5.57, Rank 10), and Assertiveness ( $M=4.53$, Rank 12). All three of these dimensions have high absolute scores and are located in Band A among other GLOBE societies. 
Turkey has low absolute and relative scores in dimensions such as Uncertainty Avoidance ( $\mathrm{M}=3.63$, Rank 49), Humane Orientation $(\mathrm{M}=3.94$, Rank 37), and Future Orientation $(\mathrm{M}=3.74$, Rank 36), which are considered in Band $\mathrm{C}$ among GLOBE societies. The Gender Egalitarianism for Turkish society "As Is" score is low in absolute scale $(\mathrm{M}=2.89$, Rank 56), but Turkey is still in Band B because most GLOBE societies engage in gender inequality practices. Finally, for both Performance Orientation and Institutional Collectivism, Turkey is in Band B with scores that are low $(M=3.83$, Rank 45) and moderate $(M=4.03$, Rank 41) respectively (Kabasakal \& Bodur, 2007). The detailed analysis of each GLOBE societal dimension for Turkey is imperative to compare future findings. The next section provides the findings for each societal dimension for Turkey in the GLOBE study.

Performance orientation. Turkey's "as is" score in Performance Orientation is low in absolute terms and low compared to other societies $(M=3.83)$. The low score reveals that Turkish society is not characterized as a high-performance orientation society and also is linked to low levels of economic productivity, foreign direct investments, and global competitive strength. For example, Turkey invests only $0.45 \%$ of gross domestic product (GDP) in research and development. The Turkish private sector has higher Performance Orientation compared to the public sector. Private organizations generally invest in their employees through training, development, and the use of performance-oriented measures for career planning.

Future orientation. Turkish society shows a low absolute $(\mathrm{M}=3.74)$ score regarding Future-oriented practices reflecting that Turkish people accept status quo and take life events as they occur rather than planning for the future. According to Kabasakal and Bodur (2002) and Kabasakal and Dastmalchian (2001), accepting, 
encouraging, and rewarding the status quo can be related to the Islam religion. Turkish society is $99 \%$ Muslim. In Islam, the concept of "fate" is considered the factor associated with accepting life events and the status quo.

Most of the large organizations have planning departments and managers responsible for long-term planning. Companies design vision and mission statements and perform strategic planning processes whereas generally, long-term plans are not used in practice, and companies focus on dealing with daily problems. The reasons for this could be high levels of inflation and economic and political instability that make planning very difficult for companies. As a result, managers focus on short term survival tactics since predicting the future is almost impossible.

Assertiveness. The "As Is" Assertiveness score of Turkish society is high in both absolute and relative scale $(M=4.53$, Rank 12$)$. Turkish society is portrayed as having high levels of dominance and toughness. The assertive and authoritarian practices in Turkish society can be observed in family, government, and education. According to Kabasakal and Bodur (2007), after the 1970s, increases in the level of political instability, high inflation, and unemployment rates, in addition to massive migration to urban areas have created an uncertain environment and made survival difficult for members of Turkish society. Consequently, relationships in Turkish society become tough and assertive in many facets of life. Strong assertiveness can be seen in all parts of Turkish society, such as students are usually afraid of being scolded and men are dominant and authoritarian toward their wives and children. In both the private sector and government, the relationship between supervisors and subordinates typically has a dominant and authoritarian style. 
Institutional collectivism. Turkish society has a moderate "as is" score in Institutional Collectivism ( $M=4.03$, Rank 41, Band B). Göregenli (1997) found that Turkey shows collectivist examples in some areas, but not all of the characteristics of a collectivist orientation as described by Hofstede (1980). For example; in corporate settings, relationships with co-workers were found to be individualistic and include aspects such as the sharing of material resources, a feeling of involvement in others' lives, and a susceptibility to social influence. Also, Turkish people decline to join institutions that are formed for different purposes such as nongovernmental organizations (NGOs) and community-based organizations (CBOs) (Inelmen, Iseri Say, \& Kabasakal, 2004). Turkish society shows collectivist tendencies in the areas of self-presentation and sharing of outcomes with coworkers. Turkish society shows a strong sense of nationalism and low level of trust in society that may be factors in reducing the level of group solidarity and association with others in teamwork in institutional settings. Turkey has one of the lowest scores in trusting others according to the World Values Survey in 1990 and 1996.

In-group collectivism. Turkish society has one of the highest In-Group Collectivism "As Is" scores among the GLOBE societies $(M=5.88$, Rank 5). Turkish people have a high trust of family members and mutual trust within the family is imperative in both rural and urban families. In Turkish society, children are taught to support and help their family members which creates interdependence among family members. In other parts of society, new interdependent relationships such as being from the same region of the country or attending the same school show a highly collectivist nature. As a result, Turkish society has a deep commitment to their relationships in a network of close interdependent relationships. 
Gender egalitarianism. As observed in most of the middle eastern cluster, the Gender Egalitarianism “As Is" score for Turkish society is low $(\mathrm{M}=2.89$, Rank 56). In Turkish society, women are expected to be involved with activities that are mostly in the house. Conversely, men engage in activities that need personal relationships outside of the house. In summary, social role differences are defined by the context of what each gender is expected to perform. Men generally have roles such as holding power, making decisions and leading while women have supporting roles. Kağıtçıbaşı (1982) stated that there is a significant variation of roles related to the status of women in rural settings and urban settings. For example, in rural and lower socioeconomic areas, women work mostly in the agricultural sector as unpaid family labor. However, in urban settings, very high percentages of educated women have highly prestigious professions. In the 1990s and early 2000s, Turkish women occupied $35 \%$ of academic, $60 \%$ of pharmacist, $19 \%$ of physician, $30 \%$ of dentist, and 34\% of lawyer positions (Acar, 1991; Gürbüz, 1988). After the Turkish revolution in 1923, significant, success was achieved in legal, education, and employment-related areas for women in urban, middle, and upper socioeconomic groups (Topaloglu, 1983).

Humane orientation. Turkey has a low Humane Orientation "As Is" score ( $M$ $=3.94$, Rank 37). As a result of Turkish social structure, individuals depend on their family and in-groups for any issues they face. An interdependent network of close relationships in Turkish society enables individuals to get help and assistance from their close circle where both material and psychological support is available without asking for it. Regardless of people's economic class, rural or urban location, family, neighbors, and school friends are the primary resources for help. However, people 
outside of the close network cannot enjoy the same level of help and act in a generous, friendly manner. The same pattern can be observed in organizational settings, for example, leaders of Turkish society are expected to look after the wellbeing of their employees in many personal matters such as finding jobs and hospital places and solving their bureaucratic problems (Dilber, 1967).

Power distance. Turkey has a high Power Distance "as is" score $(M=5.57$, Rank 10) which is parallel with previous cross-cultural studies (Hofstede, 1980, 2001; Schwartz, 1994). Hofstede (1980) states that, in societies with high Power Distance, employees are afraid to express their ideas and disagreement with their supervisors. Most of the Turkish managers expect obedience from their subordinates, and Turkish organizations generally have very steep hierarchical organizational structures (Trompenaars \& Hampden-Turner, 1998). In Turkish society, power and resources are allocated according to hierarchy rather than an egalitarian distribution. For example, office space, parking spaces, cars, health insurance, and eating places are allocated based on the status of the employees rather than the requirements of the work to be done. In most of the organizations, people use a title to address others if there is no intimate friendship. Furthermore, generally, people address each other in society with different pronouns and their first names with the use of sir/madam beforehand. Vast differences in socioeconomic status also create a considerable social distance among groups that belong to different levels. For instance, even middleincome groups have a domestic servant in their homes.

Uncertainty avoidance. Turkish society has low "as is" scores in the GLOBE's Uncertainty Avoidance scale $(M=3.63)$ that can be interpreted as tolerance toward unpredictability and uncertainty to a significant extent. Nevertheless, Hofstede 
(1980, 2001) reports Turkey as a high Uncertainty Avoidance culture which may suggest that in time Turkish society has become more tolerant of uncertainty. Turkey experienced massive political and economic instability during the 1980s and 1990s that may have reduced rule orientation in society in an attempt to create survival techniques in the highly uncertain situations. Difficult conditions such as high levels of inflation, unemployment rates, and political instability may have formed several coping mechanisms for individuals and organizations. As a result of unfavorable and uncertain conditions, Turkish people have acquired simple survival methods rather than focusing on orderliness and rules as reflected in the GLOBE's low Uncertainty Avoidance “As Is" scores.

\section{Cultural Movement in Turkey}

Turkish society has experienced a deep-rooted change, transformation, and cultural erosion over the last 30 years, according to 2012 World Value Survey whose purpose was to understand the effect of the globalization (Yoldaş, 2015). Most of the changes during the globalization process are negative according to the survey that shows the change and stability of values in Turkey from 1990 to 2012 (Esmer, 2012). The most critical areas of impact are the citizen's view of life, politics, political ideology, and economy. Furthermore, developments in information technology and tourism have a significant impact on nationalism, gender issues, family structures and religious values (Yoldaş, 2015). The 2012 World Value Survey shows that for the last 22 years, the number of devout Turkish citizens has increased enormously, and Turkey has become the most religious society in Europe (Esmer, 2012).

Hofstede (1980) suggested that fundamental cultural values change very slowly (as cited in Hoppe, 1993). Conversely, Friedman (2016) claims that humans 
and organizations have struggled to adapt to the profound and rapid changes since the 1940s in his prominent book, Thank You for Being Late. The difference in time period of industrial revolutions in history is a good example. The first industrial revolution happened around 1760; the second industrial revolution started in 1890; the third industrial revolution was around 1969, but the fourth industrial revolution was in 2010 (Sentryo, n.d.). History clearly shows that the frequency gap of change is getting shorter as Friedman suggests. As a result, the time required to change the culture of a society could be shorter than Hofstede suggested in the 1980s.

Since 1995, Turkey has experienced significant events that may alter Turkish culture. In 1996, Iraqi troops fired on Kurdish positions in the north of the country that caused significant migration from Northern Iraq to Southeast of Turkey. During the violence in the former Yugoslavia in 1998, a significant number of the Muslim population from ex-Yugoslavia migrated to Turkey. In 2001, the terrorists attacked the World Trade Center in New York; the Afghan war was started; and Turkey faced significant economic turmoil. The year 2002 was a turning point as a religious government was elected for the first time in secular Turkey. In 2003, the war in Iraq, a neighbor of Turkey, started which had significant economic and political influence on Turkey. Facebook took off in 2004, the iPhone was released in 2007 and Arab spring started in 2010. The Syrian war started in 2011 which has resulted in the influx of more than 3.5 million refugees into Turkey.

In 2013, the peaceful Gezi Park protests in Istanbul had drastic consequences on Turkish politics and society. Gezi Park, one of the last green spaces in central Istanbul, was going to be demolished to create a spot for the building of a replica of a $19^{\text {th }}$ century Ottoman barrack along with a shopping center regardless of the long-held 
opposition campaign. When a group of several hundred environmentalists started a peaceful protest against the destruction of the park at the end of May 2013, the police had dispersed the group by using tear gas, water cannons, beating them and burning their tents. Extreme violent reaction of the authorities and the cause of the protests immediately mobilized tens of thousands of protestors to take the streets not only in Istanbul but also in main cities of Turkey within a couple of days. The protests had spread to other places because the destruction of the park is only a small portion of a larger problem. Since the very beginning, the government has been ignoring the opposing ideas and opinions and eliminating constructive critiques not only in urban redevelopment projects but also in every matter related to the public realm. Not surprisingly, this approach caused people from distinctive political fractions to have a common ground and to demonstrate against the government. The response of authorities to this huge backlash was so ferocious, leaving more than 8,000 people injured. More importantly, strong evidence shows that three demonstrators died because of the brutality of the force imposed by police. Thousands of demonstrators had been detained and hundreds faced prosecution simply because of organizing or attending the protests. After the protests, the government had taken every action to silence the opposition and smear those expressing out loud their opposition to the government. The government even labeled demonstrators and supporters of the demonstrators as terrorists. Since 2013, there has been almost no progress in investigating and bringing the police officers for abusive actions to justice. This event marked a monumental moment in Turkish history as protesting, a basic human right, had almost been suspended and the belief that justice would be served was damaged (Amnesty International, 2013). 
Three years after the Gezi Park Protests, a deadly coup attempt had taken place. In this terrible event, almost 300 civilian people died and many more were injured. The attempt failed, but the reaction of the Turkish government has had persisting detrimental impact on social, economic, and political life in Turkey.

For the deadliest coup attempt, Turkish government put the blame on Fethullah Gulen, a Turkish imam and businessman who has lived in self-imposed exile in the USA since 1999. Soon after the tragic incident, the government declared a state of emergency which continued for almost three years. During those years, the Turkish parliament enacted several decree laws. Instead of judging and sentencing the people who were responsible from the attempt, the government used the decree laws to purge the people who were suspected of being followers of Mr. Gulen. The scale of the purge is unprecedented. Academics from universities, professors from high schools, army and police officials, ministry officials from various ministries, judges and judicial staff members and many others were fired by the government. Moreover, the private schools and businesses including media companies that were considered to be linked to cleric Gulen were also shut down. The purge was not limited to Mr. Gulen's supporters. The government also fired some academics who signed a petition in that year critiquing the government's war against Kurdish militants. (Keller, Mykhyalyshyn, and Timur, 2016). As several thousand state employees were fired in a very short period of time, the government had to fill these positions with people who were less qualified and less experienced officials. This approach was problematic in terms of sustaining and maintaining a sound state. Additionally, people from all walks of life started to become more cautious about revealing their discontent with the government. Hence, a huge despair spread throughout the society. All of the major 
social, economic and political events listed above may have had an impact on the national culture of Turkey; and consequently the perception for effective leadership in Turkey.

Despite the fact that there is abundant leadership literature, mostly from western countries, leadership in the Middle East is mainly ignored and was never thoroughly investigated before the GLOBE project (Kabasakal et al., 2012). Kabasakal et al. (2012) claims that widely accepted effective leadership styles might not be valid in the Middle East. They conducted a study to understand how culture influenced effective leadership models in the Middle East. The region in the study of Kabasakal et al. (2012) is called MENA (a term used by many international corporations). The acronym MENA stands for the Middle East and North Africa. However, for their research, the MENA countries only include Egypt, Iran, Israel, Kuwait, Morocco, Turkey, and Qatar. 


\section{CHAPTER THREE:}

\section{METHODOLOGY}

GLOBE project identified nine cultural and six leadership dimensions that examined the relationship between cultural values and leadership ideals. This study primarily investigated where Turkey and Turkish culture stand regarding the nine GLOBE cultural dimensions in 2019. GLOBE team grouped 62 societies into ten cultural clusters. Turkey belongs to Middle-Eastern cluster where GLOBE survey was performed in 1995. Secondly, and this study explored how ideals and perceptions of Turkish leadership have changed in the past 25 years. Finally, research aimed to understand the social, political, and economic factors that may cause any possible changes in cultural values and leadership ideals in Turkey. This study investigated three research questions (a) Where do Turkey and Turkish culture stand regarding nine GLOBE cultural dimensions in 2019? (b) How have ideals and perceptions of leadership changed in the past 25 years? and (c) What social, political, and economic factors may explain any possible changes in cultural values and leadership ideals in Turkey?

The methodology part of this dissertation is structured as follows. The first part describes the overall methodology of research. The sampling strategy is then discussed followed by the data collection section. In the data collection part, both qualitative and quantitate data collection methodologies are explained. The methodology section concludes with a detailed explanation of the data analysis.

In this study, a mixed-methods methodology was used, employing both qualitative and quantitative data to analyze, integrate findings, and draw inferences in a single research study (Creswell \& Tashakkori, 2007). Although there are three main 
types of mixed-methods designs, the explanatory sequential design was used for this research (Creswell \& Clark, 2017). This methodology consists of two distinct phases. In the first phase, quantitative data was collected and analyzed, followed by qualitative data collection and analyses. The rationale for the qualitative analysis was to further explain and interpret the findings of the quantitative analysis. The two phases in this design were connected in the intermediate stage to provide a more general and deeper understanding of the problem under investigation.

Of course, there are advantages and disadvantages of an explanatory sequential design. The main advantage of such a design is the opportunity to use qualitatively collected data to explain any quantitative findings from the initial analysis (Rossman \& Wilson, 1985; Tashakkori \& Teddlie, 1998; Creswell, Plano Clark, Gutmann, \& Hanson, 2003). In addition to explaining the quantitative findings, the explanatory sequential design is a simple but effective way to analyze any unexpected results in the quantitative study (Morse, 1991). The major weakness of the explanatory sequential mix-methods design is that it consumed more time and resources compared with a single type of design.

\section{Sampling Strategy (Participants)}

The overall purpose of this study was to replicate the research performed in Turkey in 1995 by the GLOBE Project team and to analyze the changes regarding the political, economic and social developments that have happened in Turkey since then. A very similar sampling strategy to the original research was employed to compare and interpret the results. In the original GLOBE study, a stratified sampling design was used based on the following five criteria: (a) respondents should be middle managers (b) there should be more than one respondents from each organization (c) 
there should be more than two organizations from each industry (d) At least two industries should be financial, food processing, or telecommunication (e) for each society there should be at least two industries (House et al., 2004).

The GLOBE team included organizations whose headquarters were in the host cultures in their sample and excluded foreign and multinational corporations from their sample. Their reasoning was that managers of multinational corporations might come from multiple cultures and their responses may not be indicative of the societal culture of the research that has taken place (House et al., 2004). However, this argument is controversial for societal culture. Corporate culture in local companies may be different than that in multinational companies, but not societal culture. According to Schein (1985), the culture is the phenomena that is reflected at three levels ranging from the most visible to the least visible to the observer: 1) behaviors and artifacts; 2) beliefs and values; 3) underlying assumptions. To understand the actual meaning of the behaviors or beliefs to group members, one has to surface the underlying assumptions (Schneider, 1988). In this perspective, Laurent (as cited in Schneider, 1988) asserted that corporate culture may alter the first two levels but will have very limited impact on the underlying assumptions which will provide the reflection of the national culture. Hence, one might suggest that the national culture of a subsidiary is barely modified by the corporate culture of that subsidiary's multinational company, and there is no reason to exclude the multinational companies from societal culture research. In the same manner, it is unconvincing why the GLOBE researchers excluded multinational companies in the original study.

Also, based on my 25 years of work experience in multinational corporations in several countries, this assumption was not accurate in 1995 and is unquestionably 
not valid today for at least three important reasons. The first reason is that the most multinational organizations prefer locals to manage their local business but prefer toplevel executives from the country where the corporation's headquarter is located to oversee the local operation. Another reason is that employees frequently move between local and multinational organizations throughout their careers. Lastly, since 1995, most of the relevant local companies have become part of joint ventures of big multinationals. For example, in Turkey, there are currently no financial or telecommunication companies that are $100 \%$ owned by locals, with the exception of government-owned financial organizations where conducting research is challenging because of government policies and regulations. As a result, the original sampling strategy of the GLOBE team had to be modified by collecting data from every organization possible that operates in Turkey.

From a comparative standpoint, this might cause problems if the goal of this project was to compare organizational cultures across various countries because the GLOBE team focused on three specific industries (financial, food processing, or telecommunication) that could be found in all of the countries in their study (House et al., 2004). However, this research focused only on replicating the societal culture part of the GLOBE study. Consequently, this study used samples from a wide range of industries including multinationals that are operating in Turkey. In this research, the main sampling criteria was a) Turkish citizens and b) mid-level managers.

In the original GLOBE study, during the autumn of 1995, 323 middle-level managers from 23 organizations were surveyed using one of two different questionnaires. Half of the respondents were given an instrument that measured organizational culture (version Alpha), while the GLOBE team gave the other half 
another version of the GLOBE questionnaires measured culture and leadership (version Beta). Since only half of the sample was used to measure societal culture by using the Beta version, this survey initially targeted at least 160 middle-level managers from a wide range of industries.

In accordance with the definition of explanatory sequential design that was previously discussed, the initial data collection was exclusively quantitative. Convenience sampling was used to select the companies and organizations. The reason for choosing a convenience sampling strategy was that it is a type of nonprobability sampling that involves the sample being drawn from the part of the population that is available. The initial focus was on the financial and food processing sectors that were used for the 1995 research to control for industry-specific organizational culture. However, because of the insufficient number of companies that exist, a wider range of industries was included in the sample. The selection criteria for these companies was: a) operating in Turkey more than 10 years b) size based on number of employees and yearly sales volume, with emphasis on medium and large firms, c) industry position based on market share, with the focus on the top three firms. A list of all local and multinational organizations was prepared, excluding all government institutes. Using my business networks, the human resource directors or CEOs of each organization of 48 companies were initially contacted regarding participation in the survey. Initially, 24 organizations committed to participate, but after the worst economic crisis in Turkey in September 2019, the number dropped to 13 organizations in several different industries. Table 2 summarizes the numbers and percentages of those companies that participated and did not participate in the survey. The table also provides a numerical comparison of companies based on being local or 
international and the sectoral breakdown of companies. As it can be derived from the table, there are slight numerical differences between the companies that participated in the survey and those that did not take part in the research in terms of sectoral and local-international breakdown.

Table 2

Comparison of the Companies that did and did not Participate in the Survey

\begin{tabular}{lcrrrrr}
\hline & $\begin{array}{c}\text { Companies that } \\
\text { participated }\end{array}$ & \multicolumn{2}{c}{$\begin{array}{l}\text { Companies } \\
\text { that did not } \\
\text { participate }\end{array}$} \\
& \multicolumn{7}{c}{ Number } & $\%$ & Number & $\%$ & Number & $\%$ \\
\hline Total & 13 & $100 \%$ & 35 & $100 \%$ & 48 & $100 \%$ \\
$\quad$ Local & 6 & $46 \%$ & 20 & $57 \%$ & 26 & $54 \%$ \\
$\quad$ International & 7 & $54 \%$ & 15 & $43 \%$ & 22 & $46 \%$ \\
& & & & & & \\
Sector & 13 & $100 \%$ & 35 & $100 \%$ & 48 & $100 \%$ \\
Total & 6 & $46 \%$ & 21 & $60 \%$ & 27 & $56 \%$ \\
FMCG & 2 & $15 \%$ & 2 & $6 \%$ & 4 & $8 \%$ \\
Energy & 2 & $15 \%$ & 1 & $3 \%$ & 3 & $6 \%$ \\
Retail & 1 & $8 \%$ & 4 & $11 \%$ & 5 & $10 \%$ \\
Finance & 1 & $8 \%$ & 2 & $6 \%$ & 3 & $6 \%$ \\
Logistics & - & - & 2 & $6 \%$ & 2 & $4 \%$ \\
Telecommunications & 1 & $1 \%$ & 3 & $8 \%$ & 4 & $8 \%$ \\
Other & & & & & &
\end{tabular}

After getting a commitment from 13 organizations, they were asked to select the managers who match the middle management selection criteria. A detailed email message was then prepared for each organization to be sent by their human resource departments to their mid-level managers that explains both the new research and the original GLOBE project with a unique link for the GLOBE Phase2 Beta Questionnaire. Finally, separate databases were created for each large organization to be able to identify response rates and possible future company-specific analysis. 
Industry breakdown of participating organizations is as follows: six from consumer goods (including food processing), two from oil, power and energy, two from retail, one from finance, one from logistics, and one industrial seed company. Out of the 13 organizations, six companies were local, whereas seven companies were international, and all have been operating in Turkey for more than 10 years. In addition, I reached out to individuals via my network or my ex-colleagues' network who fit the description of my sample to increase my sample size. Additionally, 23 mid-level managers filled out the survey while working for organizations not listed above but operating in Turkey.

The new analysis of culture in Turkey is based on both qualitative and quantitative data. The following data sources were used. Three hundred and eighty GLOBE Phase 2 Beta questionnaires were returned. In this Beta version of the questionnaire, there were 44 questions measuring societal culture (As is) and 112 questions measuring leadership attributes. The surveys with missing data were eliminated resulting in 271 surveys with all 44 questions regarding societal culture (As is) completed, but with incomplete leadership attributes or demographics sections. On the other hand, 237 respondents completed all 44 societal culture questions, 112 leadership attribute questions, and all demographics. As a result, the sample of 271 was used to calculate only societal culture. Finally, the sample of 237 respondents was used not only for leadership scores and the interrelations of culture and leadership scores, but also for a demographic analysis. The demographic characteristics of the survey respondents are presented in Table 3. 
Table 3

Demographic Characteristics of GLOBE Survey Participants

\begin{tabular}{lrr}
\hline & Population & $\%$ \\
\hline Gender & 74 & $31 \%$ \\
$\quad$ Female & 163 & $69 \%$ \\
$\quad$ Male & & \\
Age & 10 & $4 \%$ \\
$20-29$ & 105 & $44 \%$ \\
$30-39$ & 87 & $37 \%$ \\
$40-49$ & 27 & $11 \%$ \\
$50-59$ & 8 & $3 \%$ \\
$60+$ & & \\
Education & 56 & $24 \%$ \\
High School or lower degree & 181 & $76 \%$ \\
Bachelor's or higher degree & & \\
\end{tabular}

The demographic characteristics of the Turkish work force are presented in

Table 4.

Table 4

Demographic Characteristics of the Turkish Workforce

\begin{tabular}{lcc}
\hline & $\begin{array}{c}\text { Population } \\
\text { (Millions) }\end{array}$ & \\
\hline Gender & & \\
$\quad$ Female & 8.73 & $31 \%$ \\
$\quad$ Male & 19.46 & $69 \%$ \\
Age & & \\
$15-19$ & 1.48 & $5 \%$ \\
$20-29$ & 6.24 & $22 \%$ \\
$30-39$ & 8.21 & $29 \%$ \\
$40-49$ & 6.66 & $24 \%$ \\
$50-59$ & 3.82 & $14 \%$ \\
$60+$ & 1.78 & $6 \%$ \\
Education & & \\
High School or lower degree & 21.77 & $77 \%$ \\
Bachelor's or higher degree & 6.42 & $23 \%$ \\
\hline
\end{tabular}

Note. Turkish Statistical Institute (2017). 
In summary, the sample is representative and typical of Turkish workers. The statistics from the Turkish statistical institute include every worker including white and blue collar. As a result, there is a significant gap in education statistics that is expected since this research focused on midlevel managers. Nevertheless, age statistics are very similar and the gender breakdown is exactly representative in this research's sample.

In accordance with the definition of explanatory sequential design that was previously discussed, the secondary data collection was qualitative. After analyzing quantitative data, human resource managers from 13 participating organizations were contacted and asked to select one participant to be interviewed in-depth. A total of six individuals were available for a detailed in-depth qualitative interview. Out of the six people, four are female and two are male. The average age of the interview sample is 43. The average years of education is 17 years. The average tenure in professional life is 20.8 years.

\section{Data Collection}

\section{Quantitative Data Collection (Survey)}

The GLOBE project team initially identified 112 universally perceived leadership attributes, which were subsequently reduced to a group of 21 primary leadership subscales, and then to six higher order global leadership dimensions. These dimensions are hypothesized to either support or obstruct leadership effectiveness (Kabasakal et al., 2012). The survey that gathered this information is called the GLOBE Phase 2 Beta Questionnaire. There is also an Alpha version that measures organizational culture. In the Beta version of the questionnaire, there are 44 questions measuring societal culture (As is), and the scales were developed based on a pilot 
study from 48 countries. Every societal scale had at least two parallel items. The nonparallel items were kept on the scales to obtain the desirable psychometric properties. The questionnaire also contains 112 leadership attribute questions. In this survey, items are rated on a 7-point Likert scale ranging from 1 (this behavior or characteristic greatly inhibits a person from being an outstanding leader) to 7 (this behavior or characteristic contributes greatly to a person being an outstanding leader) (Kabasakal, et al., 2012). Questions in the survey serve to assess the organizational culture, society's culture, and middle managers' beliefs about the effectiveness of various attributes for outstanding leaders.

The GLOBE team developed scales for nine cultural dimensions: Uncertainty Avoidance, Power Distance, Institutional Collectivism, In Group Collectivism, Gender Egalitarianism, Assertiveness, Future Orientation, Performance Orientation, and Humane Orientation. There are two types of questions for each dimension. The first one measures actual practices in each society (what is), while the second one measures actual values in each society (what should be). Given the research questions in this study, only the actual practices part of the survey was used, minimizing both the cognitive load and time spent on the survey for respondents. The original GLOBE survey was translated from English to Turkish in 1995. The same translation of the Turkish language version was used for this study; this survey can be found in Appendix A.

Validity of the instrument. The GLOBE Project team used several statistical methods to show that their scales are aggregable, reliable, and unidimensional. Furthermore, they provided evidence for the construct validity of the culture scales (House, et al., 2004). To do this, archival data was used to develop alternative, non- 
questionnaire-based measures of societal cultural constructs to demonstrate construct validity and generalizability of the scales (House, et al., 2004). They also studied the connections of their scales and measures with similar cross-cultural research performed by Hofstede (1980) and Schwartz (1994). All results showed that the GLOBE scales were constructed properly (House, et al., 2004). The GLOBE researchers also showed the convergent validity of their scales by demonstrating a strong relationship between scales measuring the same construct using different methods. Finally, they showed the discriminant validity of their scales by establishing a significant relationship between different traits assessed with the same method and across different methods (House, et al., 2004).

Reliability of the instrument. The GLOBE project team also assessed the reliability of their scales. First, they computed the Cronbach's alpha to calculate the internal consistency of the scale. The average Cronbach alpha for the society cultural practice (As Is) scales is .77. Also, the majority of the 21 leadership attribute subscales exhibited adequate internal consistency with an average Cronbach alpha values of .75. Secondly, GLOBE explored the interrater reliability of scales by computing the Intraclass Correlation Coefficient Case 2 (Two ways random effect layout) (ICC (2)) (Shrout \& Fleiss, 1979). The average ICC (2) for the societal cultural practices (As Is) scales is .93. And, the average ICC (2) for the leadership attribute subscales is .90 . These results show sufficient reliability of the scales.

\section{Qualitative Data Collection}

The type of qualitative inquiry pursued was a case study analysis design. There were several rationales for this decision. First, a case study is a suitable method for collecting data on perceptions, especially when a large sample is not available. 
With this data, an essential research question could be answered about whether political, economic and social changes since 1995 have affected Turkish culture. Second, the case study approach was suitable for investigating the underlying reasons for leadership perspective change after 1995. Flyvbjerg (2011) defined a case study as "an intensive analysis of an individual unit stressing development factors in relation to environment" (p.301). The study employed each middle manager as a unit of analysis. The unit of analysis for the GLOBE project were cultural-level aggregated responses of middle managers (House et al., 2004).

Semi-structured in-depth interviews were conducted with six middle-level managers. Each middle manager was selected by their human resource department. An interview protocol was prepared and then adjusted according to the initial findings of the quantitative survey. Questions were designed around the three research questions. Based on the findings of the quantitative analysis, any significant dimensional changes from 1995 were discussed. All interviews were held in Turkish, recorded, and later transcribed verbatim. A copy of the transcriptions can be found in Appendix B. The transcribed Turkish data served as the basis for the qualitative analysis. Original Turkish transcriptions were not translated in English; only findings were presented in English in the results section of this document. A copy of the preliminary interview protocol can be found in Appendix C.

\section{Data Analysis}

\section{Quantitative Data Analysis}

This study, in principle, aimed to methodologically replicate the 1995 study procedures of House et al. (2004). However, slight modifications were made from the original study. Individual scores were aggregated to organizational scores, and then, 
organizational scores were aggregated to country scores. In the original study, the hypotheses were tested through hierarchical linear modeling analyses. However, since the data in this study was collected from one country only and no cross-country analysis was made, the level of analysis is inherently different. For example, there were no societal level tests where multiple society scores were used. Instead, the analysis was conducted at the organizational and individual levels (where applicable).

The individual scores were aggregated to organizations and then organizational scores were aggregated to country level scores through taking averages. These analyses addressed the question of where Turkey is right now in terms of the nine GLOBE cultural dimensions in 2019.

The first set of tests answered the question of whether the cultural practices changed or did not change over the last 25 years. The change in the average scores of 1995 and 2019 was used to assess whether a change exists or not. Under normal conditions, researchers use a t-test for comparing the two means; however, this could not be done properly in this case for two reasons. First, while some of the average scores for Turkey from 1995 were available, their standard deviations were not reported (e.g. Kabasakal \& Bodur, 2007) and a t-test requires the standard deviations from the same sample. Secondly, a better method was already developed to understand meaningful differences in the GLOBE scores (Hanges, Dickson, \& Sipe, 2004). For example, Switzerland had an Uncertainty Avoidance practice score of 5.37 while New Zealand had 4.75; and intuitively the difference may seem meaningful; however, GLOBE researchers deemed this difference as not significant (De Luque \& Javidan, 2004). The GLOBE researchers developed a method known as test banding (Cascio, Outtz, Zedeck, \& Goldstein, 1991), where scores were grouped into bands in 
which the scores in the band were not considered meaningfully different (Hanges et al., 2004). To come up with these bands, standard error of the difference and bandwidth are calculated. The standard error of the difference (SED) is a function of the standard deviation of the GLOBE societies and the reliability of these scales (Gulliksen, 1950). This SED was then multiplied by some standardized normal distance (C) to come up with the bandwidth. For example, the $95 \%$ confidence test band is set to 1.96. The motivation for this method comes from measurement unreliability, where it is assumed that there is random error in the score and it creates an imperfect relationship between the sample's particular dimension score and the population's actual value (if all the members of the society completed the survey) (Hanges et al., 2004). As a result, two societies can actually be very similar in a dimension, but may seem different.

Once the bandwidth was calculated, all the societies were ranked and the bandwidth was subtracted starting from the top (Hanges et al., 2004). Information regarding these bands was available from the 1995 study (House et al., 2004). Therefore, to answer the question whether the relative cultural practices have changed or have not changed significantly, I looked at whether Turkey's place in the bands has changed or not.

Yet, using these bands to assess whether there is a meaningful difference has two limitations. First, the way the bandwidth is calculated aims to assess whether two societies are relatively different to each other and not to assess a single country. Second, only one country's score was collected in this study and other countries' bands and standard deviations may have changed over time too. However, these limitations were accommodated in this study because the aim here was to understand 
whether Turkey's culture has significantly changed or not compared to 1995, not the change in its relative positioning to other countries.

The aim of the second set of tests is two-fold. First, from the leadership survey, which culturally endorsed implicit leadership (CLT) practices (e.g. participative, visionary etc.) are currently desired in Turkey? This was done using the average scores for the specific dimensions; specifically, by ranking them and then checking for statistical differences. Second, the role of cultural practices on the effective leadership perspective was assessed. The statistical method to analyze these effects should have handled multilevel constructs within a nested structure. The data was multilevel because the variables operated at different levels and the sample was nested because individuals made up the organizations and the organizations made up the societies (Hanges et al., 2004). The traditional approaches are the aggregated and disaggregated approaches. In the aggregated approach, both dependent and independent variables are averaged to the level of analysis and tests are conducted with the aggregated data. In a disaggregated approach, the averages of the higher level (for example, the organizational practices) are assigned to individuals and then the analyses are conducted on the full data.

However, both approaches have deficiencies. For example, the aggregated approach is not suitable when the variables are operating at multiple levels (Hofmann, 1997) and the disaggregated approach ignores the nested structure (Goldstein, 1995). As a result, GLOBE researchers decided to use hierarchical linear modeling (HLM) (Hofmann, 1997), which is a multistep process to test the relationships between variables at different levels. The way HLM works is that for each level a specific 
relationship equation is solved and the result is fed to the upper level and then another relationship equation is solved.

However, in this study the HLM method was not appropriate. First, the study was conducted in only one country, so societal level analyses could not be conducted. This left only two levels of data: individual and organizational. Yet, the number of organizations participating in the study was too low, an organizational level test could have limited statistical power. Therefore, a meaningful test was conducted at the individual level and regression analyses was utilized. First, dimension-specific regressions were applied to understand how a specific cultural practice (e.g. Performance Orientation) is associated with a particular leadership style (e.g. Participative leadership). Second, all dimensions were entered into the equation and tested with particular leadership styles (Hanges et al., 2004). As a result, two main groups of findings were reported: which leadership styles in Turkey are practiced and how cultural practices affect these CLT leadership styles.

\section{Qualitative Data Analysis}

The overall design of this project took a qualitative approach after the quantitative analysis, meaning that a systematic but non-numerical process was used where data was utilized to answer research questions. Polkinghorne (1995) describes two types of data analysis. The first one is a narrative analysis that is a method of combining actions, events, incidents and situations to produce clear and consistent stories. The second one is an analysis of narrative that relies on coding the interview data into categories and making a coherent case for readers to comprehend. Since I chose the case study analysis as my qualitative inquiry, I preferred to use the analysis 
of narrative approach to analyze my data. I used each mid-level manager as my unit of analysis which was also my lowest level of unit analysis.

After I collected raw data, I primarily wrote a case record and the final case study narrative to identify patterns and themes. I deconstructed the raw data through a deductive analysis around my research questions to establish themes, sub-themes, and categories to build up patterns (Patton, 2015). I transcribed the audiotapes by using a software named Happy Scribe. I manually summarized and coded each participant's narrative in the participant's local language.

QDAS helped me to compare and code the cases into general categories and patterns. I used my research questions to generate a priori coding categories. I anticipated my main categories as (a) reasons for the change in national culture (b) factors affecting the change in leadership perspective (c) effect of 25 years to change. I reported my findings according to logical and matrix analyses as Patton (2015) describes. I analyzed the data by using cross-case analysis where I was able to examine themes, similarities, and differences across cases. Since my unit of analysis was a case, in this study a mid-level manager, the cross-case analysis was the most appropriate method. 


\section{CHAPTER FOUR:}

\section{FINDINGS}

The purpose of this study was to re-investigate Turkish culture and leadership attributes using the nine cultural dimensions of the GLOBE project to understand whether changes have occurred in these phenomena in the last 23 years. This study also aimed to compare the cultural and leadership values of the new generation of Turkish middle managers with those of the GLOBE Project in 1995. For these purposes, as previously noted, this study applied an explanatory mixed-methods approach that first produced quantitative data and their subsequent analysis, followed by a qualitative study that helped to refine and explain in greater depth the statistical results derived from the quantitative study. In the quantitative phase of the study, the GLOBE Phase2 Beta Questionnaire was used to collect data from mid-level managers of corporations operating in Turkey. For the explanatory qualitative study, a series of interviews was conducted. This chapter will present the statistical findings that derived from the surveys as well as the interpretations that the interview participants made of the survey results.

\section{Calculations of Cultural Practice and Leadership Scores}

\section{The Calculation of Societal Cultural Practices}

To be able to identify Turkey's 2019 cultural practices, a sample of 271 responses was used following the GLOBE procedures. As a first step, reverse-coded items were transformed. Afterwards, to identify the cultural practices, the scores were aggregated instead of subscales as there were no subscales. Table 5 shows the scores of the nine cultural dimensions (As is) for Turkey in 1995 and 2019 and the standard 
deviations of those dimensions in 2019. The standard deviations for the1995 study are not available in the GLOBE study.

Table 5

Aggregate GLOBE Societal Cultural Practice Scores and Standard Deviations

\begin{tabular}{lccc}
\hline \multirow{2}{*}{ Societal Cultural Practices } & 1995 & \multicolumn{2}{c}{2019} \\
& Score** & Score* & SD \\
\hline Uncertainty Avoidance & 3.63 & 3.44 & 0.92 \\
Performance Orientation & 3.83 & 3.56 & 1.11 \\
Humane Orientation & 3.94 & 3.59 & 1.02 \\
Power Distance & 5.57 & 5.80 & 0.83 \\
Gender Egalitarianism & 2.89 & 2.90 & 0.80 \\
Future Orientation & 3.74 & 3.51 & 1.05 \\
Collectivism II (In-group) & 5.88 & 5.68 & 0.76 \\
Collectivism I (Institutional) & 4.03 & 3.92 & 0.87 \\
Assertiveness & 4.53 & 4.75 & 0.93 \\
\hline
\end{tabular}

Note. ${ }^{* *} \mathrm{~N}: 161$ and $* \mathrm{~N}: 271$.

\section{The Calculation of Leadership Attributes}

For leadership scores, the subscale scores were first calculated (e.g. decisive, diplomatic, etc.). A sample of 237 responses was used to identify Turkey's endorsed leadership style in 2019. After each calculation of subscales, the average was taken to find the endorsed leadership style. While Table 6 presents the GLOBE leadership subscales, Table 7 depicts the corresponding leadership scores of Turkey in 2019. 
Table 6

GLOBE Leadership Subscales

\begin{tabular}{ll}
\hline Leadership & Dimensions \\
\hline Charismatic & Charismatic 1: Visionary, Charismatic 2: Inspirational, \\
& Charismatic 3: Self-Sacrifice, Integrity, Decisive, \\
& Performance-oriented \\
& Team 1: Collaborative Team Orientation, Team 2: Team \\
Team-Oriented & Integrator, Diplomatic, Malevolent (reverse-coded), \\
& Administratively Competent \\
Self-Protective & Self-centered, Status Conscious, Conflict Inducer, Face- \\
Participative & saver, Procedural \\
Humane-Oriented & Autocratic (reverse-coded), Non-participative (reverse- \\
Autonomous & coded) \\
& Individualistic, Independent, Autonomous, Unique
\end{tabular}

Table 7

2019 Endorsed Leadership Ideals

\begin{tabular}{lcc}
\hline Organizational Leadership & Average score* & Standard Deviation \\
\hline Participative & 5.36 & 1.09 \\
Autonomous & 4.18 & 1.12 \\
Team-Oriented & 5.95 & 0.72 \\
Humane-Oriented & 5.08 & 0.98 \\
Self-Protective & 3.49 & 0.71
\end{tabular}


Note. $* \mathrm{~N}=237$

The survey data were further analyzed to explore the interrelationships among the concepts. A sample of 237 responses was used to calculate the correlations of all variables. Table 8 and Table 9 show the correlations of all variables in the 2019 and 1995 studies, respectively.

The other purpose of the study was to conduct several extensive qualitative interviews to explain and support the new quantitative findings. In this explanatory follow-up, the plan was to gather the views of a sample of six current mid-level managers and examine their perceptions on the cultural changes that may have occurred since 1995. These in-depth interviews can also demonstrate any possible discrepancies between the quantitative and qualitative data findings. Qualitative findings are explained along with the quantitative findings in the following sections. 
Table 8

Correlations between Societal Culture Dimensions and CLTs in 2019

\begin{tabular}{|c|c|c|c|c|c|c|c|c|c|c|c|c|c|c|c|}
\hline & $\begin{array}{l}\text { Uncertainty } \\
\text { Avoidance }\end{array}$ & $\begin{array}{c}\text { Future } P \\
\text { Orientation }\end{array}$ & $\begin{array}{r}\text { Power Distanc Ins } \\
\text { Co }\end{array}$ & $\begin{array}{l}\text { nstitutional } \\
\text { collectivism }\end{array}$ & $\begin{array}{l}\text { Humane } \\
\text { Orientation }\end{array}$ & $\begin{array}{l}\text { Performance } \\
\text { Orientation }\end{array}$ & $\begin{array}{l}\text { In-Group } \\
\text { Collectivism }\end{array}$ & $\begin{array}{l}\text { Gender } \\
\text { Egalitarianism }\end{array}$ & Assertiveness & $\begin{array}{l}\text { Charismatic } \\
\text { Leadership }\end{array}$ & $\begin{array}{c}\text { Team- } \\
\text { Oriented } \\
\text { Leadership } \\
\end{array}$ & $\begin{array}{c}\text { Self- } \\
\text { Protective } \\
\text { Leadership } \\
\end{array}$ & $\begin{array}{l}\text { Participative } \\
\text { Leadership }\end{array}$ & $\begin{array}{c}\text { Humane- } \\
\text { Oriented } \\
\text { Leadership }\end{array}$ & $\begin{array}{l}\text { Autonomous } \\
\text { Leadership }\end{array}$ \\
\hline Uncertainty Avoidance & 1 & & & & & & & & & & & & & & \\
\hline Future & $0.40 * * *$ & 1 & & & & & & & & & & & & & \\
\hline \multicolumn{16}{|l|}{ Orientation } \\
\hline Power & $-0.27 * *$ & $-0.40^{* * * *}$ & 1 & & & & & & & & & & & & \\
\hline \multicolumn{16}{|l|}{ Distance } \\
\hline Institutional Collectivism & $0.18^{* *}$ & 0.10 & $-0.17^{* *}$ & 1 & & & & & & & & & & & \\
\hline Humane & $0.41^{* * *}$ & $0.34 * * *$ & $-0.40^{* * * *}$ & $0.31^{* * * *}$ & 1 & & & & & & & & & & \\
\hline \multicolumn{16}{|l|}{ Orientation } \\
\hline Performance Orientation & $0.42 * * *$ & $0.33^{* * *}$ & $-0.29^{* * *}$ & $0.20^{* *}$ & $0.36^{* * *}$ & 1 & & & & & & & & & \\
\hline In-Group Collectivism & 0.003 & -0.11 & $0.34 * * *$ & 0.08 & 0.05 & 0.04 & 1 & & & & & & & & \\
\hline Gender Egalitarianism & $0.23 * * *$ & $0.20^{* *}$ & $-0.39^{* * *}$ & -0.03 & $0.24^{* * *}$ & $0.30^{* * * *}$ & $-0.22 * *$ & 1 & & & & & & & \\
\hline Assertiveness & $-0.19 * *$ & $-0.14^{*}$ & $0.24 * * *$ & -0.02 & $-0.18 * *$ & 0.00 & $0.15^{*}$ & -0.10 & 1 & & & & & & \\
\hline Charismatic Leadership & -0.10 & 0.00 & $0.14^{*}$ & 0.05 & -0.08 & -0.10 & 0.10 & -0.06 & 0.00 & 1 & & & & & \\
\hline Team-Oriented Leadership & -0.10 & 0.01 & 0.10 & 0.03 & -0.05 & $-0.14 *$ & 0.11 & -0.13 & 0.06 & $0.89 * * *$ & 1 & & & & \\
\hline Self-Protective Leadership & 0.05 & 0.03 & -0.05 & -0.13 & 0.08 & 0.02 & 0.00 & 0.08 & -0.08 & -0.04 & -0.08 & 1 & & & \\
\hline Participative Leadership & -0.01 & 0.05 & 0.07 & 0.08 & -0.03 & -0.06 & -0.02 & $-0.15^{*}$ & 0.04 & $0.27^{* * *}$ & $0.39^{* * *}$ & $-0.68 * * *$ & 1 & & \\
\hline Humane-Oriented Leadership & -0.01 & 0.08 & -0.04 & 0.02 & 0.00 & -0.05 & 0.03 & -0.05 & 0.09 & $0.69^{* * *}$ & $0.74 * * *$ & 0.10 & $0.28 * * *$ & 1 & \\
\hline Autonomous Leadership & -0.10 & -0.05 & 0.07 & 0.01 & 0.04 & 0.03 & 0.06 & 0.07 & 0.08 & $0.26 * *$ & $0.13^{*}$ & 0.12 & $-0.22 * *$ & $0.19^{* *}$ & 1 \\
\hline
\end{tabular}


Table 9

Correlations between Societal Culture Dimensions and CLTs in 1995

\begin{tabular}{|c|c|c|c|c|c|c|c|c|c|c|c|c|c|c|c|}
\hline & $\begin{array}{l}\text { Uncertainty } \\
\text { Avoidance }\end{array}$ & $\begin{array}{l}\text { Future } \\
\text { Orientation }\end{array}$ & Power Distanc In & $\begin{array}{l}\text { Institutional } \\
\text { Collectivism }\end{array}$ & $\begin{array}{l}\text { Humane } \\
\text { Orientation }\end{array}$ & $\begin{array}{l}\text { Performance } \\
\text { Orientation }\end{array}$ & $\begin{array}{l}\text { In-Group } \\
\text { Collectivism }\end{array}$ & $\begin{array}{l}\text { Gender } \\
\text { Egalitarianism }\end{array}$ & Assertiveness & $\begin{array}{l}\text { Charismatic } \\
\text { Leadership }\end{array}$ & $\begin{array}{c}\text { Team- } \\
\text { Oriented } \\
\text { Leadership }\end{array}$ & $\begin{array}{c}\text { Self- } \\
\text { Protective } \\
\text { Leadership }\end{array}$ & $\begin{array}{l}\text { Participative } \\
\text { Leadership }\end{array}$ & $\begin{array}{c}\text { Humane- } \\
\text { Oriented } \\
\text { Leadership }\end{array}$ & $\begin{array}{c}\text { Autonomous } \\
\text { Leadership }\end{array}$ \\
\hline Uncertainty Avoidance & 1 & & & & & & & & & & & & & & \\
\hline $\begin{array}{l}\text { Future } \\
\text { Orientation }\end{array}$ & $0.76 * * *$ & 1 & & & & & & & & & & & & & \\
\hline $\begin{array}{l}\text { Power } \\
\text { Distance }\end{array}$ & $-0.48 * * *$ & $-0.44 * * *$ & 1 & & & & & & & & & & & & \\
\hline Institutional Collectivism & $0.38^{* *}$ & $0.46^{* * *}$ & $-0.29 *$ & 1 & & & & & & & & & & & \\
\hline $\begin{array}{l}\text { Humane } \\
\text { Orientation }\end{array}$ & 0.00 & 0.07 & -0.15 & $0.42 * * *$ & 1 & & & & & & & & & & \\
\hline Performance Orientation & $0.58 * * *$ & $0.62 * * *$ & $-0.32 *$ & $0.42 * * *$ & $0.25^{*}$ & 1 & 1 & & & & & & & & \\
\hline In-Group Collectivism & $-0.59 * * *$ & $-0.40^{* *}$ & $0.61 * * *$ & -0.11 & $0.27 *$ & -0.11 & 1 & & & & & & & & \\
\hline Gender Egalitarianism & -0.05 & -0.06 & $-0.33 * *$ & -0.04 & -0.14 & $-0.30^{*}$ & -0.23 & 1 & & & & & & & \\
\hline Assertiveness & -0.08 & 0.07 & 0.21 & $-0.38 * *$ & $-0.42 * * *$ & 0.05 & 0.13 & -0.10 & 1 & & & & & & \\
\hline Charismatic Leadership & 0.05 & 0.13 & 0.02 & -0.11 & 0.06 & 0.11 & -0.06 & -0.04 & -0.04 & 1 & & & & & \\
\hline Team-Oriented Leadership & $-0.32 *$ & -0.17 & 0.17 & -0.25 & 0.02 & -0.15 & $0.27 *$ & 0.06 & -0.02 & $0.83^{* * *}$ & 1 & & & & \\
\hline Self-Protective Leadership & $-0.43 * * *$ & $-0.33 * *$ & 0.20 & 0.02 & $0.34 * *$ & 0.03 & $0.70^{* * *}$ & -0.22 & 0.05 & -0.19 & 0.06 & 1 & & & \\
\hline Participative Leadership & $0.32 *$ & 0.22 & -0.13 & $-0.28 *$ & $-0.29 *$ & 0.00 & $-0.57 * * *$ & 0.06 & 0.03 & 0.36 & 0.17 & $-0.79 * * *$ & 1 & & \\
\hline Humane-Oriented Leadership & -0.02 & 0.19 & 0.12 & 0.14 & $0.43^{* * *}$ & $0.37^{* *}$ & $0.41^{* *}$ & $-0.29 *$ & 0.05 & $0.38^{* *}$ & $0.35^{* *}$ & $0.47^{* * *}$ & -0.21 & 1 & \\
\hline Autonomous Leadership & 0.20 & 0.08 & -0.21 & 0.16 & 0.01 & 0.13 & -0.09 & 0.11 & -0.02 & 0.01 & -0.07 & 0.09 & -0.19 & -0.04 & 1 \\
\hline
\end{tabular}

Note. (www.globeproject.com)

$* p<0.05, * * p<0.01, * * * p<0.001$. 


\section{Findings for Research Questions}

\section{First Research Question}

Where do Turkey and Turkish culture stand regarding nine GLOBE cultural dimensions in 2019?

Quantitative study. To be able to answer the first research question, a sample of 271 respondents, who answered the 44 questions measuring societal culture (As is) on the Beta version of the questionnaire, was used. Data were analyzed by following the GLOBE procedures to identify Turkey's 2019 cultural practices. The result was presented in Table 4 above. Data in Table 5 cannot be sufficient to understand whether cultural practices have changed or not since 1995. As outlined before, the general practice is to use mean difference methods such as t-tests to determine if a statistically significant difference exits. However, in this case, the standard deviations of the 1995 sample were not available. For this reason, the test banding methodology was used in the studies (Hanges et al., 2004). The GLOBE researchers developed this method to identify the existence of the statistically significant difference (Hanges et al., 2004). By using 1995 band ranges, 2019 scores were allocated to appropriate bands. If the new band that a cultural practice is in exceeds the band that the practice was previously in (ex. A>B), then this can be interpreted as an increase in the practice. For example, if Uncertainty Avoidance was in band C in 1995 and is now in band D in 2019, it can be interpreted as Uncertainty Avoidance practices have decreased since 1995. Even if scores changed in value, it is interpreted as "Same" if the band has not changed. Table 10 presents the comparison for societal cultural practices between 1995 and 2019 in Turkey. 
Table 10

Comparison of the Scores and Bands for Societal Culture Practices

\begin{tabular}{lcccccc}
\hline \multicolumn{1}{c}{ Society Culture Practices } & $\begin{array}{c}1995 \\
\text { Turkey }\end{array}$ & $\begin{array}{c}1995 \\
\text { Band }\end{array}$ & $\begin{array}{c}2019 \\
\text { Turkey }\end{array}$ & $\begin{array}{c}2019 \\
\text { Band }\end{array}$ & $\begin{array}{c}\text { Value } \\
\text { Change }\end{array}$ & $\begin{array}{c}\text { Band } \\
\text { Change }\end{array}$ \\
\hline Uncertainty Avoidance & 3.63 & C & 3.44 & D & -0.19 & Decreased \\
Performance Orientation & 3.83 & B & 3.56 & C & -0.27 & Decreased \\
Humane Orientation & 3.94 & C & 3.59 & D & -0.35 & Decreased \\
Power Distance & 5.57 & A & 5.80 & A & 0.23 & Same \\
Gender Egalitarianism & 2.89 & B & 2.90 & B & 0.01 & Same \\
Future Orientation & 3.74 & C & 3.51 & C & -0.23 & Same \\
In-group Collectivism & 5.88 & A & 5.68 & A & -0.20 & Same \\
Institutional Collectivism & 4.03 & B & 3.92 & C & -0.11 & Decreased \\
Assertiveness & 4.53 & A & 4.75 & A & 0.22 & Same \\
\hline
\end{tabular}

As shown in Table 10, there is no major shift in Turkish culture. According to the results above, Uncertainty Avoidance, Performance Orientation, Institutional Collectivism, and Humane Orientation practices decreased in 2019 compared to those of the practices in 1995. Although other dimensions slightly changed from 1995 to 2019 , they are not considered as statistically significant changes as the bands of these dimensions did not change, but values changed slightly.

Interrelationships of societal cultural practices. Cultural practices showed various significant correlations, but their interrelations have remained quite similar to the original GLOBE findings from 1995 in terms of the directions and strength of the correlations. For example, Uncertainty Avoidance practices were positively correlated 
with Future Orientation $(r=0.40, \mathrm{p}<0.001$ in both 1995 and 2019), Institutional

Collectivism $(r=0.18, p<0.01$ in 1995 and $\mathrm{p}<0.05$ in 2019), Humane Orientation $(r=0.41$, $\mathrm{p}<0.001$ in both 1995 and 2019), Performance Orientation $(r=0.42, p<0.001$ in both 1995 and 2019) and Gender Egalitarianism ( $\mathrm{r}=0.23$, $\mathrm{p}<0.001$ in both 1995 and 2019) practices; as well as having negative relationships with Power Distance $(r=-0.27, \mathrm{p}<0.0001$ in 1995 and $\mathrm{p}<0.01$ in 2019) and Assertiveness ( $r=-0.18, \mathrm{p}<0.01$ in $1995, \mathrm{r}=-0.19, \mathrm{p}<0.001$ in 2019) practices. Other cultural practice dimensions also followed similar patterns. Even though these are weak correlations, this result is interesting because the original GLOBE study conducted its analyses at the societal level (analyzing the country-level scores) and this study collected data at the individual level as mentioned in the previous sections, but very similar conclusions are reached when compared.

Gender difference analysis. This analysis provides the differences between males and females in terms of societal cultural dimensions. The research sample reflects very similar gender characteristics with the current Turkish workforce $-69 \%$ male and $31 \%$ female exactly (Turkish Statistical Institute, 2017). Table 11 shows how the scores of societal cultural dimensions vary by gender.

Table 11

t-test Results Comparing Males and Females on Societal Cultural Dimensions

\begin{tabular}{lcccc}
\hline & $\begin{array}{c}\text { Female } \\
(\mathrm{n}=74)\end{array}$ & $\begin{array}{c}\text { Male } \\
(\mathrm{n}=163)\end{array}$ & $\begin{array}{c}\text { Absolute } \\
\text { Difference }\end{array}$ & $p$ \\
\hline Uncertainty Avoidance & 3.41 & 3.42 & 0.01 & 0.94 \\
Future Orientation & 3.47 & 3.55 & 0.08 & 0.59 \\
Power Distance & 5.81 & 5.88 & -0.07 & 0.49
\end{tabular}




\begin{tabular}{lcccc} 
Institutional Collectivism & 3.93 & 4.02 & 0.09 & 0.45 \\
Humane Orientation & 3.64 & 3.54 & 0.10 & 0.48 \\
Performance Orientation & 3.57 & 3.57 & 0.00 & 0.99 \\
In-Group Collectivism & 5.76 & 5.67 & 0.11 & 0.39 \\
Gender Egalitarianism & 2.93 & 2.68 & 0.25 & 0.02 \\
Assertiveness & 4.76 & 4.76 & 0.00 & 0.98 \\
\hline
\end{tabular}

Regarding societal cultural dimensions, only Gender Egalitarianism varies between genders: The perception of females on this particular dimension is higher than that of males.

Spoken language difference analysis. The 1995 GLOBE's sample included only local organizations by looking at whether their headquarters are in the host cultures or not. GLOBE excluded foreign and multinational corporations from their sample assuming that managers of multinational corporations might come from multiple cultures and their responses may not be indicative of the societal culture of the research that has taken place and also because the country of origin culture might influence the host country culture (House et al., 2004). However, according to my 25 years of work experience for multinational corporations in several countries, this assumption was questionable in 1995 and is most likely not valid today. Nowadays, it is challenging to determine whether an organization is entirely local or has global shareholders. Most of the time, organizations keep their ownership structure secret if they are not public. One assumption can be the language spoken in daily operations. Most likely if an organization is $100 \%$ local, the language used at work is also $100 \%$ Turkish. Demographic data shows 
that 50 respondents use only Turkish while 187 respondents use other languages besides Turkish at work. Considering 50 respondents as working in a local organization and 187 as working in a multinational organization is a valid assumption. Understanding differences between the two groups may help to test the GLOBE's initial assumption that their country of origin influences multinational organizations. Table 12 shows how cultural scores vary according to spoken language in the workplace.

Table 12

t-test Results Comparing Spoken-Language on Societal Cultural Dimensions

\begin{tabular}{lcccc}
\hline & $\begin{array}{c}\text { Turkish } \\
\text { and More } \\
(\mathrm{n}=187)\end{array}$ & $\begin{array}{c}\text { Only } \\
\text { Turkish } \\
(\mathrm{n}=50)\end{array}$ & $\begin{array}{c}\text { Absolute } \\
\text { Difference }\end{array}$ & $p$ \\
\hline Uncertainty Avoidance & 3.48 & 3.20 & 0.28 & 0.05 \\
Future Orientation & 3.45 & 3.67 & 0.22 & 0.18 \\
Power Distance & 5.86 & 5.70 & 0.16 & 0.21 \\
Institutional Collectivism & 3.95 & 3.99 & 0.05 & 0.75 \\
Humane Orientation & 3.65 & 3.46 & 0.19 & 0.24 \\
Performance Orientation & 3.55 & 3.63 & 0.08 & 0.64 \\
In-Group Collectivism & 5.71 & 5.80 & 0.09 & 0.45 \\
Gender Egalitarianism & 2.83 & 2.95 & 0.12 & 0.33 \\
Assertiveness & 4.72 & 4.89 & 0.17 & 0.25 \\
\hline
\end{tabular}

The Uncertainty Avoidance dimension can be considered marginally different between the two groups $(\mathrm{p}<0.10)$. However, overall the two groups do not show any 
statistically significant difference as there are no differences between local organizations and multinational organizations in terms of cultural perception.

Age difference analysis. Understand how age influences cultural perceptions is essential. Understanding the effect of age can explain a possible difference between 1995 and 2019 results. Furthermore, differences in age can lead to more research to explore generational differences. Table 13 shows how the results of societal cultural dimensions change by age. Results indicate that age does not have a major effect on culture perceptions as there is only a marginal difference for Institutional Collectivism where age has a negative effect $(b=-0.01, p<0.10)$.

Table 13

Regression Analysis for Age on Societal Cultural Dimensions

\begin{tabular}{|c|c|c|c|c|c|c|}
\hline & $B$ & $t$ & $p$ & $R^{2}$ & $\mathrm{~F}$ & $\operatorname{Prob}(\mathrm{F})$ \\
\hline Uncertainty Avoidance & -0.01 & -1.14 & 0.25 & 0.01 & 1.31 & 0.25 \\
\hline Future Orientation & 0.00 & -0.25 & 0.79 & 0.00 & 0.07 & 0.80 \\
\hline Power Distance & 0.01 & 1.65 & 0.10 & 0.01 & 2.73 & 0.10 \\
\hline Institutional Collectivism & 0.01 & -1.75 & 0.08 & 0.01 & 3.06 & 0.08 \\
\hline Humane Orientation & -0.01 & -1.27 & 0.20 & 0.01 & 1.62 & 0.20 \\
\hline Performance Orientation & -0.01 & -1.76 & 0.08 & 0.01 & 3.11 & 0.08 \\
\hline In-Group Collectivism & 0.01 & 1.00 & 0.32 & 0.00 & 1.01 & 0.32 \\
\hline Gender Egalitarianism & 0.00 & 0.50 & 0.62 & 0.00 & 0.25 & 0.62 \\
\hline Assertiveness & 0.00 & 0.53 & 0.59 & 0.00 & 0.28 & 0.59 \\
\hline
\end{tabular}


Educational difference analysis. Even though significant educational differences are not expected for mid-level managers, understanding the effect of years of education can help for future studies. Table 14 shows how years of formal training affects the results of societal cultural dimensions.

Table 14

Regression Analysis for Education on Societal Cultural Dimensions

\begin{tabular}{lcccccc}
\hline & $B$ & $t$ & $p$ & $R^{2}$ & $\mathrm{~F}$ & Prob(F) \\
\hline Uncertainty Avoidance & -0.01 & -0.75 & 0.45 & 0.00 & 0.56 & 0.45 \\
Future Orientation & -0.01 & -1.11 & 0.27 & 0.01 & 1.23 & 0.27 \\
Power Distance & 0.02 & 1.74 & 0.08 & 0.01 & 3.01 & 0.08 \\
Institutional Collectivism & -0.01 & -1.05 & 0.30 & 0.00 & 1.10 & 0.30 \\
Humane Orientation & -0.01 & -1.11 & 0.27 & 0.01 & 1.22 & 0.27 \\
Performance Orientation & -0.01 & -1.00 & 0.32 & 0.00 & 1.00 & 0.32 \\
In-Group Collectivism & -0.01 & -0.63 & 0.53 & 0.00 & 0.40 & 0.53 \\
Gender Egalitarianism & 0.00 & -0.09 & 0.93 & 0.00 & 0.01 & 0.93 \\
Assertiveness & & & & & & \\
\end{tabular}

Qualitative study. The follow-up interviews allowed for the exploration of possible discrepancies or support of the findings of quantitative results. Specifically, the interviewees were asked about their perception of changes in the Turkish culture in the past 20 to 25 years. The findings of qualitative analysis support the findings of the quantitative study. The results indicate that most participants did not expect any change 
in the Turkish culture during the last 23 years regardless of profound changes in worldwide and country-specific dynamics. Table 15 summarizes the answers of the participants to the question about the possible cultural change in Turkey.

Table 15

Answers to the Question "Did you expect any major change in the Turkish culture during the last 23 years?"

Participant Quote

Participant 1 "No, I do not expect any change in the Turkish culture because it is very persistent and not easily permeable to the changes in the environment... However, cultural change might happen in 15 years when new generation kids are grown up because they live in a world which is deeply shaped by the technological developments."

Participant 2 "Humans and cultures are difficult to change so that I assume that there is no major shift in the Turkish culture since 1995. I know new generations are different than us, but people also tend to be conservative and maintain the same way of doing things. For this reason, the change in generations do not alter the whole culture in the same acceleration."

Participant 3 "In the last 24 years, I think there is no change in the Turkish culture. I do not see any cultural change in our society." 
Participant 4 "The changes in the environmental dynamics would require longer time than 23 years to reflect their effects on a particular culture. For this reason, I do not foresee any cultural shift in the Turkish culture since 1995. On the other hand, a change in the Turkish culture might happen in the next 10 years as $\mathrm{X}$ generation starts to take over more leadership positions."

Participant 5 "Yes, I think Turkish culture has changed in the last 23 years. The current government has been in the power for a long time and employed an over-controlling and manipulating style while governing. We feel this suppression not only in political life but also social and economic lives. I believe, there has been a reflection of this negative approach in the Turkish culture."

Participant 6 "I think a cultural change absolutely happened in Turkey. I have been observing a cultural change since 2007 even in daily interactions at work... The profiles of employees used to be similar to each other. In the same way, the leaders were not different from each other. Since 2007, the variations among employees and leaders have increased..."

Although the participants admitted to seeing the fundamental changes in the environment, they specified that the Turkish culture did not considerably change since 1995. For example, when asked "Do you expect any major change in the Turkish culture for the last 23 years?" Participant 1 answered, "No, I do not expect any change in the 
Turkish culture because it is very persistent and not easily permeable to the changes in the environment." Similarly, Participant 2 stated, "Humans and cultures are difficult to change so that I assume that there is no major shift in the Turkish culture since 1995." However, the participants demonstrated a tendency to believe in the possibility of a cultural change in the next 10-15 years. For example, Participant 4 said:

The changes in the environmental dynamics would require longer time than 23 years to reflect their effects on a particular culture. For this reason, I do not foresee any cultural shift in the Turkish culture since 1995. On the other hand, a change in the Turkish culture might happen in the next 10 years as $\mathrm{X}$ generation starts to take over more leadership positions.

Even so, both Participant 5 and 6 expected a change in the Turkish culture. Participant 6 said, "I have been observing a cultural change since 2007 even in daily interactions at work."

\section{Second Research Question}

How have ideals and perceptions of leadership changed in the past 23 years?

Quantitative study. To answer the second research question, first the Turkish leadership scores are calculated (Table 4), and then compared with the 1995 findings. As explained before, only 237 respondents completed the leadership scales. For this reason, a sample of 237 respondents is used to answer the second research question. The same band methodology was followed to compare 1995 and 2019 leadership. Table 16 presents the data. 
Table 16

Comparison of 1995 and 2019 GLOBE CLTS

\begin{tabular}{lccccc}
\hline & $\begin{array}{c}1995 \\
\text { Turkey }\end{array}$ & $\begin{array}{c}1995 \\
\text { Band }\end{array}$ & $\begin{array}{c}2019 \\
\text { Turkey }\end{array}$ & $\begin{array}{c}2019 \\
\text { Band }\end{array}$ & Change \\
\hline Participative & 5.09 & D & 5.36 & C & Increased \\
Autonomous & 3.83 & B & 4.18 & A & Increased \\
Team-Oriented & 6.01 & A & 5.95 & B & Decreased \\
Humane Oriented & 4.90 & B & 5.08 & B & Same \\
Self-Protective & 3.57 & E & 3.49 & E & Same \\
Charismatic & 5.95 & C & 5.99 & C & Same \\
\end{tabular}

Endorsement for Autonomous and Participative leadership increased while endorsement for Team-Oriented leadership decreased in 2019 compared to the 1995 study. Other leadership styles did not show significant band changes.

Interrelationships of leadership scores. The interrelations of leadership scores have remained very similar to those in the 1995 study in terms of their directions and strength. For example, Charismatic/Value-Based leadership had positive relationships with Team-Oriented leadership $(r=0.89, \mathrm{p}<0.001$ in 1995 and $r=0.89, p<0.001$ in 2019), Participative leadership ( $r=0.27, \mathrm{p}<0.001$ in both 1995 and $\mathrm{r}=0.27, \mathrm{p}<0.001$ in 2019), Humane Oriented leadership $(r=0.69, p<0.001$ in 1995 and in $r=0.69, p<0.001$ in 2019) and Autonomous leadership ( $\mathrm{r}=0.26, \mathrm{p}<0.001$ in 1995 and $\mathrm{r}=0.26, \mathrm{p}<0.01$ in 2019). Compared to the interrelationships of the societal cultural practices, the leadership correlations are stronger and even though leadership scores were also calculated at the societal level in 1995 and this study calculated them at the individual level, the findings 
remained similar. However, this is not as surprising as the cultural findings because the underlying theory of the leadership constructs of GLOBE is individually focused (GLOBE, n.d.).

Relationships between societal cultural practices and leadership scores. In line with previous findings, the relationships between cultural practices and leadership scores have also stayed similar and were replicated. For example, Power Distance had a positive relationship with Charismatic/Value-Based leadership (r=0.14, p<0.05 in both 1995 and 2019), Performance Orientation had a negative correlation with Team-Oriented leadership ( $\mathrm{r}=-0.13$ in 1995 and $\mathrm{r}=-0.14, \mathrm{p}<0.05$ in 2019) and Gender Egalitarianism had a negative relationship with Participative leadership ( $\mathrm{r}=-0.15, \mathrm{p}<0.05$ in both 1995 and 2019). Overall, the interrelationships (albeit weak) of culture and leadership seem to have remained very similar in the last 23 years.

Gender difference analysis. This analysis summarized in Table 17 shows the perception differences between males and females on CLTs.

Table 17

t-test Results Comparing Males and Females on CLTs

\begin{tabular}{lcccc}
\hline & $\begin{array}{c}\text { Female } \\
(\mathrm{n}=74)\end{array}$ & $\begin{array}{c}\text { Male } \\
(\mathrm{n}=163)\end{array}$ & $\begin{array}{c}\text { Absolute } \\
\text { Difference }\end{array}$ & $p$ \\
\hline Charismatic & 6.00 & 5.98 & 0.02 & 0.86 \\
Team-Oriented & 5.96 & 5.93 & 0.03 & 0.77 \\
Self-Protective & 3.62 & 3.22 & 0.40 & 0.00 \\
Participative & 5.24 & 5.63 & 0.39 & 0.01 \\
Humane Oriented & 5.14 & 4.93 & 0.19 & 0.13
\end{tabular}


Females endorse Self-Protective leadership more than males. Self-Protective leadership is considered the least effective style according to House (2004). This result can be explained by recent political and economic turmoil in the country as there are constant threats from outside and female leaders may put their focus on the safety and security of their employees (House et al., 2004). Furthermore, in a Middle Eastern country, females may value individual safety and security more than males. Males, on the other hand, endorse Participative leadership more than females which can be explained as frustration with an increasing autocratic style in the political and government arena. Males may be looking for involvement in the process of decision making more than females.

Spoken language difference analysis. As noted previously, the language spoken in daily interactions at work might be helpful to test the GLOBE's initial assumption that the country of origin influences multinational organizations. For this reason, the group of organizations in which Turkish and additional languages are spoken and that of organizations in which only Turkish is spoken were compared by running a t-test. Table 18 shows how leadership scores vary according to the spoken language in the workplace. Table 18

t-test Results Comparing Spoken-Language on CLTS

\begin{tabular}{lcccc}
\hline & $\begin{array}{c}\text { Turkish } \\
\text { and More } \\
(\mathrm{n}=187)\end{array}$ & $\begin{array}{c}\text { Only } \\
\text { Turkish } \\
(\mathrm{n}=50)\end{array}$ & $\begin{array}{c}\text { Absolute } \\
\text { Difference }\end{array}$ & $p$ \\
\hline Charismatic & 5.99 & 5.99 & 0.00 & 0.98
\end{tabular}




\begin{tabular}{lcccc} 
Team-Oriented & 5.93 & 6.00 & 0.07 & 0.51 \\
Self-Protective & 3.44 & 3.67 & 0.22 & 0.04 \\
Participative & 5.37 & 5.32 & 0.05 & 0.77 \\
Humane Oriented & 5.05 & 5.20 & 0.15 & 0.32 \\
Autonomous & 4.21 & 4.07 & 0.14 & 0.43 \\
\hline
\end{tabular}

The analysis demonstrated that there is no statistically significant difference between the two groups. In this sense, it can be argued that there is no difference between local organizations and multinational organizations in terms of leadership effectiveness perception.

Age difference analysis. It was mentioned earlier that understanding the effect of age on the cultural perception might reveal clarification on the changes in results from 1995 to 2019. Moreover, exploration of age differences might lead to further research regarding generational differences. Table 19 shows how results on CLTs change by age. Table 19 Regression Analysis for Age on CLTs

\begin{tabular}{lcccccc}
\hline & $B$ & $t$ & $p$ & $R^{2}$ & $\mathrm{~F}$ & $\operatorname{Prob}(\mathrm{F})$ \\
\hline Charismatic & 0.03 & 5.53 & $0.00 * * *$ & 0.12 & 30.6 & 0.000 \\
Team-Oriented & 0.02 & 4.90 & $0.00^{* * *}$ & 0.09 & 24.4 & 0.000 \\
Self-Protective & 0.01 & 1.62 & 0.11 & 0.01 & 2.63 & 0.11 \\
Participative & 0.00 & 0.21 & 0.84 & 0.00 & 0.04 & 0.84
\end{tabular}




$\begin{array}{lllllll}\text { Humane Oriented } & 0.02 & 2.87 & 0.00 * * * & 0.03 & 8.26 & 0.00 \\ \text { Autonomous } & 0.02 & 2.61 & 0.01 * * & 0.03 & 6.79 & 0.01\end{array}$

The analysis showed differences in leadership scores by age. The older the person gets, the more s/he is likely to endorse Charismatic/Value-Based, Team-Oriented, Humane-Oriented and Autonomous leadership.

Educational difference analysis. As middle-level managers have similar years of education, it is unlikely there would be any significant effect of education on CLTs. However, as indicated before, analyzing years of education might provide guidance for future studies. Table 20 shows how years of formal training affects the results of CLTs. Table 20 Regression Analysis for Education on CLTS

\begin{tabular}{lcccccc}
\hline & $B$ & $t$ & $p$ & $R^{2}$ & $\mathrm{~F}$ & Prob(F) \\
\hline Charismatic & 0.03 & 2.73 & $0.01^{*} *$ & 0.03 & 7.46 & 0.01 \\
Team-Oriented & 0.02 & 2.04 & $0.04^{*}$ & 0.02 & 4.15 & 0.04 \\
Self-Protective & 0.00 & 0.08 & 0.94 & 0.00 & 0.01 & 0.94 \\
Participative & -0.01 & -0.47 & 0.64 & 0.00 & 0.22 & 0.64 \\
Humane-Oriented & 0.02 & 1.34 & 0.18 & 0.01 & 1.80 & 0.18 \\
Autonomous & 0.02 & 1.38 & 0.17 & 0.01 & 1.91 & 0.17 \\
\hline
\end{tabular}


The results demonstrate that the more formal education a respondent has, the more likely s/he is to endorse Team-Oriented leadership and Charismatic/Value-Based leadership.

Qualitative study. During the qualitative interviews regarding the leadership topic, most of the participants hesitated to answer questions regarding the society's leadership dynamics which might be because of the recent totalitarian political climate in Turkey. However, the participants stated that the Turkish leadership is similar to the role of the Turkish father in a family, who has the blended characteristics of an authoritative figure with a protective one. Table 21 provides the short responses of the participants to the question of ideal Turkish leadership.

Table 21

Answers to the Question "What is the ideal leadership in Turkey?"

\begin{tabular}{l} 
Participant \\
\hline Participant $1 \quad$ "Turkish leaders are assertive. They also are egocentric, \\
want their employees to be dependent on them to become \\
indispensable, do not delegate their responsibilities, and do not \\
develop their employees." \\
"Aarticipant $2 \quad$ Turkish leader is oppressive but also friendly. There \\
is a Turkish saying which is usually used to describe a father. I \\
think it summarizes the Turkish leadership: We are beater \\
lovers."
\end{tabular}


Participant 3 "Leadership does not change from one culture to another. From my point of view, $80 \%$ of the characteristics of a leader is the same in every culture. Most of the time, what changes from one culture to another is the instrument that the leader uses to lead. Such as while this instrument might be religion in Turkey, it might be another thing in Venezuela."

Participant 4 "People expect to see from their leaders the same leadership that they would see from their fathers. Turkish leadership is similar to the leadership of a father in a family. A Turkish father is expected to lead the family in a very disciplined way but also show caring when appropriate. It is the same for Turkish leaders: We are beater lovers."

Participant 5 "Throughout my life, I knew only one leader who is the president of the country. This guy is very assertive and over controlling. Therefore, I can say that Turkish leadership is very assertive in general. However, in the workplace, leaders are also caring."

Participant 6 "Assertiveness is central in Turkish leadership. Turkish leaders ask for extremely ambitious results without considering if the sources in hand are sufficient to reach those results. They do not want to be challenged by their subordinates and expect 
full obedience from them. The relationship is also essential in Turkish leadership.”

The participants described a Turkish leader as a person who acts like a Turkish father. According to the participants, a Turkish leader has thick boundaries with his employees in communication, makes decisions without taking opinions of his employees, and gives his employees direction.

On the other hand, the same Turkish leader knows his employees, takes a sincere interest in them, helps them to solve their problems, and supports and protects them. Participant 1 emphasized that the family is central in Turkish culture so that Turkish leaders behave at the workplace in the same manner as they act in their family life. Similarly, Participant 2 said "A Turkish leader is oppressive but also friendly. There is a Turkish saying which is usually used to describe a father. I think it summarizes the Turkish leadership: We are beater lovers." Participant 4 also used the same phrase while delineating the Turkish leadership. However, Participant 4 also said that "The Turkish leadership is likely to change in the future, when $\mathrm{X}$ and $\mathrm{Y}$ generations start to take more senior leadership positions.” Likewise, Participant 1 said:

New generations in the office expect to participate into decision making processes with their managers, want their managers to have their say, and know why they do what they do. In the future, Turkish leaders may have to act more as participative leaders by involving everyone in decision making process.

Participant 1 also added that "Turkish leaders are egocentric, want their employees to be dependent on them to become indispensable, do not delegate their 
responsibilities, and do not develop their employees." This statement signals that Turkish leaders generally micromanage and sometimes miss the big picture. In this sense, Participant 1 and 3 expressed that Turkish leaders focus too much on daily operational duties which results in short term planning and missed strategic long-term planning.

\section{Third Research Question}

What social, political, and economic factors may explain any possible changes in cultural values and leadership ideals in Turkey?

This research question was addressed through the six interviews. Some of the findings have already been presented in previous sections to clarify the survey results. A summary of the interview findings is presented here. Participants have very similar expectations regarding the changes in scores of the societal cultural dimensions both in 1995 and 2019. Table 22 shows the summary of each participant's perspective on the quantitative results.

Table 22

Expectations Regarding the Change in The Societal Culture Dimensions in 2019

\begin{tabular}{|c|c|c|c|c|c|c|}
\hline & $\begin{array}{c}\text { Participant } \\
1\end{array}$ & $\begin{array}{c}\text { Participant } \\
2\end{array}$ & $\begin{array}{c}\text { Participant } \\
3\end{array}$ & $\begin{array}{c}\text { Participant } \\
4\end{array}$ & $\begin{array}{c}\text { Participant } \\
5\end{array}$ & $\begin{array}{c}\text { Participant } \\
6\end{array}$ \\
\hline $\begin{array}{l}\text { Uncertainty } \\
\text { Avoidance }\end{array}$ & $\begin{array}{l}\text { No } \\
\text { change or } \\
\text { lower }\end{array}$ & $\begin{array}{l}\text { No } \\
\text { change or } \\
\text { lower }\end{array}$ & $\begin{array}{l}\text { Slightly } \\
\text { higher }\end{array}$ & $\begin{array}{l}\text { No } \\
\text { change }\end{array}$ & Lower & Lower \\
\hline $\begin{array}{l}\text { Future } \\
\text { Orientation }\end{array}$ & $\begin{array}{l}\text { No } \\
\text { change or } \\
\text { slightly } \\
\text { higher }\end{array}$ & $\begin{array}{l}\text { No } \\
\text { change or } \\
\text { lower }\end{array}$ & Lower & $\begin{array}{l}\text { No } \\
\text { change }\end{array}$ & Lower & Higher \\
\hline $\begin{array}{l}\text { In-Group } \\
\text { Collectivism }\end{array}$ & $\begin{array}{l}\text { No } \\
\text { change or } \\
\text { slightly } \\
\text { higher }\end{array}$ & $\begin{array}{l}\text { No } \\
\text { change or } \\
\text { slightly } \\
\text { lower }\end{array}$ & $\begin{array}{l}\text { No } \\
\text { change }\end{array}$ & Higher & $\begin{array}{l}\text { No } \\
\text { change }\end{array}$ & Higher \\
\hline
\end{tabular}




\begin{tabular}{|c|c|c|c|c|c|c|}
\hline $\begin{array}{l}\text { Institutional } \\
\text { Collectivism }\end{array}$ & $\begin{array}{l}\text { No } \\
\text { change }\end{array}$ & $\begin{array}{l}\text { No } \\
\text { change or } \\
\text { lower }\end{array}$ & $\begin{array}{l}\text { Slightly } \\
\text { higher }\end{array}$ & $\begin{array}{l}\text { No } \\
\text { change }\end{array}$ & $\begin{array}{l}\text { No } \\
\text { change }\end{array}$ & Lower \\
\hline Assertiveness & - & Higher & $\begin{array}{l}\text { No } \\
\text { change }\end{array}$ & Higher & - & Higher \\
\hline $\begin{array}{l}\text { Performance } \\
\text { Orientation }\end{array}$ & Higher & Higher & Lower & $\begin{array}{l}\text { Higher in } \\
\text { office / } \\
\text { Lower in } \\
\text { society }\end{array}$ & $\begin{array}{l}\text { No } \\
\text { change }\end{array}$ & Lower \\
\hline $\begin{array}{l}\text { Gender } \\
\text { Egalitarianism }\end{array}$ & Higher & $\begin{array}{l}\text { No } \\
\text { change or } \\
\text { lower }\end{array}$ & $\begin{array}{l}\text { No } \\
\text { change }\end{array}$ & Higher & Higher & $\begin{array}{l}\text { No } \\
\text { change }\end{array}$ \\
\hline $\begin{array}{l}\text { Power } \\
\text { Distance }\end{array}$ & Lower & $\begin{array}{l}\text { No } \\
\text { change or } \\
\text { lower }\end{array}$ & - & $\begin{array}{l}\text { No } \\
\text { change }\end{array}$ & Lower & $\begin{array}{l}\text { Lower in } \\
\text { office / } \\
\text { Higher in } \\
\text { society }\end{array}$ \\
\hline $\begin{array}{l}\text { Humane } \\
\text { Orientation }\end{array}$ & $\begin{array}{l}\text { No } \\
\text { change }\end{array}$ & Higher & Higher & $\begin{array}{l}\text { No } \\
\text { change or } \\
\text { lower in } \\
\text { practice / } \\
\text { Higher in } \\
\text { value }\end{array}$ & Higher & Lower \\
\hline
\end{tabular}

The participants affirmed that Turkey was in the low range in Uncertainty Avoidance, Future Orientation, and Institutional Collectivism and the high range in Ingroup Collectivism and Assertiveness in 1995. Most of the participants also supported the findings of how the scores of these specific societal culture dimensions changed in the study in 2019.

Uncertainty avoidance. It was not surprising for most of the participants that Uncertainty Avoidance was lower in 1995, and even got a lower score in 2019. Regarding lowered Uncertainty Avoidance in 2019, all participants made the same comment: It has certainly lowered further compared to 1995 because Turkish people have been constantly living in tumultuous political and economic conditions for the last six years. 
Future orientation. The participants agreed with the low scores of Future Orientation both in 1995 and 2019. For example, Participant 4 said:

Low Future Orientation score is expected for me because Turks are very shortterm oriented people. They [Turks] live day to day and tend to employ band-aid solutions for the problems ... They do not make long-term plans; they even have a saying for that: Fix it up as you go along.

Participant 2 completely agreed with the scores and said, "Turkish people make only daily decisions, let alone weekly," and similarly Participant 1 said "Turkish people do not make plans; they have only dreams for the future." Participant 6 employed a different approach than the rest of the team regarding Future Orientation. According to this participant, Future Orientation should have increased because of the current survival mode of the people in Turkish society. This participant said:

Previously, it was easier for people to manage short-term. Because of the dramatic events in the society, people began to worry about their future and started to focus on their future... People became more future conscious and consider the longterm effects of their choices such as in choosing career path, making investment, deciding the city that they reside and so on...

In-group collectivism. Participants demonstrated a complete approval for the high score in In-group Collectivism both in 1995 and 2019. In relation to the result of this score, Participant 4 said:

Turkish people always identify themselves with their families, groups, and cults and behave in favor of their groups in the society. Some people even express their identity with the physical symbols of their particular group such as having 
specific type of moustache... I believe prevailing polarization in the country might have caused In-group Collectivism increased.

In the same sense, Participant 6 said: "Uncertainty has dramatically increased so that confidence to the future has decreased. In this environment, people has become much more caring to the people in their closest circle rather than considering the welfare of the other people in the outer circle."

Institutional collectivism. As opposed to In-group Collectivism, Institutional Collectivism was in the low range in 1995 and lowered further in 2019 towards individualism. Concerning this societal culture dimension, participants in general supported the results but did not elaborate why they thought so.

Assertiveness. When it comes to Assertiveness which was high in 1995 and did not change in 2019, participants fully agreed with new results. For example, Participant 2 said:

It is so true; we [Turkish people] are very assertive. In our culture, people think that the one who shouts louder than the other is always right; no matter how this person is wrong. I think TV programs and the politicians in Turkey perpetuate this situation.

All participants acknowledged that the scores of Performance Orientation, Gender Egalitarianism, and Humane Orientation were in the low range and the score of Power Distance was in the high range in 1995 . While some participants agreed with the results of 2019, some mentioned they were expecting some changes in 2019.

Generally, participants have the tendency to consider their work environment rather than the society they live in while answering qualitative questions. As a result, 
some participants did not agree with the 2019 results of Performance Orientation and Power Distance. However, after explaining them that they should consider society, they tend to agree with the results.

Performance orientation. According to three participants, the range of Performance Orientation should have increased in 2019 or should have at least stayed the same as it was in 1995. For example, Participant 1 said:

This result is surprising for me. As a company, we make promotions and wage increases based on performance. Employees are aware of performance orientation. In my opinion, people [survey participants] did not know the concept of performance while answering the survey in 1995 and rated moderately ... Today, they thoroughly learned what performance orientation is and have experienced it so that their expectation regarding performance orientation has increased and gave lower ratings in the survey.

Similarly, Participant 2 said "The result is interesting. Our career management is based on performance ... However, if you mean performance orientation in the society, it can be understandable because knowing somebody in power is more essential than demonstrating performance in our society."

On the other hand, both Participant 3 and Participant 6 agreed with the lowered Performance Orientation score. Participant 6 said, "I think performance orientation has been worsened in Turkish society since 2000s. In promotion, nepotism and other similar factors became more important than merit-based determinants."

Power distance. Most of the participants also questioned the result of Power Distance in 2019 and expected a lowered Power Distance in 2019 compared to 1995 
instead of staying in the same range. According to the participants, there are efforts in the offices to decrease Power Distance. However, as they talked, they revealed Power Distance is a norm in Turkish society. For example, Participant 4 said "It is usual for Turkish people that somebody in power have privileges. We even have a saying for this situation: One who has something to do with a big deal will always draw some profit.” In the same way, Participant 2 said "Turkish people consider, it is fair for a person in power to have privileges. Indeed, they expect people in power should have advantages in return for their power. Otherwise, it is uncomfortable for these people." According to Participant 6, Power Distance in society and Power Distance in office settings are different from each other and each move in different directions. Regarding Power Distance, this participant said:

I think Power Distance in the society has increased throughout the years. For example, people would not mind a supposed-to-be-privileged car with blue flash light in the back (it may not to be privileged) goes in the emergency lane while they are waiting in the traffic. On the other hand, the distance between hierarchies in work life has shortened and leaders in higher level hierarchies have become more accessible.

Humane orientation. Three participants expected an increase in the range of this societal culture dimension in 2019. These three participants predicated their assumption on the increased number of non-governmental organizations in Turkey during the last 15 years. While two of the participants anticipated no change, one participant expected a decrease in this particular societal culture dimension. After learning of the decreased Humane Orientation in the 2019 study, participants who assumed an increase or no 
change in Humane Orientation provided probable explanations for this result. For example, Participant 4 said "I think polarization in the society has skyrocketed since the current government took power. This might be the reason for the decrease." Similarly, Participant 1 stated:

Turkish people first care of their families and relatives. If, then, something remains, they might spare some time and money for the others. As the uncertainty in the economy has increased and people started to become unemployed, it is more likely for people to preserve their money only for themselves and their families.

Gender egalitarianism. As previously noted, the survey analysis revealed that females perceived improvement in Gender Egalitarianism more than males did. The findings derived from the qualitative study support that result. According to the qualitative study, most female participants (three of four) anticipated an increase in the range of Gender Egalitarianism in 2019 compared to 1995, whereas male participants (two participants) expected no change. Participant 1(female) revealed a disappointment with the 2019 result in this societal culture dimension and said "In corporate life, there is an effort to increase women presence in work and senior management. It is hard to understand there is no change in the score of this dimension."

Similarly, Participant 4 (female) said, "Regarding this dimension, we have this old saying for the act of women who try to do a job generally man do: "Do not involve with the man's job with the dough in your hands" (direct translation). I expected a positive change in this approach. It apparently did not happen." On the other hand, some participants mentioned that there is a way to go regarding Gender Egalitarianism in 
Turkey. For example, Participant 2 (female) said "Regardless of the efforts to decrease the differences in the gender roles, we are still biased and do stereotype. When we need to fill a senior role in the company, we first consider male candidates."

Consequently, five important findings emerged from the qualitative research:

1. Most participants mentioned that a 23 -year term is not sufficient to shift the Turkish culture even though there have been fundamental changes in the determinants of the local and global environments.

2. The participants expressed that an ideal Turkish leader resembles the generally agreed upon role of a Turkish father in family: while leading, both are expected to act in an authoritative manner as well as to be caring for others.

3. Except for one participant, the participants had not heard before about the GLOBE study, although their companies have expats in some of their leadership positions.

4. The participants agreed that Turkey is included in the Middle East cluster in the GLOBE study as they believe Turkish culture has several commonalities with the Middle Eastern countries.

5. The participants provided similar opinions regarding the scores of the societal culture dimensions of Turkey in the GLOBE studies both in 1995 and 2019.

The summary of conclusions for the in-depth interviews of six participants can be found in Table 23. 
Table 23

Summary of the First Four Findings of the Qualitative Study

\begin{tabular}{|c|c|c|c|c|c|c|}
\hline & $\begin{array}{c}\text { Participant } \\
1\end{array}$ & $\begin{array}{c}\text { Participant } \\
2\end{array}$ & $\begin{array}{c}\text { Participant } \\
3\end{array}$ & $\begin{array}{c}\text { Participant } \\
4\end{array}$ & $\begin{array}{c}\text { Participant } \\
5\end{array}$ & $\begin{array}{c}\text { Participant } \\
6\end{array}$ \\
\hline $\begin{array}{l}\text { Change in } \\
\text { Turkish } \\
\text { Culture in } 23 \\
\text { years }\end{array}$ & $\begin{array}{l}\text { Not yet/ } \\
\text { Might } \\
\text { happen in } \\
10-15 \text { years }\end{array}$ & No & No & $\begin{array}{l}\text { Not yet/ } \\
\text { Might } \\
\text { happen in } \\
\text { near future }\end{array}$ & $\begin{array}{l}\text { Yes } \\
\text { because of } \\
\text { political } \\
\text { reasons }\end{array}$ & $\begin{array}{l}\text { Yes / Has } \\
\text { been } \\
\text { happening } \\
\text { for the last } \\
10 \text { years }\end{array}$ \\
\hline $\begin{array}{l}\text { Turkish } \\
\text { leadership }\end{array}$ & $\begin{array}{l}\text { Assertive } \\
\text { and expect to } \\
\text { be } \\
\text { indispensable }\end{array}$ & $\begin{array}{l}\text { Fatherly: } \\
\text { Assertive } \\
\text { but also } \\
\text { caring }\end{array}$ & $\begin{array}{l}\text { No specific } \\
\text { leadership } \\
\text { to Turks / } \\
80 \% \text { is the } \\
\text { same and } \\
20 \% \text { can } \\
\text { change } \\
\text { based on } \\
\text { culture }\end{array}$ & $\begin{array}{l}\text { Fatherly: } \\
\text { Assertive } \\
\text { but also } \\
\text { caring }\end{array}$ & $\begin{array}{l}\text { Assertive, } \\
\text { over } \\
\text { controlling } \\
\text { but also } \\
\text { caring }\end{array}$ & $\begin{array}{l}\text { Assertive } \\
\text { and expect } \\
\text { obedience }\end{array}$ \\
\hline GLOBE info & No & No & No & Yes & No & No \\
\hline $\begin{array}{l}\text { Turkish } \\
\text { Culture } \\
\text { Training for } \\
\text { foreign } \\
\text { managers }\end{array}$ & No & No & No & No & No & No \\
\hline $\begin{array}{l}\text { The cluster of } \\
\text { Turkey }\end{array}$ & Middle East & $\begin{array}{l}\text { Middle } \\
\text { East }\end{array}$ & $\begin{array}{l}\text { Middle } \\
\text { East }\end{array}$ & $\begin{array}{l}\text { Middle } \\
\text { East }\end{array}$ & $\begin{array}{l}\text { Middle } \\
\text { East }\end{array}$ & $\begin{array}{l}\text { Middle } \\
\text { East }\end{array}$ \\
\hline
\end{tabular}




\section{CHAPTER FIVE:}

\section{DISCUSSION AND IMPLICATIONS}

This study replicated the original 1995 GLOBE study in Turkey, using the same surveys and very similar procedures and further supplemented these findings with its qualitative research, as explained in the methods and results sections. The original study measured the practices and values of both societal and organizational culture. Unlike the 1995 study, this study measured only societal cultural practice "As is" scores. The results represent current 2019 Turkish societal practices as well as endorsed leadership styles; which makes it possible to compare the current findings with 1995 data to answer the following questions: what has changed, why they have changed, and what some potential implications of these changes are for cross-cultural research and the businesses community.

Culture is usually perceived as very stable and changing very slowly (Hofstede, 1980, as cited in Hoppe, 1993) but more recently, mega changes in people's lives have started to occur more frequently and more intensely due to technological advancements (Friedman, 2016), and these changes may have led to faster cultural shifts in shorter time periods. It has been almost 25 years since the GLOBE study initially collected data from Turkey. Meanwhile, several major economic, technological, and political events have affected the society such as a significant financial crisis in 2001, a non-secular government election in 2002, the social media's increasing embeddedness in people's lives starting in 2004 (Facebook, Twitter, Instagram, Snapchat, Tumblr etc.) with the influx of smart-phones such as the introduction of iPhone in 2007, Arab Spring, a related Syrian War causing the entrance of more than 4-5 million refugees into the society since 
2011, Gezi protests in 2013 and a deadly coup attempt in 2016 resulting in martial law. As a result, the everyday lives of Turkish people have started to change and transform with these events, naturally affecting the societal practices. The study's findings relate to these events and show that cultural practices have indeed changed - but not all of them and not significantly. In the next section, each cultural dimension will be discussed considering both the quantitative and qualitative findings presented in the results section. A summary of findings will follow, first for cultural dimensions, then for leadership dimensions.

The findings for the cultural dimension analysis suggest the events that occurred in the last 24 years altered most of the societal practices, but not all of them in the same way. Four cultural dimensions - Uncertainty Avoidance, Humane Orientation, Performance Orientation and Institutional Collectivism - have decreased in value and moved to a lower band. Two other dimensions - Power Distance and Assertiveness have increased in value, but since they were in the A band and there is no higher band than A, they are considered unchanged. Another two dimensions - In-group Collectivism, and Future Orientation - have decreased in value but not enough to move to a lower band. The Gender Egalitarianism dimension is the only dimension for which there is no change in its value as well as in its band. Qualitative research supports all of the findings from the quantitative study. Both quantitative and qualitative analysis showed that the negative events in the last 24 years have moved the Turkish culture values to the stronger direction for almost all dimensions.

Turkish culture became more tolerant to ambiguity, less coherent as a society, and less helpful to people out of their close circle. In the culture, there is increased aggressive 
interaction between members, an increased gap between power holders and followers, an increased short term focus and predetermined roles for each gender. All of the findings were expected before the research took place considering the several major events that occurred in the last 23 years. Additional quantitative analysis also showed that, except for gender egalitarianism, there is no difference between genders regarding changes in cultural dimensions. When it comes to Gender Egalitarianism, females generally think that there is an improvement, but males do not agree with females. This gap between males and females is unexpected and needs further research. Finally, educational level of participants, age of participants and the language spoken in their organization make no difference on how they perceive Turkish culture in 2019. The neutral effect of these three variables is anticipated. Especially the effects of the local aspect-Turkish language only organizations - were discussed previously in the methodology section as a criticism of the initial GLOBE assumption that only local companies can represent the local culture.

For leadership dimensions, results suggest that two leadership dimensions Participative leadership and Autonomous leadership - have increased. While one of the leadership dimensions, Team-Orientated leadership, has decreased, the other three leadership dimensions - Humane-Orientated leadership, Self-Protective leadership, and Charismatic/Value-Based leadership - remained unchanged. Results show that the current mid-level managers are demanding more than those of the previous generation to be part of the decision-making process. The new generation managers also endorse a more individualistic and independent culture and they like to be perceived as unique and different. The decreased value of Team-Oriented leadership demonstrates that the new generation of mid-level managers prefers more individualistic goals and purposes rather 
than those that require collaboration. These findings are expected and all three results show similarities with the characteristics of the millennial generation. Demographic analysis shows that female participants endorse Self-Protective leadership more than their male counterparts. This finding is not surprising when one considers the gender issues in the Middle East, in which females may focus on ensuring safety and security more than males. Conversely, males endorse Participative leadership more than females. In a culture where decision making is historically dominated by males, it is perceivable that males are more likely to ask for participation than females.

In summary, one can conclude that the significant adverse events which happened in the last 24 years may have moved the culture toward the stronger values for each dimension. In the same time frame, the perception of the effective leadership has also changed mainly because of the changes in the culture and gender composition of the current mid-level managers.

\section{GLOBE Project and Business Community}

Because of increasing globalization, organizational leadership cannot afford to practice solely within the limits of the sovereign territories of countries. Business leaders must understand the ways that societies differ, as well as how they are similar to each other. One of the aims of the qualitative part of this research was to learn whether business communities had heard of GLOBE project and whether they use the findings of 1995 GLOBE project for their decision making and especially, for international assignments. During the interviews of six mid-level managers, the first question was: Have you ever heard of the study performed by the GLOBE Project team about leadership perceptions of Turkish managers in 1994 ? 
In summary, the findings of the qualitative data state that there is no previous knowledge of the GLOBE project. The participants (except Participant 4) did not know about the GLOBE study before they participated in the 2019 survey. Only Participant 4 said "Yes" when asked "Have you heard about the GLOBE study before?" and could explain the purpose of the study. Participants also mentioned that their companies do not give any cultural training for non-Turkish leaders who were appointed to the positions in Turkey. Participant 2 said that "We do not give cultural training to the foreign managers and observed foreign managers who started to work in the Turkish office demonstrated different leadership attributes than those of the Turkish managers." From a different perspective, Participant 1 said:

Turkish culture is very powerful. Although a foreign manager who started to work in Turkey does not take any Turkish culture specific training from the company, this person begins to act like a Turkish manager nearly in one year only by being exposed to the Turkish culture ... We even say he [the foreign manager] became like a Turk.

This finding demonstrates the gap between academia and the business community. Global business means not only the relocation of goods and capital, but also of business people all over the world. According to the 2012 Global Relocation Trends Survey report, growth in the international assignee (expatriates) population has increased well beyond what had been forecasted in the last three reports (GRT, 2012). Furthermore, multinational corporations are sending expatriates to a more diverse group of countries than ever before. A total of 63 countries were listed in 2012 as emerging destinations, 
more than three times the number in any other year (GRT, 2012). As a result, the number of business professionals living abroad has steadily grown over the past decade.

Cross-cultural training should provide international assignees with the knowledge, skills, and abilities needed to execute international assignments and improve business performance effectively. Multinational companies are focusing their efforts on increasing the accomplishments of their expatriates because of the significant cost associated with international transfers. However, the early return-home rates can be as high as $40 \%$ (Black \& Mendenhall, 1990). Companies should recognize the importance of crosscultural training, improve the corporation with academic research and use academic findings to increase the performance and retention of expatriates. Thus, unsuccessful assignments mean not only a financial loss, but also an opportunity, productivity, and relationship loss (Littrell, Salas, Hess, Paley, \& Riedel, 2006).

\section{Turkey and the Middle East}

The qualitative part of the research also explored the beliefs of participants about in which study cluster Turkey should belong. GLOBE grouped the 62 societies into a set of 10 regional groupings, and Turkey is grouped as part of the Middle East cluster with Qatar, Morocco, Egypt, and Kuwait.

The Republic of Turkey is located in Western Asia, Northern Mesopotamia and partly in Southeastern Europe. Turkey's geographical location is between two continents that serve as a cultural bridge between East and West. Most of the secular Turks, especially those in white collar positions, consider themselves part of Europe. Historically, up until early 1990, most of the multinational organizations grouped Turkey in the East Europe business cluster. Turkey has also been considered as part of Europe for 
every global and European sports organization, particularly soccer tournaments.

Furthermore, Turkey has been a candidate for the European Union since 1999.

Because of those reasons, another purpose of the qualitative interviews was to understand the reflection of Turkish mid-level managers on whether they agree with the GLOBE's clustering of Turkey in the Middle East. One of the questions during the meetings was: "In the GLOBE study in 1995, the countries were separated into groups, (e.g. Europe, Asia, Latin America, Middle East, Africa, and so on). In which cluster should Turkey be in?"

There was a general agreement among the participants that Turkey should be in the Middle East cluster. Participant 4 said, "It should be the Middle East because the way of doing business in Turkey is similar to that is in the Middle East. We [Turks] do business with 'Inshallah - I hope' and 'Mashallah - Praise be' and tend to be follower of a leader like Middle Easterners." Similarly, Participant 1 said:

According to me, Turkey is culturally closer to the East; I mean the Middle East. We [Turks] are Easterner who is trying to get close to the West. I know the culture of the Middle East because my husband works there, Kuwaitis are egocentric and aggressive as Turks; the leaders in Kuwait want their employees to do what they ask them to do without any questioning.

Generally speaking, all participants mentioned the efforts of Turks to be like Westerners to some degree. Participant 3 said "We [Turks] used to emulate Western culture before this government took power. Now, we [Turks] are more like Middle Easterners," and Participant 4 said "Turkey should be in the Middle East cluster but there 
is a difference between the office culture and societal culture. Societal culture is closer to the Middle East than the West whereas the office culture is more like Western culture."

In the next section, each cultural dimension will be discussed and analyzed to understand what each change means for Turkish society. Findings of this research show that culture may not be very stable as suggested by Hofstede (1980) but also may not be changing as fast as Friedman (2016) suggested. Even though the quantitative study cannot establish causality on whether these societal practice changes occurred due to particular events, the qualitative study provides some possible explanations.

\section{Uncertainty Avoidance}

Uncertainty avoidance refers to the extent to which the members of a group strive to abstain from uncertainty (House et al., 2004) and decreased both in value and band from 1995 to 2019. In 1995, the Uncertainty Avoidance band, the C band, showed that Turkish people accept uncertainty in everyday life more than did half of the 62 societies. The Turkish score dropped from 3.63 to 3.44 in value and put Turkey in the last band D with the other six countries (according to 1995 banding). This may have been caused by the current socio-political environment of Turkey in which a major economic crisis is an issue, the politics have not been able to stabilize, the Turkish Army is currently in conflict in Syria, and hundreds of companies have been closed or seized by the government due to their claimed links with terrorist organizations. Even though these issues are current, they have been building up for the last decade. Qualitative research also supports this finding. Most of the participants state that events in the last two yearsthe coup attempt, the biggest financial crisis in Turkish history, and frequent elections- 
are the reasons for Turkish society to tolerate the unknown even further. For example, Participant 6 states that:

If Germany is on one axis, Turkey is on the other axis in Uncertainty Avoidance...In my opinion, the tolerance of Turkish people has increased in time... It is the fact that the number of uncertainties in Turkish society has increased. The political incidents that have happened since 1995 altered almost everything in society and ruined what we used to consider conventional. People have lost their jobs. People have undergone an economic crisis. Some people lost their jobs to foreigners. Some people have had to migrate. Every societal incident created a breakpoint in Turkish society. Therefore, it is not surprising for us that our high tolerance rate has increased more.

Furthermore, a non-secular political party has been ruling the country by promoting a religious lifestyle since 2003, marking a big shift in Turkish social and political lives. This fact supports Hofstede's (2001) claim that religion causes societies to accept the uncertainties that they cannot defend themselves against. Another essential discussion is about "values" (should be) scores in 1995. In the original study, Turkey had a very high score (4.67) in Uncertainty Avoidance and was in B band. This score shows the desire of Turkish society to have structural changes such as more formal interactions, obeying rules and planning before taking risks. Research in 2019 shows that none of those hopes have been achieved. Moreover, Uncertainty Avoidance is positively correlated with Future Orientation (r: 0.76) and that finding is supported by qualitative data as most of the respondents define Turkish society as a very "short term" oriented culture. 
Finally, the increased urbanization in Turkey may have affected the changes in Uncertainty Avoidance. For example, Istanbul's population, the city in which most of the participants are from, grew from 9 million to 16 million in the last 24 years. That urbanization resulted in increased traffic that made people's day-to-day timing fluid and uncertain. For example, a traffic jam may occur in any time of the day that people cannot forecast beforehand; and people have become accustomed to this kind of uncertainty in their daily life planning. Hence, Turkish people can be said to have more tolerance for uncertainty in their daily lives.

\section{Performance Orientation}

Performance orientation is the dimension that refers to the extent to which a group encourages and awards group members for demonstrating advancement in performance and high standards in execution (House et al., 2004). Turkish society places less value on these practices, which can be exemplified by placing less value on training and development, less emphasis on results, viewing formal feedback as judgmental and expecting more indirect and subtle communication. In 1995, the score for Turkish society practice was 3.83 (As is) and it was in the B band. The 2019 score dropped to 3.56 and pushed Turkish society down to the $\mathrm{C}$ band. In the same study, the values (should be) score of Turkish society was 5.39, but even this score was low compared to the other societies. After 24 years, Turkey could not get close to the "Should be" score it had in 1995. Unfortunately, let alone staying at the same score in 1995, Turkey's score of Performance Orientation went down both in value and the band. This result shows that Turkish society values social and family relations, loyalty, tradition, and seniority, over education, learning, and initiative taking. Interview respondents have conflicting 
explanations. While some of the respondents agree with the quantitative finding, the others did not agree. In-depth questioning showed that respondents tend to consider their organization when commenting about the Performance Orientation dimension. For example, Participant 1 said:

This result is surprising to me. As a company, we make promotions and wage increases based on performance. Employees are aware of performance orientation. In my opinion, people [survey participants] did not know the concept of performance while answering the survey in 1995 and rated moderately ... Today, they thoroughly learned what performance orientation is and have experienced it so that their expectation regarding performance orientation has increased and gave lower ratings in the survey.

When respondents were reminded that they should consider Turkish society, not their organizations, the tendency was to agree with the quantitative results. The lower score could have also explained the exodus of educated people, particularly academics, from Turkey. The especially extreme polarization, frequent conflicts, and increased nationalism emerging since 2003 forced people to think that they should belong to a "group" to survive instead of "perform." People have been observing that performance is not a factor to gain status in Turkish society. For example, Participant 4 states, As my company is highly performance oriented, it would be hard for me to answer this question objectively... If you mean performance orientation in society, then I assume it is low in Turkish society and has decreased further. As a society, we mainly observe that in politics. Even you do not have the required 
competencies; you can easily obtain a footing if you are a part of a particular network or you can demonstrate that you are one of them.

\section{Institutional Collectivism/In-Group Collectivism}

GLOBE measures these two dimensions separately but analyzing these two dimensions together may be beneficial to capture the dynamics of Turkish society. Institutional Collectivism refers to the importance placed on "collective distribution of resources and collective action", whereas In-Group Collectivism is described as "the degree to which individuals express pride, loyalty, and cohesiveness in their organizations or families" (House et al., 2004, p. 30).

In 1995, the Institutional Collectivism score for Turkey was 4.03 which put Turkey in the B band. However, in 2019, the score of this dimension decreased to 3.92, and Turkey dropped to the $\mathrm{C}$ band. This decrease in the score of Institutional Collectivism means Turkish people have less pride and value cohesiveness with organizations or society less when compared to 1995. Nationalism and Institutional Collectivism have been promoted and supported by the Turkish government since the foundation of the modern Turkish Republic. Founders of Turkey blamed diversity for the collapse of the Ottoman Empire that ruled between 1299 and 1923 and believed that a homogenous nation would have higher unity, stability, and success. For this reason, the early Turkish administrations suppressed and even drove minorities to leave Turkey. However, the Institutional Collectivism score is still lower than most of the 62 societies and even lower than USA (4.20), the most diverse country in the world. The value (Should be) score of 5.26 in 1995 shows the desire of the society for more Institutional Collectivism. Yet, the score for Institutional Collectivism in 2019 decreased further to 
3.92. One reason could be the distrust of the institutions of the government especially after 2003. One of the most important reasons could be the deep underlying suppressed diversity that the founders of Turkey tried to hide. Another reason could be economic instability and the excessively interventionist and intruding aspects of Turkish government. Turkish people see government as a "father figure," and think the government has the responsibility of the welfare of its people. For this reason, people see government jobs as safe and secure and develop a long-term relationship with the government from recruitment to retirement. Qualitative interviews also support the finding; participants think that the compensation and promotions in most of the Turkish companies and the government are based on seniority and personal needs, not on performance per se. This is also supported by the GLOBE dimension correlation (r: -.39) with the Performance Orientation dimension. Qualitative interviews showed a similar pattern. For example, Participant 2 said:

The score of In-group Collectivism in Turkey is absolutely the opposite of that score in Japan. If Japanese people take only whatever they need from the shelf even in the presence of a crisis, Turkish people would take the whole shelf without considering that other people might have the same need ... We [Turkish people] like to put things into inventory just in case so that take more than what we need. Turkish people first want to secure themselves. I think the score of this societal culture dimension has increased from 1994 to 2019.

Conversely, for In-group Collectivism, Turkey had a very high score (5.88) in 1995, and it has decreased slightly in value (5.68) in 2019, but stayed in A band. The value of In-group Collectivism demonstrates that Turks are relying more on themselves 
and their close family. For this dimension, there were only four societies higher than Turkey in 1995. The very high score of this dimension shows that Turks believe their focus should be the relational attributes of people around them, especially in big cities such as Istanbul (16 million population) where most of the people migrated from other cities. People tend to be close to the other people who share commonalities with them. In some cases, people who come to the big city to make a living prefer to settle down in a neighborhood where they have previously known people from their hometown. For example, even in corporate life, the first thing people try to learn about their colleagues is which city they come from. People also want to know which soccer team their colleagues support and even which university they attended. As a result, it becomes a regular practice that friendship, compensation, and promotions are based on group identity. Loyalty and in-group attitudes are expected from members of these groups. Nepotism is considered a typical practice and positive trait. One feels responsible for helping his/her classmate, family member, teammate, city mate to find a job in a big city. Also, Turks tend to adhere to societal rules and avoid inner and outer conflict with group norms. For example, Participant 1 said:

I can understand that the score of In-group Collectivism is high in Turkish society. Family members are the first and foremost important people in an individual's life in Turkey. For this reason, we [Turkish people] focus on those people who are closest to us before worrying for the other people.

Turkish people suppress their individual desires to confirm group norms and always seek membership. Economic instability for the last 100 years could be another reason for the high score in In-Group Collectivism. Similarly, 1995 GLOBE findings 
showed that economic prosperity is negatively correlated (r: -.78) within-group collectivism practice. Qualitative interviews also support and explain these quantitative results. A typical comment from a participant is that Turkish people care more for their immediate relatives. Only people in the close circle receive the material, financial, and social support. It is a regular practice that parents sacrifice themselves for their children not just when they were young but all their lives. In return, it is considered the children's responsibility to take care of their parents and mostly live together as a big family. Because of these reasons, a paternalistic and nurturing leader is considered an effective leader in Turkey.

In line with qualitative responses, decreased Institutional Collectivism and very high and stable In-group Collectivism together also imply that people might count on their close family more when they witness institutions are failing them. The OECD Trust Data Set also supports this argument by showing that the percentage of Turkish people who tend to trust the national government decreased from $80 \%$ in 2004 to $49 \%$ in 2015 , but interpersonal trust to the family has almost stayed the same, slightly declining from 99.3\% in 2007 to $99.2 \%$ in 2011 (González \& Smith, 2017) (note that the data was not available for other years).

\section{Humane Orientation}

The Humane Orientation dimension refers to "the extent to which a collective encourages and rewards individuals for being fair, altruistic, generous and kind to others" (House et al., 2004, p. 30). Turkish society performs fewer of those practices, which can be exemplified by the following characteristics: giving more importance to one's selfinterests, a lower expectation from members of the community to promote the others' 
well-being, greater motivation for power and material possessions and a greater predominance of self-enhancement. From 1995 to 2108, the score of this dimension has decreased from 3.94 to 3.59 and pushed Turkey from the $\mathrm{C}$ band to the $\mathrm{D}$ band with another small number of societies. Despite the fact that the score of Turkey for value (Should be) was quite high 5.52 in 1995, the result in 2019 shows that Turkish society is moving even further away from what they thought they should have been.

Two main factors might explain this result. The first and most critical factor relates to the institutional promotion of the Turkish race. In the society, there are several practices that perpetuate the dominancy of Turkish race. One example is that even though Turkish society has not been homogenous, the government, especially after the foundation of modern Turkey, forced everyone to use only Turkish names and Turkish language by law. Another example is as harsh as the previous example for minorities. Until 2013, there used to be a law that urged students at every elementary and middle school to pledge a student oath every day. This student oath started with "I am a Turk!" and ended with "My existence shall be dedicated to the Turkish existence." A less obligatory example is about the subtitle of the largest circulated Turkish newspaper that says, "Turkey belongs to Turks." Because of those and many more practices, all forms of racial discrimination became the norm and standard for the members of the society.

The second main factor refers to the fact that the government controls everything as a political system. Since the foundation of modern Turkey, most of the schools, universities, factories, hospitals, land, and even retailers belong to the state. Moreover, only the state can sponsor public provisions and sectors. As a result, the state is actively involved in every aspect of public life. Members of society do not feel responsible for 
promoting the well-being of others since it is considered the state's responsibility to provide social and economic support for all. Recent migration of 4-5 million Syrians could also have been a crucial factor in the worsening Humane Orientation score. Most of the Turks see Syrian refugees as a threat to their well-being because refugees take a share from Turkish government funds.

\section{Power Distance}

According to GLOBE, "Power Distance" is "the degree to which members of a collective expect power to be distributed equally" (House et al., 2004, p. 30). Turkey is one of the top scoring countries in 1995 with a score of 5.57. However, the value score (Should be) was meager with a 2.41 , which shows the desire of Turkish society is toward a more even distribution of power and resources. Nevertheless, the 2019 score was even higher with 5.80, which puts Turkey at the top of all 62 cultures. Reasons for these high scores could have historical foundations. The people, now called Turkish society, had been ruled by Sultans between 1299 and 1923. The sultan was the head of state, government, and Islam. Sultans ruled the Ottoman Empire with absolute regent of power. After the collapse of the Ottoman Empire in 1923, Mustafa Kemal (Ataturk) founded modern Turkey and changed the governance to democracy.

However, power bases stayed stable and limited. Unfortunately, democracy did not ensure equal opportunities. First of all, Mustafa Kemal was named as Ataturk which means the father of Turks and was given a savior like image. After his death, Ataturk became the immortal hero of the Turks. Ataturk's face still stares sternly down on nearly every town square, schoolyard, and workplace in the country. In schools, Ataturk's life was a mandatory class. In addition, it was forbidden by law to critique or insult him. Any 
insult to Ataturk was punished by a harsh prison sentence. Every president after Ataturk reinforced high Power Distance in the society by positioning themselves above the average citizen. For Turks, it is a standard practice for government officials to have expensive cars, disobey rules, and have lifelong privileges.

The military also contributed to a high Power Distance score. The Turkish military acts above the rule and frequently intervenes in society and demonstrates its power through political actions and coups. Moreover, every Turkish male has to serve in the military which may cause normalization of power distances hierarchies in society. The efforts to minimize power distance in society have been blocked by the administration of Mr. Erdogan since 2003 by managing "the ruling party of Turkey" and a Turkey as a "one-man show" style that makes it a norm "to have one leader way above and this leader is to be obeyed." President Erdogan, unlike other politicians, fortified his power with a closer association with Islam. This approach has led some Turks to perceive Mr. Erdogan as a religious figure. Especially after 2017, Mr. Erdogan changed the constitution to gain absolute power more similar to that of the sultans during the Ottoman Empire. For example, as a symbol of power, Mr. Erdogan built himself a 1000-room palace similar to those of the Ottoman sultans that have very expensive features. The ultra-high cost of this palace was not even questioned by President Erdogan's supporters, most of whom have to live in minimum living standards.

After the economic downturn started in 2015, civil liberties have become weaker and corruption has increased significantly. Limited access to resources and skills has blocked upward social mobility. Some of the statements from participants in this study show conflicting views of power. When asked about Power Distance, most participants 
initially considered their organizations and claim that Power Distance should have decreased since 1995 because the gap between supervisors and employees is shorter now in the corporate world. For example, participants said that the number of supervisors who expect to be called by their first names has dramatically increased since 1995. On the other hand, when participants were asked to consider society in general, they agreed with the finding that Power Distance has increased because of the fact that the government is the largest employer in the country.

\section{Future Orientation}

The Future Orientation dimension measures "the degree to which a collectivity encourages and rewards future-oriented behaviors such as planning and delaying gratification" (House et al., 2004, p. 282). Turkey's 1995 practice score was 3.74 in the C band. The value score (Should be) of this particular dimension was 5.83 which clearly demonstrates the desire of Turkish people to have better planning and a future-oriented reward structure. Adversely, the 2019 score dropped even lower to 3.51 in value, but stayed in the same band. One explanation could be that Turkey has been experiencing more moderate levels of economic success and political stability compared to when it was founded in the 1920s. A high inflation rate has been the major issue in most of the Turkish economic history. It even reached to the levels of 100\% during the 1990s. Constant high inflation rates discouraged citizens to save in local currency. Up until 1984, holding foreign currency was illegal so that citizens had to spend their money immediately for goods. Turkish people started to experience economic improvement and single digit inflation rates at the beginning of 2000s, but this flourishing economy lasted only ten years. The Turkish economy has been worsening since 2012 and, in 2018, has 
reached a point where Turkey has witnessed the worst financial crises in its history. In times of financial crises, people tend to value instant gratification so that employees become motivated only with immediate rewards. Leaders frequently use monetary incentives for motivation since employees are less intrinsically motivated. Most of the local companies have a shorter strategic orientation compared to their international counterparts and generally do not survive after the founder dies. Qualitative findings also support this quantitative conclusion. For example, Participant 5 said "I think Turkish people do not plan their lives so that it is not surprising that the score of this societal culture dimension is low." Only one participant (Participant 6) claimed that the recent economic crisis led people to save more and plan for the worst in the future.

\section{Assertiveness}

According to GLOBE, Assertiveness is "the degree to which individuals are assertive, confrontational, and aggressive in their relationships with others" (House et al., 2004, p. 30). In the 1995 study, the score for this dimension was 4.53 and was in the $\mathrm{A}$ band. This score was quite high and was above most of the 62 societies. At 2.66, the value (Should be) score for Turkey was the lowest of all societies and clearly shows the frustration of people with the aggressive and confrontational style. In this case, one might expect a decrease in the score of this dimension in the current study. Instead, the score increased to 4.75 in the 2019 study putting Turkey just one level below Albania which is the top scoring county in this dimension. Interestingly, there is a large Albanian community in Istanbul whose members are descendants of Albanians who migrated to Istanbul during the Ottoman Empire time and they call themselves Albanian Turks. In 
Istanbul, there are even two neighborhoods called "Arnavutköy" that means “Albaniantown."

Recent economic and political turmoil can be a factor in the increased practice score. Turkish society values dominant and tough behavior in every aspect of daily life. Smiling can be perceived as either craziness or stupidity, and one can get into trouble because of smiling if there is nothing funny in the context. Turkish society also puts emphasis on expressiveness and revealing thoughts and feelings. In Turkey, it is very likely for someone to see politicians either cry or shout while rallying for the election since these behaviors are perceived as a demonstration of honesty and decisiveness. Direct and unambiguous communication is also central in relationships in Turkey. Furthermore, most of the relations include competition to a certain extent. It is a normal practice for employees in corporations to sign up for "aggressive" targets and demonstrate "can-do" attitudes by using the word "Eyvallah," that means I can do it $100 \%$ with God's will. Turkish people also admire every symbol of strength and power including financial and physical ones. Qualitative data supports the quantitative findings. Participants agree on the level of aggressive and offensive behavior in everyday life especially in traffic and business interactions. Most of the participants blame the current administration and the President as he is known for his aggressive and confrontational style towards all his opponents. In one of the interviews, Participant 4 stated that "Assertiveness has been very high in Turkey because of imbalance between societal classes. While certain group of people especially those in power has become more assertive, regular citizens started to acquiesce in return instead of reacting in the same way." 


\section{Gender Egalitarianism}

The Gender Egalitarianism dimension is "the degree to which a collective minimizes gender inequality" (House et al., 2004, p. 30). The score for Gender Egalitarianism was very low in 1995 , at 2.89 . Out of 62 societies, there were only five (three of them are from the Middle-East cluster) countries lower than Turkey. The value (should be) score was 4.5 which indicates a desire for better gender equality. In the 2019 study, the score of this dimension is 2.9 and can be called "no change." When looking into Turkish society there are minor differences in literacy rates between males and females, yet males in general hold a higher level of education. Most of the rural communities force their girls to marry at early ages and mostly before age 18 . On the other hand, in corporate life, there is greater representation of women compared to that in government jobs. Qualitative and quantitative findings show that females expected an improvement in the score of Gender Egalitarianism in 2019. For example, Participant 5 said:

In my opinion, the score of Gender Egalitarianism was low in 1994 but I think and expect that an increase happened in the score of this particular dimension. We [the company] strive to make the best of what we can do about breaking gender stereotyping at work, but it is not easy to make that shift.

Even though there are efforts to increase Gender Egalitarianism in the organizations, Islam may be a factor for Turkey that counterbalances these efforts. In Turkey, Islamic culture (in fact, highly associated with Arabic culture) tends to undermine women in society and workplaces. In Turkey's history, the Ottoman Empire instituted practices that undermined women such as they could not be eyewitnesses in the 
courts. They have become equal in the eyes of the law after the Republic of Turkey was founded. Yet, it takes time for the undermining motives and behaviors (rather implicit right now) to be removed from the societies, as they are embedded in people's upbringings, behaviors and decisions. For example, there are still many organizations in Turkey that have no women on their board of directors or among their executives. When asked why, it is possible to hear from males that they would prefer working with men because they are easier to work with; showing biases against women. It is possible to say it is getting better right now, but the dominance of Islam also has powered up in Turkey in the last 25 years, hence bringing back the 19th century's mentality towards woman. The final factor is the effect of the new religious government. In the last 17 years, the government intentionally replaced members of the secular elite business community with traditional religious people. As a result, there are many organizations which are managed according to Islamic rules or beliefs.

In conclusion, the findings show that not every cultural dimension has changed in the last 24 years. This was, in some way, expected because the culture is a complex phenomenon with nine distinct dimensions in the GLOBE's original model; and these events might have affected different aspects in different strengths and ways. This study's findings show "band" changes in the four dimensions and value changes in eight dimensions in the last 24 years in Turkey, but it is also theoretically possible that if there was a different set of events in these years, the culture might have changed differently. Results also show that adverse events may shift cultural dimensions towards higher values as in Assertiveness, Power Distance and Uncertainty Avoidance. Apparently, culture is not affected by communication technologies. Turkish people have started to be 
more exposed to other cultures (especially the American culture) through Hollywood movies, TV shows, magazines, international brands, and their advertisements, etc. The popular American services and products, such as social media (e.g., Facebook, Instagram, etc.) and products (e.g., iPhone) increased the exposure of other cultures to Turkish society, but none of them seem to have had any impact on national culture yet.

\section{Leadership}

This study also investigated whether the culturally endorsed leadership styles have changed in the last 24 years. House et al. (2004) established the links between culture and leadership practices. Naturally, endorsed leadership prototypes may have changed during this timeframe. In summary, the findings show that Participative and Autonomous leadership are more endorsed while Team-Oriented leadership is marginally less supported in 2019.

Participative leadership is the degree to which managers include others in the decision making and its execution (Dorfman et al., 2012). Participative leadership has two sub-dimensions, namely autocratic and participative. Autocratic behaviors include telling subordinates what to do predominantly, making decisions in a dictatorial way, being inclined to dominate others, supporting elitism over diversity, not tolerating disagreements or questioning, and not forcing values and opinions to others. Participative behaviors refer to being willing and able to relinquish control of projects and tasks, not micromanaging, impartiality, and being concerned with group needs rather than preserving individual needs. This leadership style's endorsement has increased in the last 24 years meaning that Turks are endorsing a participative style as ideal more than in 1995. Two factors may contribute to this trend. First, the cultural practices have shifted to 
a greater Power Distance and became 5.80. However, in 1995, the Turkish society value (Should be) score was 2.41 which clearly shows that Turkish mid-level managers desire to decrease the Power Distance gap and participate in decision making processes. The increased value of Power Distance may cause the desire for a more Participative leadership style. Second, there is a new generation of managers. In 1995, managers were likely to be baby boomers or Generation X, but now more and more they come from Generation Y (millennial) and the new employees are coming from Generation Z. These generations significantly differ from each other-no country specific generation study exists-; for example, Gen $\mathrm{X}$ managers are competitive and materialistic while Gen $\mathrm{Y}$ is more globalist and questioning (Francis \& Hoefel, 2019). Therefore, the expected leadership behaviors are also disrupted by cultural and generational shifts. A bossy, dictatorial manager may have been more acceptable in the 1990s, but the new generation of leaders are expected to be more participative and less formal, a "coach" rather than a "boss."

The Autonomous leadership dimension is made up of individualism, independence, autonomous and unique (Dorfman et al., 2012), not depending to others, self-governing, but also for a usual person, having characteristics and behaviors that are different from most others (GLOBE, n.d.). This change is also in line with the increased In-group Collectivism in Turkish society. One other contributing factor may be the fact that in the last 24 years, business has created highly popular leaders who fit this description, such as Steve Jobs, Mark Zuckerberg, Richard Branson, Jeff Bezos, Elon Musk, etc. These leaders have had some of the qualities of Autonomous leadership, and even though they had exceptional but sometimes questionable attributes (such as Steve 
Jobs' temper), they were societally accepted and idealized to a degree. Hence, this kind of exposure may have led the managers to endorse (or seek) exceptional leaders who are "different."

Lastly, endorsement for Team-Oriented leadership has declined. These leadership skills reflect the ones that build a highly effective team and execution among them (Dorfman et al., 2012), and its sub-dimensions are team orientation (group-oriented, collaborative, loyal, consultative, coordinator), team integrator (communicative, team builder, knowledgeable explicit, integrator), diplomatic (tactful, having a world outlook, win-win problem solver, intra-group conflict avoider and effective bargainer), nonmalevolent (not hostile, not vindictive, not irritable and cynical, honest) and administratively competent (able to plan, organize, coordinate, orderly, organized, methodical, and ready to manage complex office work). Increased individualism (e.g., less Institutional Collectivism) may have contributed to this change. However, another point is that the decrease in the absolute score is minimal (from 6.01 to 5.95, the difference is very low in comparison with other changes) and even though its band has changed to the lower band (from A to B), it is also possible to argue that Team-Oriented leadership has only been marginally affected and changed. The participants of the qualitative research tended to stay away from commenting on leadership that can be explained by the fear of retribution from their managers and the political climate in Turkey. Regarding leadership, Participant 6 said,

In Turkish leadership, the emphasis is on relationship...I have worked with several foreign managers throughout my career. I had American, British, French, and Italian managers. Compared to those foreign managers, Turkish leaders lack 
checking whether their subordinates have sufficient sources to do what they ask for...Turkish leaders are prone to set very challenging targets for their subordinates without having any analytical study behind their decisions. These targets are more likely to be the desires of Turkish leaders who can put forward these desires as part of their relationship with their subordinates. In the relationship with the subordinates, Turkish leaders also do not want to be criticized and expect only obedience.

\section{Additional Analyses}

Given the availability of the data, some additional analyses were conducted to further shed light on culture and leadership in Turkey. For example, gender slightly affects the perception of societal practices and endorsed leadership styles. Women tend to perceive more Gender Egalitarianism practices in Turkey than men. This is rather surprising because women are in the center of the problem and they tend to experience more issues with respect to the lack of Gender Egalitarianism. On the other hand, men could be "perceiving" that Gender Egalitarianism is not an issue, or "an exaggerated one". The findings, however, show this is not the case. Men may be more "realistic" on Gender Egalitarianism, perceiving fewer of these practices in Turkey, while women may be more "optimistic" on the same issue. Some differences also hold for leadership, as women endorse Self-Protective leadership more and Participative leadership less than men.

Other demographic factors including age, education and spoken language were investigated to see if there were meaningful differences with respect to culture and endorsed leadership styles. Increased age of the participant positively predicted the 
endorsements of Charismatic/Value-Based, Team-Oriented, Humane-Oriented and Autonomous leaderships. Increased education of the participant also positively predicted the endorsements of Team-Oriented and Charismatic/Value-Based leaderships. However, these effects were rather minimal, explaining little variance in the results. As a result, gender can be interpreted as an important factor in both perception of societal practices and endorsed leadership styles; but the other demographic factors' influences are rather minimal.

Additionally, the patterns of the culture practices and endorsed leadership styles (e.g. their interrelationships) were investigated to see whether they have changed in the last 24 years. One important caveat here is that 1995 data was analyzed at the societal level, comparing the 62 countries but the 2019 data was analyzed at the individual level, comparing around 237 individuals. Even with this limitation, 2019 data showed the same pattern with 1995 data. The correlations among the variables (inter-relationships of cultural practices, inter-relationships of leadership style and relationships between cultural practices and leadership styles) in 2019-individual-level data were almost the same with 1995-societal-level data in terms of both direction and strength. These findings may imply two things: first, the internal dynamics of culture and leadership have stayed the same; and second, there is not much difference between society-level dynamics and individual-level dynamics.

\section{Conclusion}

This study focused on three questions: what things have changed, why they have changed, and what are some potential implications. Replicating the original GLOBE study in 1995 in Turkey in 2019 quantitatively revealed changes regarding cultural 
practices and endorsed leadership styles. In sum, in the last 24 years, Uncertainty Avoidance, Performance Orientation, Humane Orientation and Institutional Collectivism practices have decreased according to the GLOBE "band" definition, but eight dimensions changed in value. Participative and Autonomous leadership are endorsed more and Team-Oriented leadership is endorsed less than before.

To understand why these aspects have changed, the study conducted six qualitative interviews with mid-level managers. The interview results supported overall that there have been changes in the culture, but in general, the interview participants were expecting even greater changes. The changes may have occurred due to several political, economic and technological events mentioned above and the interviews supported the idea that these events had an impact on the culture as well. Lastly, it is important to note why these changes matter. Kabasakal and Bodur (2007) state that Turkish society has both contrasts and combinations of east and west with some elements of modernity, but mostly of traditionalism and Islamism. Hence, this study also revealed that international companies should be more careful when doing business in Turkey due to the changing dynamics of the business world. Companies, especially international organizations, should consider academic research during their daily practices. Most of the participants stated that they have never heard of the GLOBE project and they have never used findings from the GLOBE project to train their expats, leaders, and managers. In particular, Turkish leaders should embrace the differences and diversity. Unfortunately, Turkish society still forces each individual to act as one unique type of individual and hides the diversity coming from thousands of years of history. Organizations should 
encourage and support the practice of demonstrating individual differences which may cause positive shifts in culture.

This study makes further contributions to the existing knowledge. First, this study challenges the "stability of culture" assumption, existing in both GLOBE and Hofstede data and their applications. Both of the studies' data collection were conducted in a specific timeline (e.g. GLOBE in the 1990s) and all following studies used the same data to test their hypotheses. This approach assumes that since the culture is stable and has not changed since the time of data collection continuing to use the data today is valid. However, this study shows that this may not be valid; and the conclusions from these studies should be viewed with more caution. The GLOBE researchers are also aware of this weakness and with similar questions in mind, they are embarking a new phase of the GLOBE study as "GLOBE 2020" and plan to focus on drivers and dynamics of culture change (GLOBE, n.d.). Their data collection is planned to end by late 2019 and they plan to publish their results in 2021.

This study also shows that not only the culture, but also the culturally endorsed leadership styles have changed in the last 24 years. Even though in the GLOBE studies, there was no argumentation regarding the "stability of leadership endorsements", this study shows that endorsed leadership styles may also change along with the cultures in the countries. Moreover, this study's qualitative analyses of the changes contribute to the understanding of cultural change, showing that it may get affected by major events in people's lives, and the speed of cultural change might be increasing.

Lastly, even though they were not part of the research problems of the study, replication of the same study allowed for further comparisons between the 1995 data and 
2019 data. One important finding was that relationships between cultural practice variables and endorsed leadership styles were found to be similar. Even though the culture has been changing with time, this finding shows that the culture's and culturally endorsed leadership styles' internal dynamics may have stayed similar with time.

In conclusion, understanding a country's culture and related leadership styles is important to conduct international business correctly. Companies and societies are becoming more and more global with the help of the advancing communication technologies. This globalization brings further challenges to conduct effective and efficient business across borders. Making it more complicated, culture is also a living thing and it changes and gets affected by the events occurring in the countries. Hopefully, future studies will help researchers and practitioners to understand the dynamics of cultural change and how these changes affect business.

\section{Limitations and Significance of the Study}

The purpose of the study was to provide an answer to the question of whether Turkish societal culture and leadership perceptions have changed since the first GLOBE study was conducted in 1995, and, if so, how. The study has two notable limitations. The first concerns the study being conducted only in one country that has unique characteristics. The second limitation relates to the sample and data collection.

The first set of limitations refers to the fact that current study cannot be compared to other countries. In the original study, individual scores were aggregated to organizational scores, and then, organizational scores were aggregated to country scores. Later, the hypotheses were tested through multi-level hierarchical linear modeling analyses. However, in this study, since the data were collected from only one country and 
cross-country analysis could not be made, the level of analysis was inherently different. For example, societal level tests could not be performed because multiple society scores were not available. Instead, organizational and individual level analyses (where applicable) were performed. Furthermore, in the original study, a method known as test banding was used (Cascio et al., 1991) where societal scores were grouped into bands and the scores in the bands were not considered meaningfully different (Hanges et al., 2004). Since the 2019 study was performed in only one country, the current study had to use the bands of the 1995 study to decide whether Turkey's band has changed or not. As a result, if the other 61 societies had changed since 1995, the values of the bands could be different and could have affected the bands in 2019.

Moreover, as this study is a single country study, the level of analysis also differed from the original GLOBE study. In the original study, analyses were conducted on an organizational and societal level (as they had cross-country variance in their country), but this study was on the individual and organizational level which could have affected correlation results between societal and leadership dimensions. Nevertheless, the results allow for conclusions regarding the specific dimensions under study and comparison of those dimensions to the 1995 study to see how Turkey's culture has evolved. The fact that the overall findings were similar to those in 1995 is a noteworthy finding for future research.

The case study approach used in the qualitative part also had limitations because case studies are based on the researcher's interpretation, cannot be generalized to the broader population, and are difficult to replicate. Another limitation of the sample is the subjectivity of qualitative participants. Because of the political climate and existing 
martial law in Turkey, it is likely that participants may have hesitated to share their views on leadership questions openly. Lastly, the data were collected at one time so that common method bias may affect the results. However, this data collection method was in line with the 1995 study, so it was not changed for replication purposes.

Lastly, it is also worth mentioning the researcher's subjectivity as an interviewer of the qualitative data collection process. As a Turkish and professional who worked in Turkey for more than 15 years, I had some preconceptions about Turkish culture and what has been changing. Similar to Peshkin's (1988) Ethic-Maintenance intrinsic subjectivity - mine has no religious base — I have beliefs, a value system, experiences and observations that might have had an impact on the study, especially in the data collection and analysis parts of the qualitative research. I was aware of my subjectivity and tried to prevent potential influence by continually monitoring and taming my subjectivity (Peshkin, 1988). On the other hand, my background and first-hand knowledge of the Turkish culture and society were potentially beneficial as it enhanced my ability to interact with the participants during interviews and to access organizations.

While these limitations are significant, the study is prominent and has the potential to illustrate the factors and length of time that may cause a shift in a nation's culture. This study is also unique in terms of allowing the researcher to analyze how gender, education level, age, and generations are affected differently by the same factors. Another significance of the study is data triangulation. The data from the qualitative research has strengthened the research by providing possible explanations to quantitative findings and has deepened the understanding of the phenomena. Finally, not only did the 
qualitative research verify the findings, but also offered new research questions for future studies which will be covered in the next section.

\section{Future Research and Conclusions}

This study can open up some new discussions in the existing literature with its future research recommendations. First, the study may have some implications for the GLOBE Project. Initially, GLOBE was planned as a four-phase study. In the first two phases, the researchers developed the cultural framework and its measurement, conducted the 62-country research and published their results. In the third phase, the focus shifted more to leadership and data were collected from over 1000 CEOs and more than 5000 Top Management Team (TMT) members across cultures and countries. Currently, the last phase is running (GLOBE 2020) and is focused on the same question as this study: whether the culture has changed or not and what are the drivers and dynamics of culture shift (Study 1). GLOBE will also research the relationship between national culture, leadership and organizational practices (Study 2). In the last phase, GLOBE will expand to 136 countries and collect data from $300-500$ middle managers. The data collection is expected to be completed by late 2019. GLOBE can use the findings of this study to modify their process such as comparing generations, analyzing gender differences and reviewing assumptions regarding the headquarters of sample organizations.

The findings suggest that significant events occurring in the last 24 years affected some societal practices, but not all of them. Five out of nine cultural practices and three out of six leadership styles have stayed the same - as bands - in the same timeline. New research may focus on identifying which external factors affect which dimensions and 
how societies can control them. In this case, there are two directions to be taken. First, there may be additional single-country studies focusing on the role of major local events (e.g., political, economic and social) and identifying which dimensions have changed. Secondly, some of these events were also global events that could have affected many countries, rather than a local event affecting a single state. Hence, these events could have effects on the societies in several countries as well. In addition to the significant events' influence on culture dimensions not being uniform, these events may also affect different countries in different ways. As a result, the position of Turkey in the Middle East cluster may have changed, not because of major changes in Turkey, but because the other countries in the cluster may have shifted in other directions. Future research could determine whether global changes have affected the GLOBE clusters and researchers should look at some other countries that are affected by global events and examine whether the changes share commonalities, and, if so, why. These investigations would help researchers to understand the change processes in the cultures within or outside the sovereign boundaries.

While the survey method allows for broad generalizations, conducting qualitative research to provide rich data regarding cultural and social shifts and their potential impact would be highly informative. The results of the survey in this study does show some shifts in some cultural variables. More extensive interviews may allow researchers to gain a better understanding of how and why those shifts have occurred while other dimensions have remained the same. For example, a qualitative follow up could answer why females think Gender Egalitarianism has improved in Turkey. In addition, 
millennials could be interviewed for their leadership perception which could shed some light on the quantitative findings regarding age.

A factor that has not been included in cross-cultural leadership research such as GLOBE is the potential for gender differences. This study analyzed gender differences and identified how the same events influenced each gender, specifically how Gender Egalitarianism is perceived. Global research would discover whether gender is a factor and if each gender shows similar patterns all over the world. More specifically, a comprehensive study on the perception of each gender about Gender Egalitarianism is crucial in the era of efforts toward closing the gender gap for leadership positions.

Moreover, this study looked into generational differences, something that has also been overlooked in cross-cultural studies. The results of this study indicate that the older a person gets, the more s/he is likely to endorse Charismatic/Value-Based, TeamOriented, Humane-Oriented and Autonomous leadership. Similar to gender, future research should consider how generational similarities and differences may impact cultural values and leadership ideals. As opposed to previous generations, Millennials and members of Generation Z use the same technology to connect such as Facebook, Instagram, and Twitter which may impact both how and how fast culture changes. New research may illustrate the effect of these new technologies on nations' cultures.

Finally, the results demonstrate that the more formal education a respondent has, the more likely s/he is to endorse Team-Oriented Leadership and Charismatic/ValueBased leadership. This finding also needs to be explored to understand the effect of education on leadership expectations. 
Overall, Turkish society has been undergoing significant political, economic and technological changes, and these changes also seem to be reflected in the cultural practices as well as culturally endorsed leadership styles. By coupling the replication of GLOBE study in Turkey with the interviews, this study provided answers to what has changed, why Turkish culture evolved and what are some implications of these changes. In conclusion, findings show that Turkish society has moved towards stronger values in each dimension they represented in 1995. 


\section{REFERENCES}

Acar, F. (1991). Women in academic science careers in Turkey. In V. Stolte-Heiskanen, F. Acar, N. Ananiveva, D. Guadart, \& R. Fürst-Dilic (Eds.), Women in science: Token women or gender equality (pp. 147-171). New York, NY: St. Martin's Press.

Amnesty International. (2013). Gezi park protests: Brutal denial of the right to peaceful assembly in Turkey. Retrieved from https://www.amnestyusa.org/files/eur440222013en.pdf

Ashkanasy, N. M. (2002). Leadership in the Asian century: Lessons from GLOBE. International Journal of Organizational Behavior, 5, 150-163.

Ashkanasy, N. M., Trevor-Roberts, E., \& Earnshaw, L. (2002). The Anglo cluster: Legacy of the British empire. Journal of World Business, 37(2), 28-39. doi:10.1016/S1090-9516(01)00072-4

Bakacsi, G., Sandor, T., Andras, K., \& Viktor, I. (2002). Eastern European cluster: Tradition and transition. Journal of World Business, 37, 69-80. doi:10.1016/S1090-9516(01)00075-X

Black, J. S., \& Mendenhall, M. (1990). Cross-cultural training effectiveness: A review and a theoretical framework for future research. Academy of Management Review, 15(1), 113-136. doi:10.5465/AMR.1990.11591834

Brett, J. M., \& Okumura, T. (1998). Inter-and intracultural negotiation: US and Japanese negotiators. Academy of Management Journal, 41, 495-510. doi:10.2307/256938 
Cascio, W. F., Outtz, J., Zedeck, S., \& Goldstein, I. L. (1991). Statistical implications of six methods of test score use in personnel selection. Human Performance, 4, 233 264. doi:10.1207/s15327043hup0404_1

Central Intelligence Agency (CIA). (2019). The world factbook: Turkey. Retrieved from https://www.cia.gov/library/publications/the-world-factbook/geos/tu.html

Chhokar, J. S., Brodbeck, F. C., \& House, R. J. (Eds.). (2007). Culture and leadership across the world: The GLOBE book of in-depth studies of 25 societies. New York, NY: Taylor \& Francis.

Cottle, T. J. (1968). The location of experience: A manifest time orientation. Acta Psychologica, 28, 129-149. doi:10.1016/0001-6918(68)90009-7.

Creswell, J. W., \& Clark, V. L. P. (2017). Designing and conducting mixed methods research. Los Angeles, CA: SAGE.

Creswell, J. W., Plano Clark, V. L., Gutmann, M. L., \& Hanson, W. E. (2003). Advanced mixed methods research designs. In A. Tashakkori \& C. Teddlie (Eds.), Handbook of mixed methods in social and behavioral research (pp. 209-240). Thousand Oaks, CA: SAGE.

Creswell, J. W., \& Tashakkori, A. (2007). Differing perspectives on mixed methods research. Journal of Mixed Methods Research, 1, 303-308, doi: $10.1177 / 1558689807306132$

De Luque, M. S., \& Javidan, M. (2004). Uncertainty avoidance. In R. J. House, P. J. Hanges, M. Javidan, P. W. Dorfman, \& V. Gupta (Eds), Leadership, culture, and organizations: The GLOBE study of 62 societies (pp. 602-653). Thousand Oaks, CA: SAGE. 
De Luque, M. S., Lelchook, A. M., \& Quigley, N. R. (2015). Project GLOBE: Insights into the study of culture and leadership. In C. L. Cooper, M. Vodosek, D. N. Hartog, \& J. M. McNett (Eds.), Wiley encyclopedia of management (pp. 1-9). doi:10.1002/9781118785317.weom060096

Dickson, M. W., Aditya, R. N., \& Chhokar, J. S. (2000). Definition and interpretation in cross-cultural organizational culture research: Some pointers from the GLOBE research program. In N. Ashkanasy, C. Wilderom, \& M. Petersen (Eds.), Handbook of organizational culture and climate (pp. 447-464). Thousand Oaks, CA: SAGE.

Dilber, M. (1967). Management in the Turkish private sector industry. Ann Arbor, MI: University Microfilms.

Dobbs, R., Smit, S., Remes, J., Manyika, J., Woetzel, J., \& Agyenim-Boateng, Y. (2013). Urban world: The shifting global business landscape. Retrieved from https://www.mckinsey.com/ /media/McKinsey/Featured Insights/Urbanization/Urban world The shifting global business landscape/MGI_Urban_world3_Full_report_Oct2013.ashx

Dorfman, P., Javidan, M., Hanges, P., Dastmalchian, A., \& House, R. (2012). GLOBE: A twenty-year journey into the intriguing world of culture and leadership. Journal of World Business, 47, 504-518. doi:10.1016/j.jwb.2012.01.004

Esmer, Y. (2012). Türkiye değerler atlası 2012 değişimin kültürel sınırları. İstanbul, Turkey: Bahçeşehir Üniversitesi Yayınları.

Flyvbjerg, B. (2011). Case study. In N. Denzin \& Y. Lincoln (Eds.), The SAGE handbook of qualitative research ( $4^{\text {th }}$ ed., pp.301-316). Thousand Oaks, CA: SAGE. 
Francis, T., \& Hoefel, F. (2019). 'True gen': generation z and its implications for companies. Retrieved from https://www.mckinsey.com/industries/consumerpackaged-goods/our-insights/true-gen-generation-z-and-its-implications-forcompanies

Friedman, T. L. (2016). Thank you for being late. New York, NY: Macmillan.

Global Leadership and Organizational Behavior Effectiveness (GLOBE). (n.d.). Retrieved from https://globeproject.com/

Goldstein, H. (1995). Hierarchical data modeling in the social sciences. Journal of Educational and Behavioral Statistics, 20, 201-204. doi: 10.2307/1165357

González, S., \& Smith, C. (2017). The accuracy of measures of institutional trust in household surveys: Evidence from the OECD trust database. OECD Statistics Working Papers, 2017(11), 1-38. OECD Publishing, Paris.

Göregenli, M. (1997). Individualist-collectivist tendencies in a Turkish sample. Journal of Cross-Cultural Psychology, 28, 787-794. doi:10.1177/0022022197286009

Graen, G. B. (2006). In the eye of the beholder: Cross-cultural lesson in leadership from project GLOBE: A response viewed from the third culture bonding (TCB) model of cross-cultural leadership. Academy of Management Perspectives, 20(4), 95101. doi:10.5465/AMP.2006.23270309

Grove, C. N. (2005). Worldwide differences in business values and practices: Overview of GLOBE research findings. GroveWell. Retrieved from https://www.grovewell.com/wp-content/uploads/pub-GLOBE-dimensions.pdf 
GRT. (2012). Global Relocation Trends 2012 Survey Report. Brookfield Global Relocation Services, LLC. Retrieved from https://espritgloballearning.com/wpcontent/uploads/2011/03/2012-Brookfield-Global-Relocations-Trends-Survey.pdf

Gulliksen, H. (1950). Intrinsic validity. American Psychologist, 5(10), 511 doi: $10.1037 / \mathrm{h} 0054604$

Gupta, V., Hanges, P. J., \& Dorfman, P. (2002). Cultural clusters: Methodology and findings. Journal of World Business, 37(1), 11-15. doi:10.1016/S10909516(01)00070-0

Gupta, V., Surie G., Javidan, M., \& Chhokar, J. (2002). Southern Asia cluster: Where the old meets the new? Journal of World Business, 37, 16-27. doi:10.1016/S10909516(01)00071-2

Gürbüz, E. (1988). A measurement of sex-trait stereotypes (Doctoral dissertation, Bogazici University, Institute for Graduate Studies in Social Sciences, Istanbul, Turkey).

Hanges, P. J., Aiken, J. R., Park, J., \& Su, J. (2016). Cross-cultural leadership: Leading around the world. Current Opinion in Psychology, 8, 64-69. doi: 10.1016/j.copsyc.2015.10.013

Hanges, P. J., Dickson, M. W., \& Sipe, M. T. (2004). Rationale for GLOBE statistical analyses: Societal rankings and test of hypotheses. In R. J. House, P. J. Hanges, M. Javidan, P. W. Dorfman, \& V. Gupta, (Eds), Leadership, culture, and organizations: The GLOBE study of 62 societies (pp. 219-234). Thousand Oaks, CA: SAGE. 
Helson, R., Jones, C., \& Kwan, V. S. (2002). Personality change over 40 years of adulthood: Hierarchical linear modeling analyses of two longitudinal samples. Journal of Personality and Social Psychology, 83, 752-766. doi:10.1037//00223514.83.3.752

Hofmann, D. A. (1997). An overview of the logic and rationale of hierarchical linear models. Journal of Management, 23, 723-744. doi: $10.1177 / 014920639702300602$

Hofstede Insight. (2019). National culture. Retrieved from https://www.hofstedeinsights.com/models/national-culture/

Hofstede, G. (1980). Culture and organizations. International Studies of Management \& Organization, 10(4), 15-41.

Hofstede, G. (1994). The business of international business is culture. International Business Review, 3, 1-14. doi:10.1016/0969-5931(94)90011-6

Hofstede, G. (1996). Riding the waves of commerce: A test of Trompenaars" "model" of national culture differences. International Journal of Intercultural Relations, 20, 189-198. doi:10.1016/0147-1767(96)00003-X

Hofstede, G. (1998). Attitudes, values and organizational culture: Disentangling the concepts. Organization Studies, 19, 477-493. doi: 10.1177/017084069801900305

Hofstede, G. (2001). Cultural consequences. Thousand Oaks, CA: SAGE.

Hofstede, G. (2006). What did GLOBE really measure? Researchers' minds versus respondents' minds. Journal of International Business Studies, 37, 882-896. Retrieved from http://www.jstor.org/stable/4540391 
Hoppe, M. (1993). The effects of national culture on the theory and practice of managing R\&D professionals abroad. R\&D Management, 23, 313-325. doi:10.1111/j.14679310.1993.tb00837.x

House, R. J., Hanges, P. J., Javidan, M., Dorfman, P. W., \& Gupta, V. (2004). Culture, leadership, and organizations: The GLOBE study of 62 societies. Thousand Oaks, CA: SAGE.

House, R. J., Hanges, P. J., Ruiz-Quintanilla, S. A., Dorfman, P. W., Falkus, S. A., \& Ashkanasy, N. M. (1999). Cultural influences on leadership and organizations: Project GLOBE. In W. H. Mobley, M. J. Gessner, \& V. Arnold (Eds.), Advances in global leadership (pp. 171-233). Warrington, England: Emerald.

House, R. J., Javidan, M., Dorfman, P. W., \& De Luque, M. S. (2006). A failure of scholarship: Response to George Graen's critique of GLOBE. Academy of Management Perspectives, 20, 102-114. doi:10.5465/AMP.2006.23270311

House, R. J., Javidan, M., Hanges, P., \& Dorfman, P. W. (2002). Understanding cultures and implicit leadership theories across the globe: An introduction to project GLOBE. Journal of World Business, 37, 3-10. doi:10.1016/S10909516(01)00069-4

House, R. J., Wright, N. S., \& Aditya, R. N. (1997). Cross-cultural research on organizational leadership: A critical analysis and a proposed theory. In P. C. Earley \& M. Erez (Eds.), New perspectives on international/organizational psychology (pp. 535-625). San Francisco: New Lexington.

Inelmen, K., Iseri Say, A., \& Kabasakal, H. (2004). Participation lethargy in disaster preparedness organizations within the framework of a Turkish CBO. International 
Journal of Sociology and Social Policy, 24, 130-158.

doi:10.1108/01443330410791082

Javidan, M., \& Dastmalchian, A. (2009). Managerial implications of the GLOBE project: A study of 62 societies. Asia Pacific Journal of Human Resources, 47, 41-58. doi:10.1177/1038411108099289

Javidan, M., \& House, R. J. (2001). Cultural acumen for the global manager: Lessons from Project GLOBE. Organizational Dynamics, 29, 289-305. doi:10.1016/S0090-2616(01)00034-1

Javidan, M., Dorfman, P. W., De Luque, M. S., \& House, R. J. (2006). In the eye of the beholder: Cross cultural lessons in leadership from project GLOBE. The Academy of Management Perspectives, 20, 67-90. doi:10.5465/AMP.2006.19873410

Javidan, M., House, R. J., Dorfman, P. W., Hanges, P. J., \& De Luque, M. S. (2006). Conceptualizing and measuring cultures and their consequences: A comparative review of GLOBE's and Hofstede's approaches. Journal of International Business Studies, 37, 897-914. doi:10.1057/palgrave.jibs.8400234

Javidan, M., Stahl, G. K., Brodbeck, F., \& Wilderom, C. (2005). Cross-border transfer of knowledge: Cultural lessons from Project GLOBE. Academy of Management Executive, 19, 59-76. doi:10.5465/AME.2005.16962801

Jesuino, J. C. (2002). Latin Europe cluster: From south to north. Journal of World Business, 37, 81-89. doi:10.1016/S1090-9516(01)00076-1

Kabasakal, H., \& Bodur, M. (2002). Arabic cluster: A bridge between East and West. Journal of World Business, 37, 40-54. doi:10.1016/S1090-9516(01)00073-6 
Kabasakal, H., \& Bodur, M. (2007). Leadership and culture in Turkey: A multifaceted phenomenon. In J. S. Chhokar, F. C. Brodbeck, \& R. J. House (Eds.), Culture and leadership across the world: The GLOBE book of in-depth studies of 25 Societies, (pp. 835-874). New York, NY: Taylor \& Francis.

Kabasakal, H., \& Dastmalchian, A. (2001). Introduction to the special issue on leadership and culture in the Middle East. Applied Psychology, 50, 479-488. doi:10.1111/1464-0597.00069

Kabasakal, H., Dastmalchian, A., Karacay, G., \& Bayraktar, S. (2012). Leadership and culture in the MENA region: An analysis of the GLOBE project. Journal of World Business, 47, 519-529. doi:10.1016/j.jwb.2012.01.005

Kağıtçıbaşı, Ç. (1982). Sex roles, family \& community in Turkey. Bloomington: Indiana University, Turkish Studies.

Keating, M. A., Martin, G. S., \& Szabo, E. (2002). Do managers and students share the same perceptions of societal culture? International Journal of Intercultural Relations, 26, 633-652. doi:10.1016/S0147-1767(02)00039-1

Keller, J., Mykhyalyshyn, I., \& Timur, S. (2016). The scale of Turkey's purge is nearly unprecedented. New York Times. Retrieved from https://www.nytimes.com/interactive/2016/08/02/world/europe/turkey-purgeerdogan-scale.html

Kluckhohn, F. R., \& Strodtbeck, F. L. (1961). Variations in value orientations. Evaston, IL: Row, Peterson.

Landes, D. S. (1998). The wealth and poverty of nations: Why some are so rich and some so poor. New York, NY: W.W. Norton. 
Leung, K. (2006). Editor's introduction to the exchange between Hofstede and GLOBE. Journal of International Business Studies, 37, 881-881. doi:10.1057/palgrave.jibs.8400232

Littrell, L. N., Salas, E., Hess, K. P., Paley, M., \& Riedel, S. (2006). Expatriate preparation: A critical analysis of 25 years of cross-cultural training research. Human Resource Development Review, 5(3), 355-388. doi: $10.1177 / 1534484306290106$

Lord, R., \& Maher, K. (1991). Leadership and information processing: Linking perception and performance. Boston, MA: Unwin Hyman.

Martinelli-Lee, T., \& Duncan, K. B. (2015). International joint ventures at the crossroads: Building leadership bridges. In B. Christiansen (Ed.), Handbook of research on global business opportunities (pp. 150-167). IGI Global.

Maseland, R., \& Van Hoorn, A. (2009). Explaining the negative correlation between values and practices: A note on the Hofstede-GLOBE debate. Journal of International Business Studies, 40, 527-532. doi:10.1057/jibs.2008.68

McClelland, D. C. (1985). Human motivation. Glenview, IL: Scott, Foresman. McCrae, R. R., Terracciano, A., Realo, A., \& Allik, J. (2008). Interpreting GLOBE societal practices scales. Journal of Cross-Cultural Psychology, 39, 805-810. doi:10.1177/0022022108323806

Mensah, Y. M., \& Chen, H. Y. (2012). Global clustering of countries by culture - An extension.

Meyer, E. (2014). The culture map: Breaking through the invisible boundaries of global business (pp. 252). New York, NY: Public Affairs. 
Minkov, M., \& Blagoev, V. (2012). What do Project GLOBE's cultural dimensions reflect? An empirical perspective. Asia Pacific Business Review, 18, 27-43. doi:10.1080/13602381.2010.496292

Morse, J. M. (1991). Approaches to qualitative-quantitative methodological triangulation. Nursing research, 40, 120-123. doi:10.1097/00006199-199103000-00014

Parsons, T., \& Shils, E. A. (1951). Values, motives, and systems of action. Toward a general theory of action (pp. 247-275). Cambridge, MA: Harvard University Press.

Patton, M. Q. (2015). Designing Qualitative Studies. In V. Knight (Ed.), Qualitative Research \& Evaluation Methods (4th, pp. 245-327). Thousand Oaks, CA: SAGE.

Peshkin, A. (1988). In search of subjectivity_one's own. Educational researcher, 17, 1721. doi:10.3102/0013189X017007017

Peterson, M. F., \& Castro, S. L. (2006). Measurement metrics at aggregate levels of analysis: Implications for organization culture research and the GLOBE project. The Leadership Quarterly, 17, 506-521. doi:10.1016/j.leaqua.2006.07.001

Pfeffer, J. (1982). Organizations and organization theory. Marshfield, WI: Pitman.

Polkinghorne, D. E. (1995). Narrative configuration in qualitative analysis. International Journal of Qualitative Studies in Education, 8(1), 5-23.

doi:10.1080/0951839950080103

Rossman, G. B., \& Wilson, B. L. (1985). Numbers and words: Combining quantitative and qualitative methods in a single large-scale evaluation study. Evaluation Review, 9(5), 627-643. 
Rotter, J. B. (1966). Generalized expectancies for internal versus external control of reinforcement. Psychological Monographs: General and Applied, 80(1), 1-28. doi:10.1037/h0092976

Schein, E.H. (1985) Organizational culture and leadership. San Francisco: Jossey-Bass Publishers.

Schneider, S. C. (1988). National vs. corporate culture: Implications for human resource management. Human Resource Management, 27(2), 231-246. doi: 10.1002/hrm.3930270207

Schwartz, S. H. (1992). Universals in the content and structure of values: Theoretical advances and empirical tests in 20 countries. Advances in Experimental Social Psychology, 25, 1-65. doi:10.1016/S0065-2601(08)60281-6

Schwartz, S. H. (1994). Are there universal aspects in the structure and contents of human values? Journal of Social Issues, 50, 19-45. doi: 10.1111/j.15404560.1994.tb01196.x.

Schwartz, S. H. (1999). A theory of cultural values and some implications for work. Applied Psychology, 48, 23-47. doi:10.1080/026999499377655.

Sentryo. (n.d.). The 4 industrial revolutions. Retrieved from https://www.sentryo.net/the4-industrial-revolutions/

Shi, X., \& Wang, J. (2011). Interpreting Hofstede model and GLOBE model: Which way to go for cross-cultural research? International Journal of Business and Management, 6, 93-99. doi:10.5539/ijbm.v6n5p93 
Shrout, P. E., \& Fleiss, J. L. (1979). Intraclass correlations: Uses in assessing rater reliability. Psychological Bulletin, 86(2), 420-428. doi:10.1037/00332909.86.2.420

Smith, P. B. (2006). When elephants fight, the grass gets trampled: The GLOBE and Hofstede projects. Journal of International Business Studies, 37, 915-921. doi:10.1057/palgrave.jibs. 8400235

Smith, P. B., \& Schwartz, S. H. (1997). Values. In J. W. Berry, C. Kagitcibasi \& M. H. Segall (Eds.), Handbook of cross-cultural psychology (2nd ed., Vol. 3, pp. 77119). Boston, MA: Allyn \& Bacon.

Smith, P. B., Dugan, S., \& Trompenaars, F. (1996). National culture and the values of organizational employees: A dimensional analysis across 43 nations. Journal of Cross-Cultural Psychology, 27, 231-264. doi:10.1177/0022022196272006

Smith, P. B., Fischer, R., Vignoles, V. L., \& Bond, M. H. (2013). Understanding social psychology across cultures: Engaging with others in a changing world. London, England: SAGE.

Steenkamp, J. B. E. (2001). The role of national culture in international marketing research. International Marketing Review, 18, 30-44. doi:10.1108/02651330110381970

Steers, R. M., Sanchez-Runde, C., \& Nardon, L. (2012). Leadership in a global context: New directions in research and theory development. Journal of World Business, 47, 479-482. doi:10.1016/j.jwb.2012.01.001 
Szabo, E., Brodbeck, F. C., Den Hartog, D. N., Reber, G., Weibler, J., \& Wunderer, R. (2002). The Germanic Europe cluster: Where employees have a voice. Journal of World Business, 37, 55-68. doi:10.1016/S1090-9516(01)00074-8

Taras, V., Kirkman, B. L., \& Steel, P. (2010). Examining the impact of culture's consequences: A three-decade, multilevel, meta-analytic review of Hofstede's cultural value dimensions. Journal of Applied Psychology, 95, 405-439. doi:10.1037/a0018938

Taras, V., Steel, P., \& Kirkman, B. L. (2010). Negative practice--value correlations in the GLOBE data: Unexpected findings, questionnaire limitations and research directions. Journal of International Business Studies, 41(8), 1330-1338.

Tashakkori, A. \& Teddlie, C. (1998). Mixed methodology: Combining qualitative and quantitative approaches (Vol. 46). Thousand Oaks, CA: SAGE.

Topaloglu, B. (1983). Women in Islam. Istanbul, Turkey: Yagmur Yayinevi.

Trompenaars, A. (1993). Riding the waves of culture: Understanding diversity in business. London, England: The Economist Books.

Trompenaars, A., \& Hampden-Turner, C. (1998). Riding the waves of culture: Understanding diversity in global business. London, England: Nicholas Brealey.

Tung, R. L., \& Verbeke, A. (2010). Beyond Hofstede and GLOBE: Improving the quality of cross-cultural research. Journal of International Business Studies, 41, 12591274. doi:10.1057/jbs.2010.41

Turkish Statistical Institute. (2017). Statistics by theme: Employment, unemployment and wages: Statistical tables and dynamic search: Labor force statistics (2014 and after). Retrieved from https://biruni.tuik.gov.tr/medas/?kn=72\&locale=tr 
United Nations Development Programme (UNDP). (2016). Human development report 2016. Ottawa, Canada: Lowe-Martin Group. Retrieved from http://hdr.undp.org/en/content/human-development-report-2016-humandevelopment-everyone

Venaik, S., \& Brewer, P. (2008). Contradictions in national culture: Hofstede vs GLOBE. Paper presented at the 50th annual meeting of the Academy of International Business, Milan, Italy.

Venaik, S., \& Brewer, P. (2013). Critical issues in the Hofstede and GLOBE national culture models. International Marketing Review, 30, 469-482. doi:10.1108/IMR03-2013-0058

Venaik, S., Zhu, W., \& Brewer, P. (2013). Looking into the future: Hofstede long term orientation versus GLOBE future orientation. Cross Cultural Management: An International Journal, 20, 361-385. doi:10.1108/CCM-02-2012-0014

World Values Survey. (1990). World Values Survey Wave 2 Results (1995-1998) [Data file]. Retrieved from http://www.worldvaluessurvey.org/WVSDocumentationWV2.jsp

World Values Survey. (1996). World Values Survey Wave 3 Results (1990-1994) [Data file]. Retrieved from http://www.worldvaluessurvey.org/WVSDocumentationWV3.jsp

Yoldaş, L. D. Ö. B. (2015). Cultural reflections of value changes in Turkey. European Journal of Business and Social Sciences, 3(10), 66-72. Retrieved from http://www.ejbss.com/Data/Sites/1/vol3no10january2015/ejbss-1509-15culturalreflectionsofvaluechangesinturkey.pdf 


\author{
APPENDIX A \\ Survey Questions (Quantitative Part)
}

Anket Katılımeı Onay Formu

\title{
I.Araştırma Çalışmasının Amacı
}

1994 yılında, Türkiye dahil dünyanın 62 bölgesinde yapılan GLOBE liderlik araştırmasının Türkiye bölümünü tekrarlamak üzere bir çalışma yapıyoruz. Bu çalışmanın amac1, 1994 yılından sonra dünyada ve Türkiye'de gerçekleşen politik, sosyal ve ekonomik olayların Türk yöneticilerin sosyal kültürlerini ve liderlik anlayışlarını nasıl değiştirdiğini anlamaya yöneliktir. Ayrıca; bu proje San Diego Üniversite'nde Organizasyonel Liderlik doktora programını tamamlamak için Zeki Pağda tarafından yürütülen tez araştırma çalışmasında da kullanılacaktır.

\section{Sizden Beklenilen}

Eğer bu çalışmaya katılmaya karar verirseniz, sizden konuyla ilgili anketi doldurmanız istenecektir. Çevrimiçi olan bu anketin doldurulması yaklaşı olarak 40-45 dakika sürecektir. Çeşitli sebeplerden anketi ilk girişte bitiremediğiniz durumda aynı anket bağlantısını kullanarak daha sonra ankete kaldığınız yerden devam edebilirsiniz. Ankette toplumunuzdaki standartlar, değer yargıları ve alışkanlıkların durumu ve bunların nasıl olması gerektiği ile birlikte lider davranışlarını ve özelliklerini değerlendirmeniz istenecektir.

\section{III. Öngörülebilir Riskler}

$\mathrm{Bu}$ çalışma, sizlere günlük hayatta karşılaşabileceğinizden daha büyük bir risk oluşturmaz.

\section{Araştırma Çalışmasının Faydaları}

Çalışmaya katılımınızdan dolayı direkt fayda elde edemeyebilirsiniz. Fakat araştırmaya yaptığınız katkılar, araştırmacıların liderlik yetkinliklerinin geliştirilmesinde en etkin uygulamaları tespit etmesine yardımcı olarak endirekt fayda sağlayacaktır.

\section{Gizlilik}

Katılımınız gizli kalacaktır. Katılımınızdan çıkacak olan bilgiler saklı tutulacak ve bu bilgilere araştırmacı dışındaki kişilerin erişimi olmayacaktır. Herhangi bir şekilde bilgilerin raporlanması durumunda sizin ya da kurumunuzun çalışmaya katılımı açık edilmeyecektir.

\section{VI. Ödül}


Ankete katılımınız karşılığı olarak herhangi bir ödül temin edilmemektedir.

\section{Gönüllü Katılım İlkesi}

$\mathrm{Bu}$ çalışmaya katılım tamamıyla gönüllük ilkesine dayanır. Katılımınız zorunlu olmadığı gibi anketi dilediğiniz zaman bırakma hakkınız da saklı tutulmaktadır.

\section{VIII. Ỉletişim Bilgileri}

Çalışma ile ilgili sorularınız olması durumunda aşağıdaki iletişim bilgilerini kullanmanızı rica ederiz.

\section{1- Zeki Pağda}

Email: zpagda@sandiego.edu

Tel: +90 5332990053

2- Dr. Afsaneh Nahavandi - Tez Kurul Başkanı

Email: anahavandi@sandiego.edu

Tel: +1 6192604181

Lütfen aşağıdaki seçeneklerden birini işaretleyiniz.

- Formu okudum ve anladım; bu çalışmaya katılmayı kabul ediyorum.

- Bu çalışmaya katılmayı tercih etmiyorum. 


\section{Bölüm - Bu toplumda durum nasildır?}

Bu bölümde toplumunuzdaki standartlar, değer yargıları ve alışkanlıklar hakkındaki görüşlerinizle ilgileniyoruz. Bir başka deyişle, toplumunuzun nasıl olması gerektiği hakkındaki düşüncenizi değil, şu andaki durumu ile ilgileniyoruz.

Hiçbir şekilde doğru veya yanlış cevap yoktur ve vereceğiniz cevaplar toplumunuzun iyiliğini veya kötülüğünü göstermez.

Lütfen soruları toplumunuz hakkındaki görüşlerinizi en iyi şekilde temsil eden sayıyı işaretleyerek cevaplayınız.

1. bölümün soruları burada başlıyor.

1-1. Bu toplumda değişik şeyler deneme ve yenilik yaratmayı engelleme pahasına olsa bile düzenlilik ve tutarlılık üzerinde ssrarla durulur.

Tamamen aynı fikirdeyim. / Ne aynı ne karşıt fikirdeyim. / Tamamen karşıt fikirdeyim.

1-2. Bu toplumda insanlar genellikle Saldırgandır. / Saldırgan değildir.

1-3. Bu toplumda başarılı olmanın yolu Önceden plan yapmaktır. / Olayları oluştukça ele almaktır.

1-4. Bu toplumda kabul gören uygulama Geleceğe yönelik plan yapmaktır. / Hali hazırdaki uygulamaları devam ettirmektir.

1-5. Bu toplumda kimin sözünün geçtiği Onun yeteneğine ve topluma yaptığı katkıya dayanır. / Onun mevkiine dayanır.

1-6. Bu toplumda insanlar genellikle Kendi fikirlerini ortaya koymada israrcıdırlar. / Kendi fikirlerini ortaya koymada ssrarcı değillerdir.

1-7. Bu toplumda liderler, bireysel amaçlar zarar görse bile, gruba bağl1lı̆̆ teşvik ederler. Tamamen aynı fikirdeyim. / Ne aynı ne karşıt fikirdeyim. / Tamamen karşıt fikirdeyim.

1-8. Bu toplumda sosyal etkinlikler 
Epey önceden planlanır (en az iki hafta önceden). / O anda oluşur (bir saatden az bir süre içinde).

1-9. Bu toplumda insanlar genellikle Başkalarını hep düşünürler. / Başkalarını hiç düşünmezler.

1-10. Bu toplumda insanlar genellikle Hükmedicidirler. / Hükmedici değildirler.

1-11. Bu toplumda çocuklar ebeveynlerinin kişisel başarılarından gurur duyarlar. Tamamen aynı fikirdeyim. / Ne aynı ne karşıt fikirdeyim. / Tamamen karşıt fikirdeyim.

1-12. Bu toplumdaki ekonomik sistem

Bireysel çıkarları azami dereceye yükseltmeyi amaçlar. / Toplu çıkarları azami dereceye yükseltmeyi amaçlar.

1-13. Bu toplumda taraftarların

Liderlerine koşulsuz itaat etmeleri beklenir. / Anlaşamadıkları takdirde liderlerini sorgulamaları beklenir.

1-14. Bu toplumda insanlar genellikle

Serttir. / Narindir.

1-15. Bu toplumda genç öğrenciler, sürekli gelişen bir performans göstermeleri için teşvik edilirler.

Tamamen aynı fikirdeyim. / Ne aynı ne karşıt fikirdeyim. / Tamamen karşıt fikirdeyim.

1-16. Bu toplumda çoğu insanlar beklenmeyen olaylar pek az olan, çok programlı bir hayat sürerler.

Tamamen aynı fikirdeyim. / Ne aynı ne karşıt fikirdeyim. / Tamamen karşıt fikirdeyim.

1-17. Bu toplumda kızlardan çok erkekler daha yüksek bir eğitim görmeleri için teşvik edilirler.

Tamamen aynı fikirdeyim. / Ne aynı ne karşıt fikirdeyim. / Tamamen karşıt fikirdeyim.

1-18. Bu toplumda başlica ödüllendirmeler:

Sadece başarılara dayalıdır. / Başarılara ve diğer faktörlere dayalıdır (örneğin, kıdem veya kurduğunuz ilişkiler). / Sadece başarılardan başka faktörlere dayalıdır (örneğin, kıdem veya kurduğunuz ilişkiler). 
1-19. Bu toplumda toplumsal kurallar ve talimatlar ayrıntılarıyla açıklanmıştır, bu nedenle insanlar kendilerinden ne yapmaları gerektiğini bilirler.

Tamamen aynı fikirdeyim. / Ne aynı ne karşıt fikirdeyim. / Tamamen karşı1t fikirdeyim.

1-20. Bu toplumda performansı geliştirmek için yapılan yenilikler, Önemli ölçüde ödüllendirilir. / Biraz ödüllendirilir. / Ödüllendirilmez.

1-21. Bu toplumda insanlar genellikle, Başkalarına karşı çok hassastırlar. / Başkalarına karşı hiç hassas değildir.

1-22. Bu toplumda atletik programlar daha çok:

Erkek çocuklar içindir. / Kız çocukları içindir.

1-23. Bu toplumda ebeveynler çocuklarının kişisel başarılarından gurur duyarlar. Tamamen aynı fikirdeyim. / Ne aynı ne karşıt fikirdeyim. / Tamamen karşıt fikirdeyim.

1-24. Toplumumuzdaki kurallar ve yasalar: Hemen hemen her durumu kapsar. / Bazı durumları kapsar. / Çok az durumu kapsar.

1-25. Bu toplumda insanlar genellikle

Çok arkadaşçadır. / Hiç arkadaşça değildir.

1-26. Bu toplumda yetkili mevkilerdeki kişiler:

Kendilerinden daha az güçlü kişilerle aralarındaki sosyal mesafeyi artırırlar. /

Kendilerinden daha az güçlü kişilerle aralarındaki sosyal mesafeyi azaltırlar.

1-27. Bu toplumda hiyerarşiye bağlı olarak mevkii ve görevlerin özel ayrıcalıkları vardır. Tamamen aynı fikirdeyim. / Ne aynı ne karşıt fikirdeyim. / Tamamen karşıt fikirdeyim.

1-28. Bu toplumda yaşlanan ebeveynler genellikle evde çocukları ile beraber otururlar. Tamamen aynı fikirdeyim. / Ne aynı ne karşıt fikirdeyim. / Tamamen karşıt fikirdeyim.

1-29. Bu toplumda, bir grupta bulunan diğer üyeler tarafından kabul görmek çok önemlidir.

Tamamen aynı fikirdeyim. / Ne aynı ne karşıt fikirdeyim. / Tamamen karşıt fikirdeyim.

1-30. Bu toplumda kişilerin çoğu

Gelecek için değil, bugün için yaşarlar. / Bugün için değil, gelecek için yaşarlar.

1-31. Bu toplumda insanlar daha çok: 
Günlük sorunları çözmeye önem verirler. / Geleceğe yönelik plan yaparlar.

1-32. Bu toplumda insanlar genellikle, Hatalar karşısında çok hoşgörülüdür. / Hatalar karşısında hiç hoşgörülü değildir.

1-33. Bu toplumda insanlar genellikle, Çok cömerttirler. / Hiç cömert değildir.

1-34. Bu toplumda güç ve yetki:

Tepede yoğunlaşmıştır. / Toplumun her kesiminde paylaşılır.

1-35. Bu toplumda:

Grup birlikteliği bireyden daha önemlidir. / Grup birlikteliği bireyle eşit derecede önemlidir. / Birey grup birlikteliğinden önemlidir.

1-36. Bu toplumda erkeklerin okuldaki başarısızlığı, kadınların okuldaki başarısızlığından daha kötüdür.

Tamamen aynı fikirdeyim. / Ne aynı ne karşıt fikirdeyim. / Tamamen karşıt fikirdeyim.

1-37. Bu toplumda insanlar genellikle:

Fizikseldir. / Fiziksel değildir.

1-38. Bu toplumda üst yönetimde çalışma olasılığı:

Daha fazla erkeklerdedir. / Kadın ve erkeklerde eşittir. / Daha fazla kadınlardadır.

1-39. Bu toplumda çocuklar genellikle evleninceye kadar evde ebeveynleriyle beraber otururlar.

Tamamen aynı fikirdeyim. / Ne aynı ne karşıt fikirdeyim. / Tamamen karşıt fikirdeyim.

1-40. Bu toplumdaki şirketlerde çalışanlar bir aile gibi birlik içindedir. Tamamen aynı fikirdeyim. / Ne aynı ne karşıt fikirdeyim. / Tamamen karşıt fikirdeyim.

1-41. Bu toplumdaki şirketler çalışanlarının bireysel ve ailevi sorunları ile ilgilenir. Tamamen aynı fikirdeyim. / Ne aynı ne karşıt fikirdeyim. / Tamamen karşıt fikirdeyim.

1-42. Bu toplumdaki çalışan kadınlar iş ortamında:

Gösterişsiz giyinirler. / Gösterişli giyinirler.

1-43. Bu toplumdaki şirketlerde kadınlar ve erkekler genellikle: Aynı mekanda çalışırlar. / Ayrı mekanda çalışırlar. 
1-44. Bu toplumdaki şirketler iş saatlerinde isteyene namaz k1lma:

İzni ve olanakları sağlar. / İzin vermez.

1-45. Bu toplumdaki şirketlerin liderleri:

Genç ve dinamik yöneticilerdir. / Yaşlı ve temkinli yöneticilerdir.

Anketin 1. bölümü burada sona eriyor. Lütfen 2. bölüme devam ediniz.

2. Bölüm - Liderlerin Davranıșları

Talimatlar

Kurumunuzda veya sanayinizde sizi, başkalarını veya grupları teşvik etmekte, etkilemekte veya kurumunuzun veya işin başarısına katkıda bulunmada olağanüstü becerisi olan bazı kişileri biliyor olabilirsiniz.

Bu ülkede böyle kişileri “olağanüstü başarılı liderler” olarak nitelendirebiliriz.

Bunu izleyen sayfalarda liderleri tasvir eden bazı davranış ve özellikler vardır. Her davranış veya özellikten sonra onu açıklayan kısa bir tanım bulunmaktadır.

Yukarıdaki olağanüstü başarılı liderler için kullandığımız tanımı rehber olarak kullanarak ilerideki sayfalardaki davranış ve özellikleri derecelendirin. Bunu yapmak için her davranış ve özelliğin karşısında bulunan sayılardan aşağıdaki değerlendirmede kullanılan liderin olağanüstü başarılı olması için o davranış ve özelliğin ne kadar önemli olduğunu en iyi belirten sayıyı işaretleyiniz.

Değerlendirme

1: $\mathrm{Bu}$ davranış veya özellik bir kimsenin önemli bir lider olmasını çok fazla engeller.

2: Bu davranış veya özellik bir kimsenin önemli bir lider olmasını biraz engeller.

3: Bu davranış veya özellik bir kimsenin önemli bir lider olmasını çok az engeller.

4: Bu davranış veya özellik bir kimsenin önemli bir lider olmasında hiç etkisi yoktur.

5: Bu davranış veya özellik bir kimsenin önemli bir lider olmasına çok az katkıda bulunur.

6: Bu davranış veya özellik bir kimsenin önemli bir lider olmasına biraz katkıda bulunur.

7: Bu davranış veya özellik bir kimsenin önemli bir lider olmasına çok fazla katkıda bulunur.

Özellik veya Davranış

2-1. Diplomat: Dengeli iletişim kuran, kişilerle ilişkilerinde becerikli, nezaketli

2-2. Fikrini söylemekten sakınan: İnsanlarla olan iyi ilişkileri korumak ve onları zor durumda bırakmamak için olumsuz yorum yapmaktan kaçınan

2-3. Arabulucu: Kişiler arasındaki anlaşmazlıkları çözümlemek için araya girer

2-4. Söz geçiren: Astlarına emir verir gibi ne yapmaları gerektiğini söyler

2-5. Olumlu: Genellikle iyimser ve kendinden emin 
2-6. Grup içinde rekabetçi: Grubundaki kişilerin icraatlarını geçmek için çaba gösterir

2-7. Özgür: Bağımsız hareket eder, başkalarına bağımlı değildir

2-8. Bağımsız: Başkalarına bağımlı değildir; kendi başına hareket eder

2-9. İnsafsız: Cezalandırıcı, acıma duygusu ve şefkati olmaya

2-10. Nazik: Kolaylıkla incinen, kırlan

2-11. Gelişmeye yönelik: İcraatını sürekli geliştirmeyi arzu eder

2-12. İlham veren: Başkalarının duygularına, inançlarına, değer yargılarına ve davranışlarına ilham verir. Başkalarına çok çalışma güdüsü aşılar.

2-13. İleriye dönük: İleriyi düşünür, olacakları tahmin etmeye çalışır, gelecekte olacakları düşünür

2-14. Risk alan: Esas kaynakları başarı oranı yüksek olmayan atılımlara yatıran

2-15. İçten: Her söylediğini kasteden, samimi

2-16. Güvenilir: Güvene layık olan, sözünü tutacağına inanılan ve güvenile

2-17. Dünyevi: Dünyadaki işlerle ilgili, dünya görüşü olan

2-18. Grup içinde sürtüşmeden kaçan: Grubundaki kişilerle sürtüşmekten kaçan

2-19. İdari becerisi olan: Plan yapabilen, çok sayıda (70'den fazla) kişinin işlerini koordine ve kontrol edebilen

2-20. Adil: Doğruluk ve hakka göre hareket eden

2-21. Her iki tarafın da problemini çözen: Birbirine zıt ve çakışan çıkarları olan kişileri tatmin eden çözümler bulan

2-22. Açık: Kolayca anlaşılan

2-23. Kendine düşkün: Kendi çıarlarının peşinde olan

2-24. Zorba: Zorba gibi hareket eder, despot, gaddar

2-25. Birleştirici: İnsanları ve işleri çalışan bir bütün haline getiren, birleştiren

2-26. Sakin: Kolayca dertlenmeyen

2-27. Kışkırtıcı: Kargaşayı teşvik eder

2-28. Sadık: Sorunları ve zorlukları olduğunda bile arkadaşlarıyla kalır ve onlara destek olur

2-29. Benzeri olmayan: Olağandışı bir kişi, çoğu kişiden farklı kişiliği ve davranışları olan

2-30. Beraberliğe önem veren: Başkaları ile birlikte çalışı

2-31. Cesaretlendirici: Tavsiye ve güvenceler yoluyla cesaret, güven ya da ümit verir

2-32. Moral verici: Kendine bağlı çalışanların moralini cesaretlendirme, övgü ya da kendinden emin oluşuyla güçlendirir

2-33. Kibirli: Kendini beğenmiş ve küstah

2-34. Düzenli: İşinde muntazam ve sistemli

2-35. Hazırlıklı: Gelecekteki olaylara hazırlıklı

2-36. Otoriter: Diktatörce kararlar veren

2-37. Bilgi gizleyen: Elinde olan bilgileri başkalarından saklama eğilimindedir

2-38. Toplumdan kaçan: İnsanlardan ve gruplardan kaçar, kendine kendine olmayı yeğler

2-39. Kardeşçe: Astlarla iyi arkadaş olmaya çalışır

2-40. Cömert: Başkalarına zaman, para, kaynak ve yardım sunmaya istekli

2-41. Resmi: Kurallara, alışkanlıklara ve törelere göre hareket eder

2-42. Alçakgönüllü: Övünmez, kişiliğini alçakgönüllülükle sergiler 
2-43. Zeki: Akıllı, kolayca kavrar

2-44. Kararlı: Kesin ve çabuk karar veri

2-45. Danışan: Plan yapmadan ve harekete geçmeden evvel başkalarına danışır

2-46. Çabuk öfkelenen: Ruh durumu çabuk değişen, kolayca kızan

2-47. Yalnızlığı seven: Başkalarından ayrı çalışan ve hareket eden

2-48. Heyecanlı: İşe yönelik olumlu duygular sergiler ve başkalarının da hissetmesini sağlar

2-49. Risk almaz: Riski sevmez ve risk almamaya çalışır

2-50. Kinci: Hınçlı, yanıldığında intikam almak ister

2-51. Şevkatli: Başkalarının duygularını anlar, onlara yardım eder, merhamet eder

2-52. Boyun eğmiş: Bastırılmış, sakin ve utangaç

2-53. Ben merkezci: Kendine düşkün, yalnız kendi öz varlığını düşünen

2-54. Açık değil: Açıkça konuşmayan, kinaye metaforlar ve örnekler ile iletişim kurar

2-55. Uzak: Soğuk, diğerlerinden ayrı duran, arkadaş olması zor

2-56. Özgür düşünceye teşvik eden: Başkalarını düşünmeye ve akıllarını kullanmaya teşvik eder, inançlara, tekdüzeliğe ve başkalarının tavırlarına meydan okur

\section{Bölüm - Liderlerin Davranıșları (II. Kısım)}

Bu bölümdeki sorular 2. Bölüm'deki sorularla aynı tiptir. Bu bölümde tekrar lider davranışlarını ve özelliklerini değerlendirmeniz istenmektedir. Bunu yapmak için her davranış ve özelliğin karşında bulunan sayılardan aşağıdaki ölçekte kullanılan liderin olağanüstü başarılı olması için o davranış ve özelliğin ne kadar önemli olduğunu en iyi belirtecek olanını seçip, işaretleyiniz.

Değerlendirme

1: Bu davranış veya özellik bir kimsenin önemli bir lider olmasını çok fazla engeller.

2: Bu davranış veya özellik bir kimsenin önemli bir lider olmasını biraz engeller.

3: Bu davranış veya özellik bir kimsenin önemli bir lider olmasını çok az engeller.

4: Bu davranış veya özellik bir kimsenin önemli bir lider olmasında hiç etkisi yoktur.

5: Bu davranış veya özellik bir kimsenin önemli bir lider olmasına çok az katkıda bulunur.

6: Bu davranış veya özellik bir kimsenin önemli bir lider olmasına biraz katkıda bulunur.

7: Bu davranış veya özellik bir kimsenin önemli bir lider olmasına çok fazla katkıda bulunur.

Özellik veya Davranış

3-1. Tedbirli: Büyük bir dikkatle ilerler, hareket eder ve riske girmez.

3-2. Düzenli: Muntazam, sistemli ve düzenli

3-3. Düzenbaz: Kurnaz, aldatic1, hile dolu

3-4. Bilgili: Olaylardan haberdar

3-5. Etkili pazarlıkçı: Etkili bir şekilde pazarlık yapabilen, avantajlı alış-verişler yapan

3-6. Kendini beğenmiş: Kibirli, kendi yeteneklerinden emin

3-7. İş birliği yapmayan: Başkaları ile birlikte çalışmaya istekli olmayan 
3-8. Mantıklı: Mantıklı düşünen

3-9. Mevkiye önem veren: İnsanların, toplumda kabul edilen mevkilerinin farkında olan 3-10. İleriyi görebilen: Gelecekteki olayları tahmin eder

3-11. İleriye yönelik: Önceden sezinler ve hazırlıklı olur

3-12. Kurallara bağlı: Grubunda kabul gören uygulamalara göre hareket eder

3-13. Bireyselliğe önem veren: Bireysel ihtiyaçları gözetmeyi grubun ihtiyaçlarının üstünde tutan

3-14. Eşitlikçi olmayan: Bireylerin eşit olmadığına ve sadece bazılarının eşit haklara ve avantajlara sahip olması gerektiğine inanan

3-15. Sağduyu sahibi: Sezgileri güçlü olan

3-16. İma eden: Söyleyeceğini doğrudan belirtmez, konuşmalarında öğüt verici hikayeler, benzetmeler kullanır

3-17. İşlerini alıştığı gibi yapan: Değişmez, sabit iş programına göre hareket eder

3-18. Kendini gösteremeyen: Kendini alçakgönüllülükle sunan

3-19. Öngörüşlü: Başarılı bir şekilde gelecekteki ihtiyaçları görebilen

3-20. Harekete geçiren: Diğerlerini aktif bir hale getirip, harekete geçiren

3-21. Duyarlı: Diğerlerinin ruh halindeki değişiklerin farkına varan, tartışmaları mahcubiyete yol açmadan sınırlandırabilen

3-22. İ kna edici: Kendi bakış açısını diğerlerine kabul ettirmede olağanüstü yetenekli

3-23. Açık yürekli: Diğgerleriyle sık sık iletişim kuran

3-24. Mükemmelci: Kendisinin ve astlarının icraatında mükemmelliğe ulaşmak için uğraşan

3-25. Yöntemli: Yerleşmiş yöntemleri izler

3-26. Güven geliştirici: Karşısındakilere olan güvenini göstererek, onların kendilerine olan güvenini artırır.

3-27. Gruba yönelik: Grubun iyiliğini düşünen

3-28. Sosyal sınıf özelliklerinin bilincinde: Sosyal sınıfların sınırlarının farkındadır, ona göre hareket eder.

3-29. Katılımcı olmayan: Başkalarına katılmaz

3-30. Kendini fade eden: Kendi çıkarlarından vazgeçer ve bir amaç uğruna kendi çıkarlarından fedakârlık yapar

3-31. Sabırlı: Sabırlıdır, sabırlı davranır

3-32. Dürüst: Doğruyu söyleyen ve doğru davranan

3-33. Hükmedici: Başkalarını idaresi almaya çalışan

3-34. Grup içindekilerin küçük düşmelerini önleyen: Diğer grup üyelerinin mahcup olmamalarını sağlayan

3-35. Dinamik: Enerji dolu, olaylarla yakından ilgili, heyecanlı

3-36. Koordinatör: Kendine bağlı olanların işini bütünleştirerek yönetir

3-37. Mutlu azınlığa inanan: Benzer geçmişi olan az sayıda kişinin üstün olduğuna ve ayrıcalıklardan faydalanması gerektiğine inanır

3-38. Takım kurucu: Grup üyelerinin beraber çalışmalarını sağlar

3-39. Alaycı: İnsanlar ve olaylar hakkında en kötü şeye inanmaya yönelik

3-40. İcraata yönelik: Yüksek standartlar koyar

3-41. Hırslı: Yüksek amaçlar koyan ve çok çalışan 
3-42. Harekete geçiren: Başkalarını, görevlerinin gereğinin üstünde ve ötesinde çaba göstermelerine teşvik eder

3-43. 'Mikro' yönetici: Çok yakından denetleyen ve tüm kararları kendisi almaya ısrarlı

3-44. Yetki vermeyen: Projeleri veya işleri kendi kontrolünde tutan

3-45. Olumsuzluklardan kaçınan: Kendisinden bir şey yapması istendiğinde yapılamayacak bir şey olsa bile hayır demekten sakınır

3-46. Vizyonu olan: Geleceği gören; ve gelecek hakkında amaçları ve hayalleri olan

3-47. İstekli: Direnç gösteren, kararlı, azimli, ısrarlı

3-48. Emreden: Anlaşmazlıktan veya sorgulanmaktan hoşlanmaz, emir verir

3-49. Dürüst olmayan: Sahtekâr, samimi olmayan

3-50. Düşmanca davranan: Hareketlerinde arkadaşça olmayan, başkalarına karş1 olumsuz

3-51. Geleceğe yönelik: Gelecekteki amaçlar üzerinde planlar yapar ve harekete geçer

3-52. İyi idareci: Karmaşık ofis işlerini ve yönetim sistemlerini yönetme yeteneği

3-53. Güvenilir: İtimat edilir, emniyetli

3-54. Diktatör: Kendi değer yargılarını ve görüşlerini başkalarına zorlar olan

3-55. Bireyci: Kendisi ile aynı konumda olanlardan farklı hareket eder

\section{Bölüm-Kișisel Sorular}

Bu bölümdeki sorular sizle ve çalıştığınız yerle ilgilidir. Bu sorular, farklı insanların bu anketteki sorulara farklı cevaplar verip vermediğini görmek açısından önemlidir.

Herhangi bir kişiyi belirlemek için sorulmamışlardır.

Geçmişinizle ilgili sorular:

4-1. Kaç yaşındasınız? yaşında / Doğum yılınızı aşağıdaki listeden seçiniz.

4-2. Cinsiyetinizi seçiniz: Erkek / Kadın

4-3. Hangi ülkenin vatandaşısınız? Türkiye / Diğer

4-4. Hangi ülkede doğdunuz? Türkiye / Diğer

4-5. Şu anda yaşamakta olduğunuz ülkede kaç yıldır yaşıyorsunuz? ................ y1ldir

4-6. Doğdunuz ülke dışında, kaç ülkede bir yıldan fazla yaşadınız? ülkede

Ailenizin geçmişi ile ilgili sorular:

4-7. Anneniz hangi ülkede doğmuştur?

4-8. Babanız hangi ülkede doğmuştur?

İş hayatınız ile ilgili sorular:

4-9. Kaç yıl tam-zamanlı olarak çalıştınız? ................ yıl

4-10. Kaç yıl yönetici olarak çalıştınız? ................ yıl 
4-11. Şu andaki işvereniniz için ne kadar süredir çalışmaktasınız? y1l ve ........ ay

4-12. Çok uluslu bir şirkette (yabancı sermayeli/ortaklı) hiç çalıştınız mı? Evet / Hayır 4-13. Bir meslek odasina veya meslek grubuna dahil misiniz? Evet / Hayır

4-14. Sanayi veya ticaret odalarının faaliyetlerine katılıyor musunuz? Evet / Hayır

Eğitiminiz ile ilgili sorular:

4-15. Almış olduğunuz formel eğitim kaç yıldır? y1l

4-16. Eğitiminizde hangi dalda uzmanlaştınız?

4-17. Batı'nın yönetim uygulamaları ile ilgili resmi eğitim/yetiştirme programlarına katildiniz mi? Evet / Hayır

Çalıştığınız kurum ile ilgili sorular:

4-18. Lütfen yönettiğiniz birimin ana faaliyetini belirtiniz.

- İdari

- Mühendislik, fabrika veya üretim

- Finans veya muhasebe

- İnsan kaynakları yönetimi veya personel yönetimi

- Pazarlama

- Planlama

- Satın alma

- Araştırma ve geliştirme

- Satış

- Destek hizmetleri (örneğin: makine tamiri)

- Diğer (Lütfen tarif ediniz)

4-19. Emir komuta zincirinde size doğrudan bağlı kaç kişi vardır? kişi

4-20. Kurumunuzun yönettiğiniz alt biriminde kaç kişi çalışmaktadır? kişi

4-21. Kurumunuzun genel müdürü ile sizin aranızda kaç kademe vardır? kademe

4-22. Kurumunuzda veya bölümünüzde idari görevi olmayan memurlar/işçiler ile sizin aranızda kaç tane kademe vardır? ............... kademe

4-23. İş yerinde hangi lisan(lar)1 kullanıyorsunuz? Uygun olanlarını işaretleyiniz.

Türkçe

İngilizce

Almanca

Fransizca

Arapça

Diğer (belirtiniz) 
$\mathrm{Bu}$ anket burada tamamlanmıştır. $\mathrm{Bu}$ anketin tamamlanması için gösterdiğiniz ilgiden ve araştırmaya yapmış olduğunuz katkılardan dolayı teşekkür ederiz. 


\section{APPENDIX B \\ Interview Questions (Qualitative Part)}

1. Have you ever heard the study performed by GLOBE Project team about Leadership perception of Turkish managers in 1994 ?

2. If yes, have you ever considered the findings of GLOBE project to shape your management and leadership style?

3. In your management capacity, have you ever used GLOBE Project findings in training of your team?

4. If you have not heard GLOBE project before, what do you think where your management and leadership style is derived from? What are critical factors affecting your leadership style?

5. According to GLOBE Project findings, Turkey is part of Middle Eastern Cluster with Egypt, Morocco, Kuwait, and Qatar. Do you agree with this classification and why?

6. Do you think the perspective and practice of leadership in Turkey is different than other countries? And why?

7. Do you believe to be successful in Turkey, all foreign employees should learn Turkish leadership dynamics?

8. Were you in a management role in 1994? If Yes, can you please share of observations whether leadership perception of Turkish management culture has changed or not? 
9. According to your opinion, whether you observe that Turkish leadership perception has changed or not? What do you think what factors affected your judgment?

10. According to your knowledge, what historical events (economic, social and political) since 1994 may have influenced the leadership perception of today's new generation managers? 


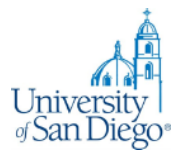

Apr 27, 2018 8:43 AM PDT

Zeki Pagda

Sch of Leadership \& Ed Science

Re: Expedited - Initial - IRB-2018-416, Leadership and Culture in Turkey: How GLOBE project findings have changed since 1994 amid political, social and economic transformations in Turkey.

\section{Dear Zeki Pagda:}

The Institutional Review Board has rendered the decision below for IRB-2018-416, Leadership and Culture in Turkey: How GLOBE project findings have changed since 1994 amid political, social and economic transformations in Turkey..

Decision: Approved

Selected Category: 7. Research on individual or group characteristics or behavior (including, but not limited to, research on perception, cognition, motivation, identity, language, communication, cultural beliefs or practices, and social behavior) or research employing survey, interview, oral history, focus group, program evaluation, human factors evaluation, or quality assurance methodologies.

Findings: None

Research Notes:

Internal Notes:

Note: We send IRB correspondence regarding student research to the faculty advisor, who bears the ultimate responsibility for the conduct of the research. We request that the faculty advisor share this correspondence with the student researcher.

The next deadline for submitting project proposals to the Provost's Office for full review is N/A. You may submit a project proposal for expedited or exempt review at any time.

Sincerely,

Dr. Thomas R. Herrinton

Administrator, Institutional Review Board

Office of the Vice President and Provost

Hughes Administration Center, Room 214

5998 Alcalá Park, San Diego, CA 92110-2492

Phone (619) 260-4553 • Fax (619) 260-2210 • www.sandiego.edu 